Universidade de São Paulo

Instituto de Física

\title{
SBI-IFUSP
}

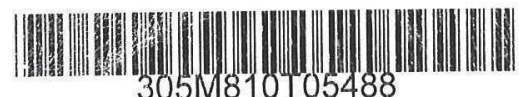

\section{Difração Bragg-Superfície no estudo de sistemas epitaxiais baseados em pontos quânticos de InAs/GaAs}

\author{
Raul de Oliveira Freitas
}

Orientador: Prof. Dr. Sérgio Luiz Morelhão

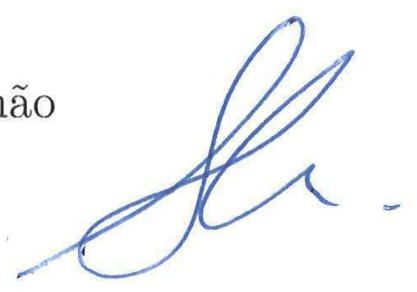

Tese de doutorado apresentada ao Instituto de Física para a obtenção do título de Doutor em Ciências

Banca examinadora:

Prof. Dr. Sérgio Luiz Morelhão (IFUSP)

Prof. Dr. Irineu Mazzaro (UFPR)

Prof. Dr. Eduardo Abramof (INPE)

Prof. Dr. Giancarlo Espósito de Souza Brito (IFUSP)

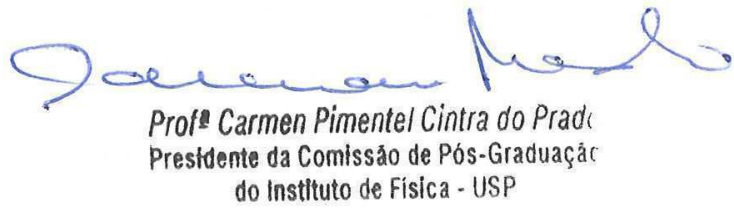

Prof. Dr. Manfredo Harri Tabacniks (IFUSP)

São Paulo

2011 
FICHA CATALOGRÁFICA

Preparada pelo Serviço de Biblioteca e Informação do Instituto de Física da Universidade de São Paulo

Freitas, Raul de Oliveira

Difração Bragg-Superficie no estudo de sistemas epitaxiais baseados em pontos quânticos de InAs/GaAs.

São Paulo 2011.

Tese (Doutorado) - Universidade de São Paulo.

Instituto de Física, Departamento de Física Aplicada.

Orientador: Prof. Dr. Sérgio Luiz Morelhão

Área de concentração: Física

Unitermos: 1. Pontos quânticos; 2. Nanomateriais; 3. Dispositivos

optoeletrônicos; 4. Difração múltipla de raios X; 5 . Difração Bragg-Superfície.

USP/IF/SBI-020/2011 
A todos que me apoiaram na busca de meus sonhos, dentre eles e especialmente, aos meus avós, aos meus pais e à minha esposa. Também dedico este trabalho ao meu sobrinho Arthur, cuja existência mudou meu modo de ver as coisas. 


\section{Agradecimentos}

Agradeço à minha esposa Sandra pelo apoio incondicional e por sempre acreditar em meus ideais, mesmo quando só eu parecia acreditar neles. Agradecimento similar é direcionado aos meus pais, à minha irmã e ao meu cunhado, os quais nunca deixaram de me apoiar nesta jornada tortuosa da Física.

Agradeço especialmente ao professor Sérgio Morelhão pela referência na minha formação, pelas frutíferas discussões científicas, pela grande disponibilidade, pelo profissionalismo e pela seriedade durante este trabalho. Além disso, sou grato à grande amizade construída em nosso convívio. Sugestões de tema de pesquisa, retificações e ratificações durante o trabalho são meros detalhes perto do total envolvimento dispensado ao longo destes 5 anos.

I would like to thank professor Stefan Kycia for the amazing reception in Canada during the one-year scholarship, for the support and discussion during the experiments, for the wise advices on my future research, for the reference as a researcher as well as a human being.

Ao professor Alain Quivy pelas ricas discussões, pelo fornecimento de 100\% das amostras utilizadas nesta pesquisa e pela grande receptibilidade de idéias durante esta colaboração. Agradeço igualmente aos pesquisadores Tomás Lamas e Álvaro Diego pelo crescimento das amostras e pela descrição dos experimentos de crescimento via MBE e de fotoluminescência em dispositivos com pontos quânticos.

Ao amigo Ariel Gomez pela recepção maravilhosa durante o estágio no Canadá. Sou muito grato pelo seu suporte no laboratório, pelas discussões, idéias e amizade. Conhecer você nos fez sentir em casa mesmo em situações de nevasca e $-20^{\circ} \mathrm{C}$ na rua.

Aos amigos Fernando, Tiago, Jean, Carioca, Cabelo, Cris, Fefê, Nenê, Soneca, Emerson, Sandro, Edson, Rose, Thais Karina, Rafaela Fonseca, Carlos Amado, Fernando Massa, Juliano Neves. Cada um de vocês contribuiu essencialmente neste trabalho. A special thank to the great friend Kenneth Doren. Bill Callahan, Great Lake Swimmers, Kings of Convenience, Bombay Bicycle Club, Shout out Louds, The Arcade Fire, Broken Social Scene and so on, for making such great music and for keeping me alive during the writing work.

Ao LNLS por possibilitar a realização da maioria dos experimentos de difração de raios X, ao laboratório de Cristalografia-IFUSP e ao LNMS-IFUSP pelo fornecimento das amostras.

The Physics Department of the University of Guelph for the great reception during the scholarship and for making available all the needs and facilities for the research. I would like to thank Bill Morton, Dave Wright and the whole team from the machine shop for making such amazing parts for the experiments. I also thank David Atkinson for the great support in the Chemistry Lab.

Às agências de fomento CNPq e FAPESP pelo financiamento pleno desta pesquisa. 


\section{Epígrafe}

Uma coisa que se esclarece deixa de nos interessar. - Que queria dizer o deus que aconselhou:

"Conhece a ti mesmo"? Isto significava talvez: "Deixa de interessar-te por ti! torna-te objetivo!" —E Sócrates? —E o "homem científico"? -

Friedrich Nietzche 


\section{Resumo}

Nanodispositivos são objetos fabricados pelo homem com estruturas internas as quais têm ao menos uma dimensão física em escala nanométrica. A baixa dimensionalidade implica em níveis de energia quantizados, conferindo notáveis diferenças às propriedades optoelétricas desses dispositivos, o que os torna bastante atrativos para a indústria de micro e optoeletrônica. Para tais dispositivos, por exemplo os baseados em poços quânticos, técnicas de difração de raios $\mathrm{X}$ de alta resolução são largamente empregadas e tipicamente alcançam acurácia de $10^{-4}$ na análise de variações no parâmetro de rede $\Delta a / a$. Por outro lado, a caracterização de nanoestruturas com mais de uma nanodimensão, em particular pontos quânticos (QDs), se apresenta mais complexa devido à pequena porção de material responsável pelo espalhamento de raios X. Técnicas de incidência rasante de raios X são viáveis para se obter informação de grandes conjuntos de QDs expostos devido a pouca penetração da onda incidente, porém, pouca informação pode ser acessada quando os QDs estão cobertos. Varreduras Renninger de raios X e mapeamentos angulares $\theta-\varphi$ em torno da condição de difração múltipla Bragg-Superfície em amostras dos sistemas de QDs de InAs/GaAs(001) indicaram importantes alterações estruturais introduzidas pelo processo de cobrimento das ilhas (deposição da sobre-camada de 30nm de GaAs). O método de varredura Renninger demonstrou uma acurácia da ordem de $10^{-5}$ no estudo do parâmetro de rede do material do entorno das ilhas e os mapas $\theta-\varphi$ sugerem um mecanismo de acomodação de tensão baseado em inclinação da rede da sobre-camada nas proximidades das ilhas. 


\section{Abstract}

Low-dimensional devices are objects with quantized energy levels due to at least one of their internal structures dimension in a nanometer scale. It confers notable differences onto the optoelectrical properties of such devices, which met important applications in microand opto-electronics. For devices with at least one dimension in the nanoscale range, such as quantum wells, high-resolution x-ray diffraction techniques are widely used, and routinely attains an accuracy of $10^{-4}$ measuring variation of lattice parameters, i.e. in $\Delta a / a$. On the other hand, characterization of nanostructures with more than one nano-dimension, in particular quantum dots (QDs), is more complicated due to the very small amount of material responsible for the x-ray scattering. Grazing incidence techniques are useful to access information on statistically large ensembles of exposed QDs due to the very shallow penetration of the incident wave field. But, these techniques have little access to the QDs when they are covered. X-ray Renninger Scanning and $\theta-\varphi$ angular mapping of Bragg-Surface diffraction cases were used for analyzing samples of the InAs/GaAs(001) QD system. They have demonstrated that major structural changes were introduced by the covering process (deposition of a 30nm GaAs capping layer). The Renninger scanning method has shown an accuracy of $\simeq 10^{-5}$ on the lattice parameter study of the surrounding material of the InAs islands and the $\theta-\varphi$ meshes suggested a strain minimization mechanism via tilt of the capping layer lattice near to the InAs islands. 


\section{Conteúdo}

1 Introdução geral 1

2 Difração de raios X em cristais $\quad 6$

2.1 Princípios básicos . . . . . . . . . . . . . . . . . . . . 9

2.2 Absorção de raios X f . . . . . . . . . . . . . . . . . . . . . . . . . 18

2.2 .1 Ressonância atômica . . . . . . . . . . . . . . . . . . . . . . . . . . . 20

2.3 Geometria 3D da difração de raios X . . . . . . . . . . . . . . . . . . . . 22

3 Experimental $\quad 26$

3.1 QDs de InAs crescidos sobre GaAs . . . . . . . . . . . . . . . 27

3.2 Arranjo experimental de difração de raios X . . . . . . . . . . . . . . . . . 37

3.2.1 Linha de difração XRD1-LNLS . . . . . . . . . . . . . . . . . . . . 38

3.2.2 Difratômetro de 4 círculos do X-ray Lab/UoGuelph - Canadá . . . . 38

3.2.3 Linha de difração XRD2-LNLS . . . . . . . . . . . . . . . . . . . . . 40

3.3 Preparação de amostras . . . . . . . . . . . . . . . . . . . . 41 
4 Varreduras Renninger e medidas ultra-precisas de parâmetro de rede 46

4.1 Geometria de Difração Múltipla e Varreduras Renninger . . . . . . . . . . . 47

4.2 Medidas de Parâmetro em sistemas nanoestruturados baseados em QDs . . . 50

5 A difração Bragg-superfície no estudo de pontos quânticos cobertos 66

6 Conclusões da pesquisa $\quad 88$

A Alinhamento de goniômetro de 4 círculos via efeito Borrmann 92

$\begin{array}{ll}\text { B Algoritmo Genético } & 98\end{array}$

B.1 Procedimento de ajuste dos dados . . . . . . . . . . . . . . . . . . 99

B.2 Aplicação em sistemas de camadas epitaxiais . . . . . . . . . . . . . . . . . 101

B.3 Código fonte de programa Matlab para ajuste de curvas de varredura $\theta \mathrm{em}$ sistemas de camadas epitaxiais . . . . . . . . . . . . . . . . 105

C Arquivo fonte de programa para ajuste de picos de DM - FITTER 110 


\section{Capítulo 1}

\section{Introdução geral}

Desde meados da década de 70, a pesquisa em dispositivos semicondutores tem direcionado grandes esforços no estudo de estruturas com dimensões reduzidas - as denominadas estruturas nanométricas ou simplesmente nanoestruturas - em função das novas oportunidades tecnológicas oferecidas por dispositivos com níveis discretos de energia. A discretização ocorre devido às drásticas modificações nas estruturas de bandas dos materiais quando reduzidos à dimensões de poucas dezenas de angstroms. O recurso da quantização permite a restrição do movimento dos portadores em direções específicas do material, resultando em dispositivos com características singulares. Embora tenham recebido amplo reconhecimento em seu surgimento, o novo horizonte de aplicações das nanoestruturas ainda era restrito a previsões teóricas e estudos experimentais eram limitados pela tecnologia insuficiente de fabricação dos dispositivos [1].

Com a chegada de novas técnicas de deposição epitaxial, como epitaxia de feixe molecular e deposição química a vapor, foi possível a realização dos primeiros dispositivos semicondutores baseados em camadas coerentes com espessuras nanométricas. O termo "ca- 
madas coerentes" se refere a camadas crescidas com reduzida densidade de defeitos. Tais nanocamadas marcam a chegada dos primeiros dispositivos baseados em poços quânticos já produzidos, os quais forneceram demonstrações diretas dos efeitos de quantização dimensional e atestaram a aplicação da mecânica quântica na explicação de fenômenos de transporte em nanofilmes [2].

$\mathrm{Na}$ área de optoeletrônica, o surgimento dos poços quânticos trouxe uma nova linhagem de dispositivos, possibilitando a criação de laseres de longo comprimento de onda cujo processo de irradiação era baseado em transições entre bandas quantizadas. Tais laseres, atualmente conhecidos como "laseres de cascata", só foram realizados alguns anos mais tarde $[3,4]$ e assim passaram a ser fabricados em larga escala até os dias atuais. Estudos ópticos sobre os poços quânticos e Super-redes (SLs - do inglês Super Lattices) revelaram importantes resultados na engenharia desses dispositivos e ao final da década de 80 as suas propriedades mais importantes já eram razoavelmente bem compreendidas. Assim, grande parte das pesquisas desta natureza mudou o foco para estruturas ainda mais reduzidas, ou seja, dispositivos com quantização em mais de uma de suas dimensões como fios quânticos e pontos quânticos (QDs - do inglês Quantum Dots). A redução das dimensões "infinitas" remanescentes nos fios quânticos para dimensões nanométricas ocasiona na localização tridimensional dos portadores. Desta forma os QDs possuem níveis de energia discretos e as propiedades físicas são, em sua maioria, bastante similares aos casos de átomos confinados em caixas. Ainda no contexto de fabricação de laseres, dispositivos baseados em poços quânticos apresentam uma forte susceptibilidade da eficiência de emissão com o aumento da temperatura, o que pode ser um fator limitante em algumas aplicações. Tal dependência térmica é drasticamente minimizada em dispositivos baseados em QDs pois a distância entre os níveis (discretos) de energia nessas estruturas é grande o suficiente de forma a minimizar efetivamente a ocorrência de estados excitados por flutuações térmicas (ruídos na emissão) 
em situações normais de operação.

Dentre vários sistemas possíveis, os QDs de InAs crescidos sobre substratos de GaAs têm revelado um novo horizonte de aplicações na manufatura de fontes de luz (laseres) para redes de comunicação por fibra óptica. Isso se deve aos excelentes resultados iniciais de emissão em longos comprimentos de onda (até $1.1 \mu \mathrm{m}$ ), o que representou um expressivo avanço na área de telecomunicações de médio e longo alcance. Pouco tempo após os primeiros resultados de emissão, dispositivos similares emitindo em $1.3 \mu \mathrm{m}$ [5] constataram um relevante acréscimo na eficiência da emissão como resultado do desenvolvimento de tais estruturas. Recentemente dispositivos baseados em QDs de InAs emitindo em até $1.48 \mu \mathrm{m}$ $[6,7]$ tornam cada vez mais real a possibilidade de construção de laseres comerciais de QDs emitindo em $1.55 \mu \mathrm{m}$. Tal interesse em obter laseres emitindo nessa faixa pode ser justificado pelo fato dos mínimos de absorção das fibras ópticas construídas em sílica - tipo mais comercial de fibras ópticas - estarem nessa faixa de comprimento de onda[8], o que possibilita transmitir informações com reduzida perda de sinal, disponibilizando a tecnologia para redes mais extensas, ou seja, redes metropolitanas de fibra óptica. Além da típica aplicação dos dispositivos baseados em QDs de InAs como fontes luz para transmissão de informação em fibras ópticas, está em pauta a hipótese promissora que considera tais nanoestruturas, na configuração específica de QDs isolados, fortes candidatas para realização de portas quânticas em dispositivos de comunicação ou computação quântica [9].

Na manufatura de dispositivos optoeletrônicos tais como LEDs, laseres e fotodetectores, onde os QDs são as estruturas emissoras ou receptoras de luz, na grande maioria dos casos é necessário encapsular os QDs. Após o crescimento dos QDs sobre a superfície do substrato, o encapsulamento consiste em cobrir os QDs por uma fina camada, denominada camada de cobrimento ou sobre-camada (em inglês "capping-layer"), em geral do mesmo 
material do substrato. Usualmente, esse recurso de encapsulamento e crescimento de novos QDs pode ser repetido várias vezes dando origem a uma super-rede de QDs e aumentando o número de estruturas opticamente ativas. Um importante requisito na construção dos dispositivos recai sobre as interfaces dos QDs, as quais devem estar livre de defeitos estruturais para não comprometer a integridade dos QDs, de forma a garantir tanto as propriedades optoeletrônicas específicas como também a durabilidade e eficiência do dispositivo [10, 11]. Desenvolver meios de fabricação de forma a evitar tais defeitos ainda é um dos grandes desafios do segmento. Um dos obstáculos para o aprimoramento dos métodos de fabricação inside no fato das técnicas usuais de caracterização de superfície, como microscopia de força atômica (AFM), microscopia de tunelamento (STM) e microscopia eletrônica de transmissão (TEM), não conseguirem analisar o estado de tensão ou deformação dos QDs na configuração final dos dispositivos, estágio no qual os QDs encontram-se encapsulados. Técnicas alternativas empregadas na região de clivagem (como "cross-sectional" TEM ou X-TEM) podem fornecer informações sobre os QDs cobertos[12], porém, além de exigir muito tempo na preparação das amostras, a técnica analisa QDs isolados ou apenas um pequeno número deles, o que representa uma amostragem estatística insatisfatória diante das distribuições de QDs que determinam as propriedades de emissão do dispositivo. Outra característica importante desta técnica é o fato de que a realização da clivagem na região dos QDs pode alterar o possível campo de tensão presente na amostra, alterando assim as características originais do processo de crescimento. Por esse motivo, técnicas não destrutivas de análise estrutural as quais também possibilitem penetração, tal como a difração de raios X, são essenciais para caracterização de tais dispositivos.

Devido à reduzida dimensão dos QDs, o uso de fontes intensas de radiação, como radiação síncrotron, tem se mostrado essencial para a investigação dessas nanoestruturas. Adicionalmente, a necessidade de instrumentação de alta resolução, como óptica de raios 
$\mathrm{X}$ para feixe monocromático de baixa divergência e goniômetros robustos com grande estabilidade e precisão mecânica, restringe ainda mais esse tipo de pesquisa aos laboratórios síncrotron. Esses grandes laboratórios já possibilitaram a realização de importantes investigações nesse tema, em sua maioria focadas no estudo de dispositivos com QDs expostos [13, 14, 15, 16]. Em alguns casos, estações inteiras são dedicadas a esses estudos, como o caso do experimento de análise in situ do processo de deposição via MBE com feixes ultra intensos, o qual investigou as várias etapas do processo de deposição, formação e auto-organização dos QDs sobre a superfície do substrato [17].

Em suma, o cenário atual, tanto tecnológico como de fundamentos básicos em ciência dos materiais, justifica a importância de se estudar os mecanismos que regem a fabricação e a atuação de sistemas nanoestruturados semicondutores. O cenário também ilustra a necessidade de avanço dos meios de investigação de tais mecanismos, o que implica em uma grande demanda de novas alternativas em termos de métodos de análise estrutural desses nanosistemas. Nesse contexto, esta pesquisa se concentrou no desenvolvimento de novos métodos de investigação estrutural, explorando conceitos sedimentados na difração de raios X em monocristais e em filmes epitaxiais. Mais especificamente, a pesquisa explorou geometrias de difração particulares nas quais mais de uma reflexão Bragg são simultâneamente excitadas por um feixe monocromático de baixa divergência, as quais oferecem condições extremamente favoráveis para investigar interfaces e camadas superficiais nanométricas[18, 19, 20]. Apesar da restrição desse trabalho ao sistema composto por QDs de InAs/GaAs(001) cobertos por sobre-camadas de GaAs, a pesquisa sugere fortemente a extensão da aplicação da metodologia desenvolvida a outros sistemas nanoestruturados similares. 


\section{Capítulo 2}

\section{Difração de raios $\mathrm{X}$ em cristais}

No ano de 1912, após analisar o trabalho publicado naquele mesmo ano por Friedrich, Knipping e Laue, Sir William Lawrence Bragg em seu trabalho intitulado "The diffraction of short electromagnetic waves by crystal", publicado na Proc. Camb. Phil. Soc., 18 (I), 43 (1912), concluiu que os diagramas de Laue poderiam ser explicados como gerados pela difração da radiação X nos planos atômicos dos cristais [21]. Tal conclusão teve forte impacto científico por implicar no surgimento de uma poderosa ferramenta para determinar estruturas cristalinas e por sua especial simplicidade. Bragg, ainda naquele ano de 1912, utilizou a difração de raios X na resolução das estruturas do $\mathrm{NaCl}, \mathrm{KCl}, \mathrm{KBr}$ e $\mathrm{KI}$, além de outros compostos com estruturas semelhantes. Essas foram, portanto, as primeiras determinações completas de estruturas cristalinas já realizadas. Estruturas metálicas simples como as do Fe e Cu também não haviam sido resolvidas antes do trabalho de Bragg [22].

A derivação direta da Lei de Bragg pode ser obtida primeiro pela análise do espalhamento da radiação eletromagnética por um único plano atômico e posteriormente por um conjunto desses planos periodicamente espaçados. Ondas eletromagnéticas com 
frequência na faixa espectral dos raios X (em torno de $10^{18} \mathrm{~Hz}$ ) são espalhadas pelos átomos aproximadamente como se esses fossem constituidos de elétrons livres. Assim, para que uma reduzida fração da onda plana incidente, com vetor de onda $\boldsymbol{k}_{0}$, possa ser refletida por um plano material com espessura atômica, todos os elétrons, ou átomos, do plano devem espalhar em fase numa certa direção dada por $\boldsymbol{k}$, como ilustrado na Figura 2.1. Isso ocorre quando a variação de fase com relação à origem

$$
\delta=\left(k-k_{0}\right) \cdot r
$$

é nula $(\delta=0)$ para qualquer vetor posição $r$ contido no plano.

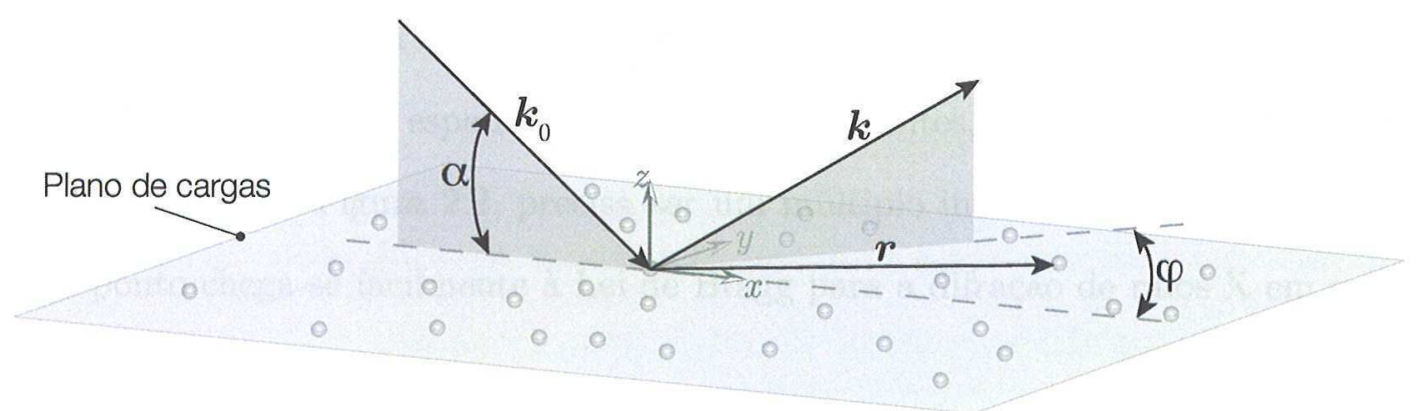

Figura 2.1: Espalhamento de uma frente de onda por um plano atômico qualquer onde $\boldsymbol{k}_{0}$ e $k$ são os vetores de onda incidente e espalhado, respectivamente. $r$ é o vetor posição no plano $x y$.

A partir da Eq.(2.1), a qual será demonstrada mais adiante, e escrevendo

$$
\begin{gathered}
r=(x, y, 0) \\
\boldsymbol{k}_{0}=\frac{2 \pi}{\lambda}\left(\cos \alpha_{0}, 0,-\sin \alpha_{0}\right) \text { e } \\
k=\frac{2 \pi}{\lambda}(\cos \alpha \cos \varphi, \cos \alpha \sin \varphi, \sin \alpha)
\end{gathered}
$$


obtém-se que

$$
\delta=\frac{2 \pi}{\lambda}\left[\left(\cos \alpha \cos \varphi-\cos \alpha_{0}\right) x+(\cos \alpha \sin \varphi) y\right]
$$

Claramente, a diferença de fase $\delta$ será nula para quaisquer valores de $x$ e $y$ se, e somente se, $\varphi=0$ e $\alpha=\alpha_{0}$, resultado esse que permite a seguinte conclusão: uma frente de onda plana sofre reflexão especular $\left(\alpha=\alpha_{0}\right.$ e $\left.\varphi=0\right)$ quando espalhada por um plano atômico de extensão infinita.

No caso de um conjunto de planos idênticos igualmente espaçados com período $d_{h k \ell}$, Figura 2.2, o espalhamento somente ocorrerá em determinados ângulos de incidência $\theta$, para os quais os campos de onda espalhados por todos os planos estejam em fase, ou seja, na condição de interferência construtiva conhecida como Lei de Bragg. A diferença de caminho percorrido pelas ondas espalhadas em planos adjacentes, representada pelo seguimento $\overline{\mathrm{MOP}}=2 d_{h k \ell} \sin \theta$ na Figura 2.2, precisa ser um múltiplo inteiro do comprimento de onda $\lambda$. Deste ponto chega-se facilmente à Lei de Bragg para a difração de raios X em cristais

$$
m \lambda=2 d_{h k \ell} \sin \theta
$$

onde $m$ é a ordem de difração e $d_{h k \ell}$ é a distância interplanar de uma dada família de planos atômicos da rede cristalina. O conjunto de valores de $d_{h k \ell}$ é característico a cada cristal, fato que é, por exemplo, utilizado para identificar materiais por meio da difração de raios X em amostras policristalinas [22].

Embora a Lei de Bragg seja suficiente para a aplicação de algumas técnicas de análise de materiais por difração de raios X, uma abordagem mais abrangente é necessária para estudos onde a intensidade das reflexões Bragg e os efeitos de forma do cristal precisam ser levados em conta. No caso de filmes epitaxiais assim como em sistemas epitaxiais 


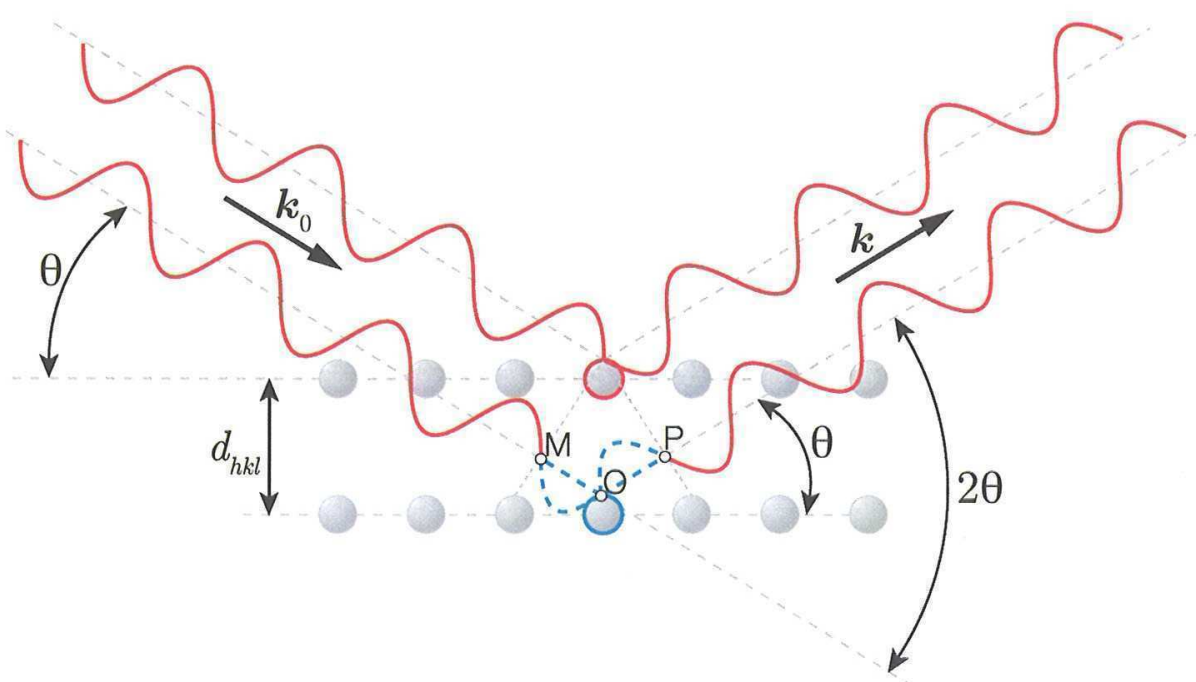

Figura 2.2: Difração de raios X por um conjunto de planos atômicos com distância interplanar $d_{h k \ell}$. Para um dado ângulo de incidência $\theta$, a diferença de caminho $\overline{\mathrm{MOP}}=2 d_{h k \ell} \sin \theta$, percorrida pela onda entre planos adjacentes, será um múltiplo inteiro do comprimentos de onda na condição de difração dada pela Lei de Bragg, Eq. (2.6). $k_{0}$ e $k$ representam os vetores de onda da radiação incidente e difratada, respectivamente.

nanoestruturados, como os investigados nesta pesquisa, a abordagem conhecida como $T e$ oria Cinemática, a qual será apresentada a seguir, formece grande parte das ferramentas necessárias na interpretação dos dados.

\subsection{Princípios básicos}

O fenômeno da difração de raios X é o resultado da combinação dos processos de espalhamento da radiação por elétrons atômicos, e a pela interferência dos campos espalhados por arranjos periódicos de átomos. Como ponto de partida, será tomado o estudo da interferência de ondas espalhadas por um volume elementar contendo $d q$ elétrons na posição $\mathrm{P}$ em relação à origem $\mathrm{O}$, como esquematizado na Figura 2.3. Sendo $\hat{\mathbf{S}}_{0}$ e $\hat{\mathbf{S}}$ versores que denotam a direção da onda plana incidente e da onda espalhada, respectivamente, a diferença 
de fase $\delta$ em relação à origem será determinada pelo comprimento do caminho $\overline{\mathrm{MON}}$,onde $\overline{\mathrm{MO}}=-\hat{\mathrm{S}}_{0} \cdot \boldsymbol{r}$ e $\overline{\mathrm{ON}}=\hat{\mathbf{S}} \cdot \boldsymbol{r}$, resultando em $\overline{\mathrm{MON}}=\left(\hat{\mathbf{S}}-\hat{\mathbf{S}}_{0}\right) \cdot \boldsymbol{r}$. Levando em conta apenas o processo de espalhamento elástico, $\left|\boldsymbol{k}_{0}\right|=|k|=2 \pi / \lambda$, obtém-se

$$
\delta=2 \pi \frac{\overline{\mathrm{MON}}}{\lambda}=\left(\boldsymbol{k}_{0}-\boldsymbol{k}\right) \cdot \boldsymbol{r}=2 \pi \boldsymbol{s} \cdot \boldsymbol{r}
$$

onde

$$
s=\frac{\left(\hat{\mathbf{S}}-\hat{\mathbf{S}}_{0}\right)}{\lambda}
$$

$s$ é denominado vetor de espalhamento nas teorias de espalhamento [23] por ser proporcional ao vetor de tranferência de momento entre os fótons incidentes e espalhados (Fig.2.3(b)).

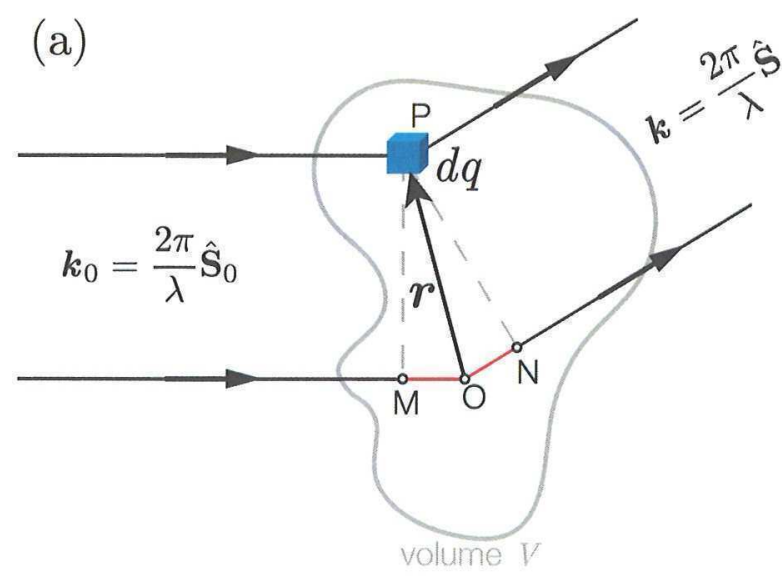

(b)

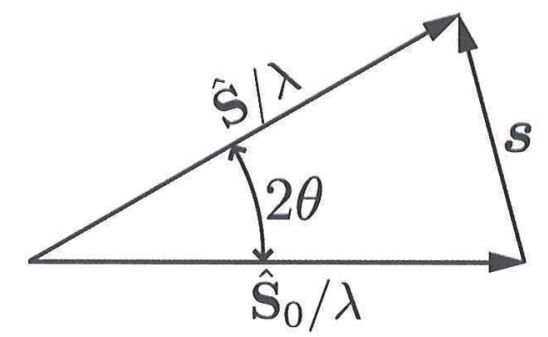

Figura 2.3: (a) Diferença de caminho $\overline{\mathrm{MON}}$ em relação à origem associada ao espalhamento de um feixe de raios $\mathrm{X}$ por um elemento de carga $d q$ localizado em $\mathrm{P}$ dentro do volume $V$. $\overline{\mathrm{MO}}=-\hat{\mathrm{S}}_{0} \cdot r, \overline{\mathrm{ON}}=\hat{\mathbf{S}} \cdot r$, tal que $\overline{\mathrm{MON}}=\left(\hat{\mathbf{S}}-\hat{\mathbf{S}}_{0}\right) \cdot r$, onde $\hat{\mathbf{S}}_{0}$ e $\hat{\mathbf{S}}$ são versores nas direções incidente e espalhada, e $\boldsymbol{r}$ é o vetor posição dentro do volume. (b) Definição do vetor de espalhamento.

A amplitude total espalhada pelo volume $V$ depende portanto do número de elétrons $d q$ em cada elemento de volume $\mathrm{d} V$, ou seja, da densidade volumétrica de elétrons $\rho_{e}(\boldsymbol{r})$ tal que $d q=\rho_{e}(\boldsymbol{r}) \mathrm{d} V$. Assim, considerando também a diferença de fase da onda espalhada por cada ponto do volume, a amplitude total para um dado vetor de espalhamento 
$s$ será

$$
A(s)=E_{e} \int_{V} \rho_{e}(r) e^{2 \pi i r \cdot s} \mathrm{~d} V
$$

onde $E_{e}$ corresponde ao campo espalhado por um elétron livre (espalhamento Thomson). Quando necessário, efeitos da polarização da radiação serão descritos tomando-se $E_{e}$ como um vetor, mas por enquanto ele será tratado como um escalar.

Arranjos periódicos de átomos, ou seja, cristais, são efetivamente descritos pela densidade eletrônica

$$
\rho_{\text {crist }}(\boldsymbol{r})=\left[\sum_{m, n, p}^{\infty} \rho_{c e l}(\boldsymbol{r}) \otimes \delta\left(\boldsymbol{r}-\boldsymbol{R}_{m n p}\right)\right] \Omega(\boldsymbol{r}),
$$

onde $\otimes$ simboliza a operação matemática de convolução e $\delta(r)$ é a função delta de Dirac. A distribuição dos elétrons atômicos dentro do elemento de periodicidade, i.e., da célula unitária, fica a cargo da função densidade de elétrons $\rho_{c e l}(r)$.

$$
\Omega(\boldsymbol{r})=\left\{\begin{array}{l}
1 \text { se } \boldsymbol{r} \in V_{\text {crist }} \\
0 \text { se } \boldsymbol{r} \notin V_{\text {crist }}
\end{array}\right.
$$

delimita as dimensões físicas do volume $V_{\text {crist }}$ do cristal considerado e

$$
\boldsymbol{R}_{m n p}=m \boldsymbol{a}+n \boldsymbol{b}+p \boldsymbol{c}
$$

contém as informações sobre a periodicidade da rede cristalina uma vez que $\boldsymbol{a}, \boldsymbol{b}$ e $\boldsymbol{c}$ são os vetores de rede e $m, n$ e $p$ números inteiros, conforme ilustrado na Figura 2.4.

Ao substituir $\rho_{\text {crist }}(\boldsymbol{r})$, Eq. (2.10), na expressão da amplitude espalhada por um volume qualquer, Eq. (2.9), e usando as propriedades matemáticas da Transformada de 


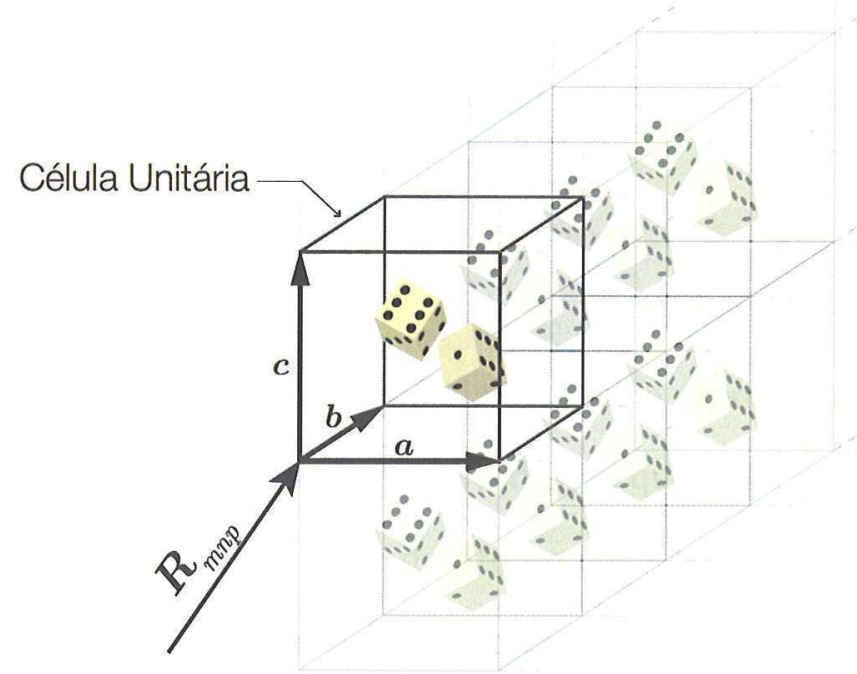

Figura 2.4: Rede cristalina formada por células unitárias cujas arestas determinam os vetores de translação, ou vetores de rede $\boldsymbol{a}, \boldsymbol{b}$ e $\boldsymbol{c}$. O vetor $\boldsymbol{R}_{m n p}$, Eq. (2.12), fornece a localização das células unitárias no cristal.

Fourier (TF) para a convolução de duas funções, obtém-se que

$$
A(s)_{c r i s t}=E_{e}\left[F(s) \sum_{m, n, p}^{\infty} e^{2 \pi i \boldsymbol{R}_{m n p} \cdot s}\right] \otimes \Omega^{T F}(s)
$$

O primeiro termo dessa nova expressão da amplitude de espalhamento é conhecido como Fator de Estrutura e corresponde à TF da densidade de elétrons dentro do volume $V_{c e l}$ da célula unitária, ou seja,

$$
F(\boldsymbol{s})=\int_{V_{c e l}} \rho_{c e l}(\boldsymbol{r}) e^{2 \pi i r \cdot s} \mathrm{~d} V
$$

Porém, como a densidade de elétrons na célula unitária advém dos elétrons atômicos, pode-se representar essa densidade diretamente em termos dos átomos constituintes, resultando em

$$
\rho_{c e l}(\boldsymbol{r})=\sum_{a} \rho_{a}(\boldsymbol{r}) \otimes \delta\left(\boldsymbol{r}-\boldsymbol{r}_{a}\right)
$$


onde $\rho_{a}\left(\boldsymbol{r}-\boldsymbol{r}_{a}\right)$ é a densidade de elétrons ao redor do $a$-ésimo átomo da célula unitária situado na posição $r_{a}$. Isso permite reescrever a expressão para o fator de estrutura,

$$
F(s)=\sum_{a} f_{a} e^{2 \pi i r_{a} \cdot s}
$$

como sendo a soma das amplitudes $f_{a}$, espalhadas por cada átomo da célula unitária levando também em conta as fases relativas dessas amplitudes, as quais são dadas pelo termo $2 \pi i \boldsymbol{r}_{a} \cdot \boldsymbol{s}$. A amplitude $f_{a}$ descreve a eficiência de cada átomo em espalhar a radiação e, em geral, é chamada de fator de espalhamento atômico. Muitas literaturas se referem à amplitude $f_{a}$ como fator de forma atômico devido ao fato de depender da forma da nuvem eletrônica dos átomos através da expressão

$$
f_{a}(\boldsymbol{s})=\int \rho_{a}(\boldsymbol{r}) e^{2 \pi i r \cdot s} \mathrm{~d} V
$$

onde $\rho_{a}$ corresponde então à soma dos módulos quadrados das funções de onda dos elétrons ligados ao a-ésimo átomo. Soluções numéricas das funções de onda, como as desenvolvidas por Douglas Hartree e Vladimir Fock [24, 25], permitem calcular teoricamente os fatores de espalhamento atômico, cujos valores são tabelados [26]. Alternativamente, Don Cromer e David Liberman [27] propuseram uma expressão paramétrica para reproduzir a dependência de $f_{a}$ com o vetor de espalhamento a partir da direção do feixe incidente. Os parâmetros dessa expressão empírica para cada átomo também são tabelados [26] e são largamente utilizados nas teorias de espalhamento e difração de raios X. Além disso, existem outras correções que incidem sobre $f_{a}$ as quais levam em conta os fenômenos de absorção fotoelétrica e ressonância atômica. Essas correções serão explicadas e implementadas oportunamente quando necessárias.

Voltando à Eq. (2.13), a somatória em mnp implica que todas as células unitárias 
espalham em fase quando

$$
\boldsymbol{R}_{m n p} \cdot s \in \mathbb{Z}
$$

Quais vetores de espalhamento $s$ satisfazem a condição de difração? A resposta a esta pergunta é conhecida como rede recíproca do cristal. Seja

$$
\boldsymbol{G}=h \boldsymbol{a}^{*}+k \boldsymbol{b}^{*}+\ell \boldsymbol{c}^{*}
$$

um vetor qualquer da rede recíproca onde $h, k$ e $\ell$ são números inteiros,

$$
a^{*}=\frac{b \times c}{a \cdot(b \times c)}, \quad b^{*}=\frac{c \times a}{b \cdot(c \times a)} \text { e } \quad c^{*}=\frac{a \times b}{c \cdot(a \times b)} .
$$

Assim é possível verificar que

$$
\boldsymbol{a} \cdot\left[\boldsymbol{a}^{*}, \boldsymbol{b}^{*}, \boldsymbol{c}^{*}\right]=[1,0,0], \quad \boldsymbol{b} \cdot\left[\boldsymbol{a}^{*}, \boldsymbol{b}^{*}, \boldsymbol{c}^{*}\right]=[0,1,0], \boldsymbol{c} \cdot\left[\boldsymbol{a}^{*}, \boldsymbol{b}^{*}, \boldsymbol{c}^{*}\right]=[0,0,1]
$$

e, portanto, para qualquer $s=G$ a condição de difração será satisfeita pois

$$
\boldsymbol{R}_{m n p} \cdot G=m h+n k+p \ell \in \mathbb{Z}
$$

Os números hkl são conhecidos como índices de Miller [22] e referem-se a cada uma das reflexões Bragg possíveis num dado cristal. A Lei de Bragg pode ser verificada diretamente a partir da Eq. (2.8) e da igualdade $|\boldsymbol{G}|=1 / d_{h k \ell}$ onde $d_{h k \ell}$ é a distância entre os planos atômicos responsáveis pela reflexão $h k \ell$ em questão. Além disso, vale a pena mencionar que pelo fato da amplitude $A(s)_{\text {crist }}$ da onda difratada pelo cristal ser significante apenas em torno das condições de difração, i.e., quando $s \approx G$, os fatores de estrutura das reflexões 
podem ser calculados pela expressão

$$
F(\boldsymbol{s})=F(\boldsymbol{G})=\sum_{a} f_{a} e^{2 \pi i\left(h x_{a}+k y_{a}+\ell z_{a}\right)}
$$

uma vez que as posições dos átomos dentro da célula unitária são dadas pelas coordenadas fracionárias $\left(x_{a}, y_{a}, z_{a}\right)$, ou seja

$$
\boldsymbol{r}_{a}=x_{a} \boldsymbol{a}+y_{a} \boldsymbol{b}+z_{a} \boldsymbol{c} .
$$

O fator somatório da expressão 2.13 também pode ser escrito como

$$
\sum_{m, n, p}^{\infty} e^{2 \pi i \boldsymbol{R}_{m n p} \cdot s}=\left(\frac{1}{V_{c e l}}\right) \sum_{h k \ell} \delta\left(s-G_{h k \ell}\right),
$$

e a TF das dimensões físicas do cristal é dada pela expressão

$$
\Omega^{T F}(s)=\int \Omega(\boldsymbol{r}) e^{2 \pi i r \cdot s} \mathrm{~d} V
$$

Portanto, a expressão 2.13 é re-escrita na forma

$$
A(s)_{c r i s t}=E_{e}\left(\frac{F(s)}{V_{c e l}}\right) \sum_{h k \ell} \delta\left(s-G_{h k \ell}\right) \otimes \Omega^{T F}(s)=E_{e} \sum_{h k \ell}\left(\frac{F(s)}{V_{c e l}}\right) \Omega^{T F}\left(s-G_{h k \ell}\right),
$$

e portanto, a intensidade espalhada é dada por

$$
I_{h k \ell}(\boldsymbol{G})=\frac{\left|E_{e}\right|^{2}}{V_{c e l}^{2}}\left|F_{h k \ell}\right|^{2}\left|\Omega^{T F}\left(\boldsymbol{G}-\boldsymbol{G}_{h k \ell}\right)\right|^{2} .
$$


Usando como exemplo os compostos abordados nesta tese, Arseneto de Gálio (GaAs) e Arseneto de Índio (InAs), a tabela 2.1 apresenta as coordenadas fracionárias para os átomos os quais compõem esses compostos. A estrutura "blenda de zinco" formada pelos átomos quando posicionados na célula unitária e a disposição das monocamadas (MC) são ilustradas na Fig.2.1.

\begin{tabular}{cccc}
\hline \multirow{2}{*}{ Elemento } & \multicolumn{3}{c}{ Posições } \\
\cline { 2 - 4 } Ga & $x$ & $y$ & $z$ \\
\hline \multirow{2}{*}{ Ga } & 0 & 0 & 0 \\
\cline { 2 - 4 } & $1 / 2$ & $1 / 2$ & 0 \\
\cline { 2 - 4 } & $1 / 2$ & 0 & $1 / 2$ \\
\cline { 2 - 4 } & 0 & $1 / 2$ & $1 / 2$ \\
\hline \multirow{2}{*}{ As } & $1 / 4$ & $1 / 4$ & $1 / 4$ \\
\cline { 2 - 4 } & $3 / 4$ & $3 / 4$ & $1 / 4$ \\
\cline { 2 - 4 } & $3 / 4$ & $1 / 4$ & $3 / 4$ \\
\cline { 2 - 4 } & $1 / 4$ & $3 / 4$ & $3 / 4$ \\
\hline
\end{tabular}

(a)

\begin{tabular}{cccc}
\hline \multirow{2}{*}{ Elemento } & \multicolumn{3}{c}{ Posições } \\
\cline { 2 - 4 } & $x$ & $y$ & $z$ \\
\hline \multirow{3}{*}{ In } & 0 & 0 & 0 \\
\cline { 2 - 4 } & $1 / 2$ & $1 / 2$ & 0 \\
\cline { 2 - 4 } & $1 / 2$ & 0 & $1 / 2$ \\
\cline { 2 - 4 } & 0 & $1 / 2$ & $1 / 2$ \\
\hline \multirow{2}{*}{ As } & $1 / 4$ & $1 / 4$ & $1 / 4$ \\
\cline { 2 - 4 } & $3 / 4$ & $3 / 4$ & $1 / 4$ \\
\cline { 2 - 4 } & $3 / 4$ & $1 / 4$ & $3 / 4$ \\
\cline { 2 - 4 } & $1 / 4$ & $3 / 4$ & $3 / 4$ \\
\hline
\end{tabular}

(b)

Tabela 2.1: Posições fracionárias dos átomos de Ga, In e As nas células unitárias (a) do GaAs e (b) do InAs. Ambas as estruturas, chamadas blenda de zinco, são resultantes da soma de duas redes FCC com origens deslocadas de $(1 / 41 / 41 / 4)$.

A partir das coordenadas fracionárias dos átomos e utilizando a Eq.2.23 é possível calcular o campo espalhado pela célula unitária $\left(F_{h k \ell}\right)$ e consequentemente a intensidade espalhada $\left(\propto\left|F_{h k \ell}\right|^{2}\right)$ para um dado vetor de recíproco $\mathbf{Q}$, ou seja, para uma dada reflexão com índices $h k \ell$. Um exemplo de cálculo de intensidades é apresentado na Tabela 2.2.

Em resumo, a difração de raios $\mathrm{X}$ em cristais depende dos seguinte fatores: i) da periodicidade da rede cristalina, a qual implica nas condições de difração dadas pela Lei de Bragg ou, de modo equivalente, pela rede recíproca do cristal; ii) das dimensões físicas do cristal, as quais determinam a extensão, ou volume, dos pontos da rede recíproca (extremidade dos vetores $\boldsymbol{G}$ ); e iii) dos arranjos atômicos dentro da célula unitária, responsáveis 
(a)

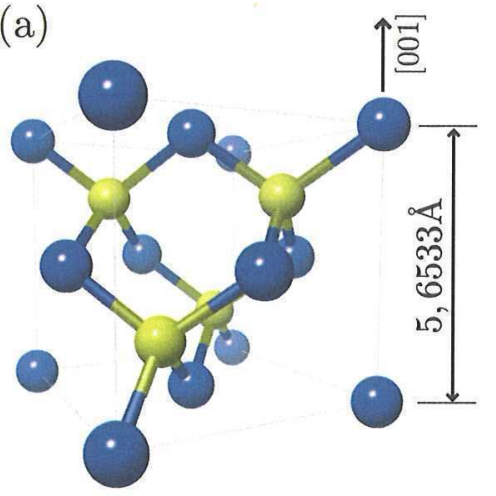

(b)

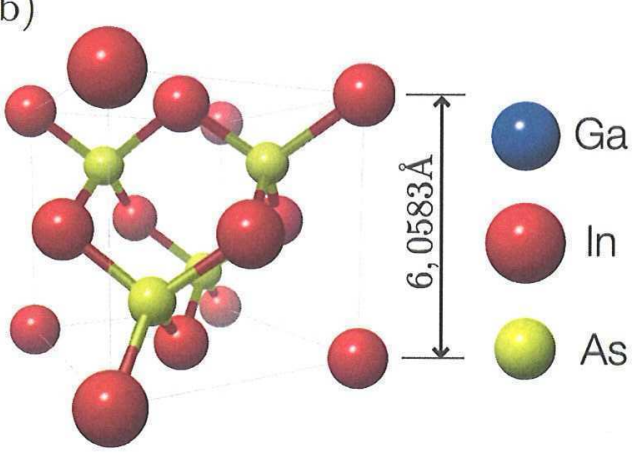

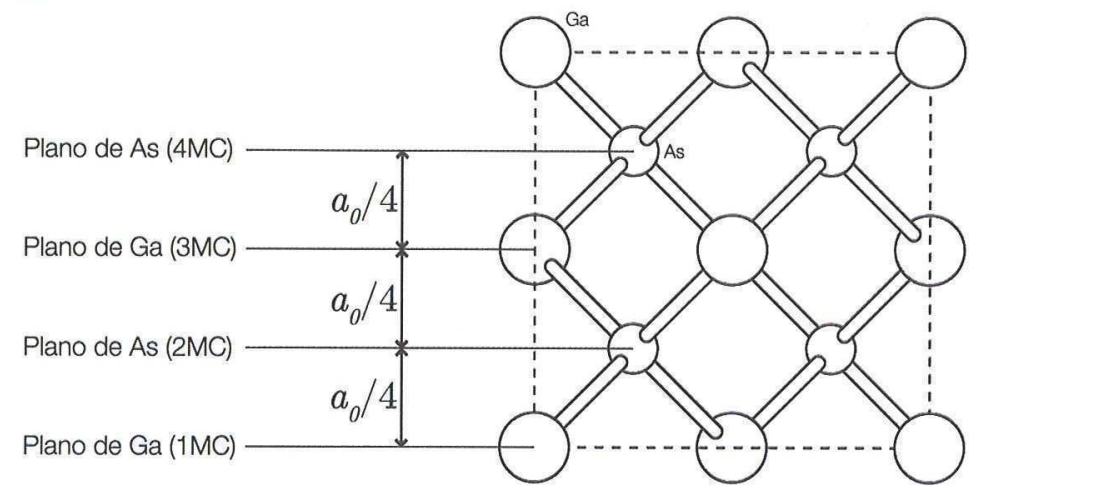

(c)

Figura 2.5: Estrutura blenda de zinco do (a) GaAs e (b) InAs. (c) Monocamadas (MC) ao longo da direção [001] na célula unitária cúbica de aresta $a_{0}$.

\begin{tabular}{llll}
\hline Índices $h k \ell$ & $h+k+\ell$ & $F_{h k \ell}$ & $\left|F_{h k \ell}\right|^{2}$ \\
\hline Pares & $(2 n+1) 2$ & $4\left(f_{G a}-f_{A s}\right)$ & $16\left(f_{G a}-f_{A s}\right)^{2}$ \\
& $4 n$ & $4\left(f_{G a}+f_{A s}\right)$ & $16\left(f_{G a}+f_{A s}\right)^{2}$ \\
\hline Ímpares & $(4 n+3)$ & $4\left(f_{G a}-i f_{A s}\right)$ & $16\left(f_{G a}{ }^{2}+f_{A s}{ }^{2}\right)$ \\
& $(4 n+1)$ & $4\left(f_{G a}+i f_{A s}\right)$ & $16\left(f_{G a}{ }^{2}+f_{A s}{ }^{2}\right)$ \\
\hline Mistos & $n$ & 0 & 0 \\
\hline
\end{tabular}

Tabela 2.2: Fator de estrutura do GaAs para diferentes combinações de reflexões $h k \ell . n \in \mathbb{Z}$ e mistos indica ímpares e pares.

pela amplitude de espalhamento (fator de estrutura), ou intensidade, de cada reflexão $h k \ell$ do cristal. 


\subsection{Absorção de raios $\mathrm{X}$}

A seção-de-choque de absorção é uma grandeza de suma relevância no estudo dos fenômenos de interação de ondas eletromagnéticas com a matéria por ser um elo entre a teoria e o experimento. É por meio dela que se obtém o coeficiente de atenuação dos materiais e assim quantifica-se a eficiência de absorção dos mesmos para fótons de uma dada energia. $\mathrm{O}$ clássico experimento para medição do coeficiente de atenuação $\mu$ é ilustrado na Fig.2.6. Um feixe de raios X de seção transversal $S$ com intensidade incidente $I_{0}$ interage com $N$ átomos de uma fatia de material de espessura $x$. O fluxo incidente de raios X é dado por $\Phi_{0}=I_{0} / S$. O número de eventos de absorção por unidade de tempo é dado por $W=\Phi_{0} N \sigma_{a}$ onde $N$ é o número de centros absorvedores imersos no fluxo e $\sigma_{a}$ a seção-de-choque de absorção.

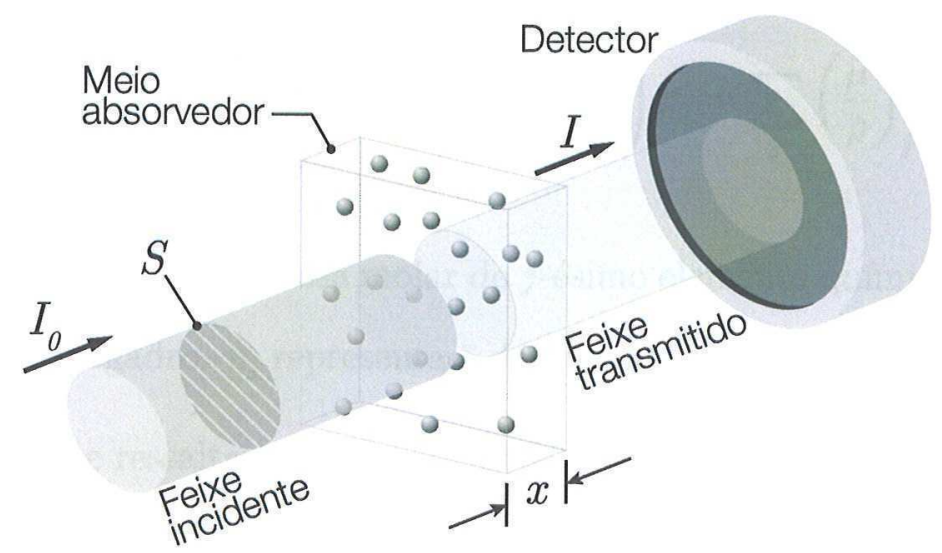

Figura 2.6: Modelo de atenuação de um feixe paralelo de raios X por uma fatia material de espessura $x$. O feixe incidente $I_{0}$ interage com os centros absorvedores do material e é transmitido com intensidade $I$. A atenuação de $I_{0}$ depende da densidade de centros absorvedores e da eficiência de absorção dos mesmos.

Em um material composto por um único elemento químico, contendo $\eta$ átomos por unidade de volume, a atenuação da intensidade devido a uma camada de espessura $d x$ é dada por 


$$
d I=I(x+d x)-I(x)=-\underbrace{(\eta S d x)}_{N} \Phi_{0} \sigma_{a}=-\underbrace{I(x)}_{S \Phi_{0}} \underbrace{\mu}_{\eta \sigma_{a}} d x
$$

Consequentemente, a intensidade do feixe transmitido por uma fatia de material de espessura $x$ será

$$
I(x)=I_{0} e^{-\mu x} .
$$

O coeficiente $\mu$ ou a razão $(\mu / \rho)$ são facilmente encontrados em livros-texto $[22,26]$, onde $\rho$ é a densidade de massa do material. Para materiais constituídos por mais de um elemento químico (por exemplo "j" elementos químicos), o coeficiente de atenuação é dado por

$$
\mu=\sum_{j} \underbrace{\left(\frac{\rho_{j} N_{A}}{A_{j}}\right)}_{\eta_{j}} \sigma_{a_{j}}=\sum_{j}\left(\frac{N_{A} \sigma_{a j}}{A_{j}}\right) \rho_{j}=\sum_{j}\left(\frac{\mu}{\rho}\right)_{j} \rho_{j}
$$

onde $\rho_{j}$ e $A_{j}$ são a densidade e a massa molar do $j$-ésimo elemento químico, respectivamente, e $N_{A}$ é o número de Avogadro. $\eta_{j}$ representa a densidade atômica do elemento $j$ no material.

É importante ressaltar que o coeficiente de atenuação apresentado na Eq.2.31 não possui nenhuma dependência com o arranjo dos átomos e apenas depende da concentração dos mesmos em um dado volume do material. Esta expressão somente é válida em situações onde a seção-de-choque $\sigma_{a}$ de cada átomo possui fraca dependência com o meio em que o mesmo está inserido. No entanto, os estados quânticos disponíveis nos arredores de um átomo sofrem perturbações devido a presença de átomos vizinhos. Experimentos para medição do coeficiente de atenuação em função da energia $\mu(\mathcal{E})$ fornecem informações das alterações de $\sigma_{a}$ e, consequentemente, das ligações químicas do arranjo atômico nas vizinhanças de um determinado átomo do material. Tais experimentos contituem a base de técnicas de 
espectroscopia de absorção de raios X.

\subsubsection{Ressonância atômica}

O fenômeno de ressonância atômica está intrinsicamente relacionado ao processo de absorção da radiação. A existência de níveis quânticos disponíveis no entorno de um átomo torna possível que um elétron de camadas mais internas (elétron de caroço) salte para um nível disponível, porém, ao invés do elétron permanecer nesse nível (processo típico de absorção), o elétron retorna ao seu nível inicial reemitindo um fóton com defasagem de $\pi / 2$ com relação à onda incidente de raios X, como esquematizado na Fig.2.7(a). Devido a essa correlação de fase do fóton emitido com a onda primária, a amplitude ressonante cria um termo imaginário na amplitude espalhada pelo átomo, ou seja, o fator de espalhamento atômico deixa de ser um número puramente real uma vez que $e^{i \pi / 2}=i$. Além disso, ele também passa a ser uma função da energia em consequência da dependência da ressonância com a energia. Em termos práticos, a ressonância implica em $f(Q) \rightarrow f(Q, \mathcal{E})$ e $\operatorname{Im}\{f(Q, \mathcal{E})\} \neq 0$.

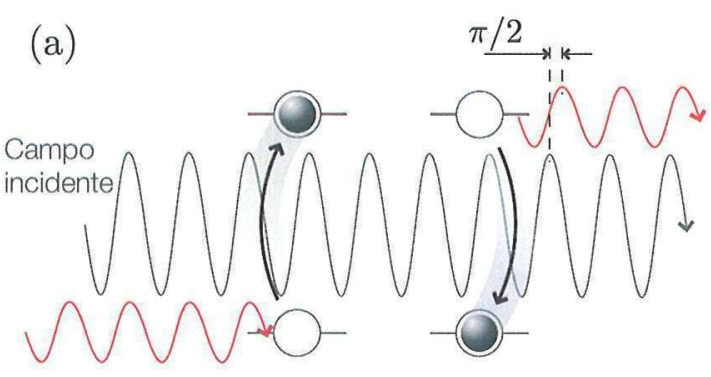

Ressonância

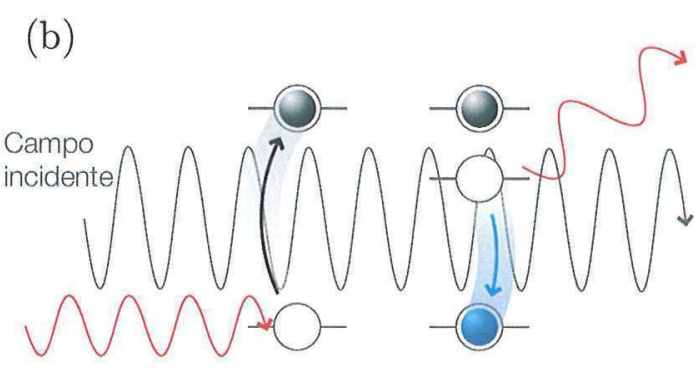

Absorção e fluorescência

Figura 2.7: (a)Ressonância atômica: fótons de raios X ejetam elétrons de camadas profundas $(\mathrm{K}$ ou $\mathrm{L}$ ) para níveis quânticos intermediários vazios nos arredores do átomo que, ao retornarem ao estado inicial, reemitem fótons de mesma energia mas com defasagem de $\pi / 2$. (b) Absorção de raios X: a lacuna deixada pelo elétron ejetado é preenchida por um elétron de outro nível atômico, efetivando o processo de absorção e gerando fótons de menor energia que os fótons primários. 
Como a transição eletrônica responsável pela absorção é também a transição primária na ressonância (Fig.2.7(a)), é intuitivo se esperar que quanto maior for a taxa de absorção, i.e. a seção-de-choque $\sigma_{a}$, maior também será a contribuição da componente imaginária de $f(Q, \mathcal{E})$. Embora a demonstração explícita da relação entre absorção e componente imaginária seja possível através da abordagem clássica do oscilador forçado, somente a abordagem da mecânica quântica[28] fornece a noção exata dos processos de absorção e ressonância, i.e. em termos de aniquilação e criação de fótons, permitindo tratar vários outros fenômenos em física da matéria condensada relacionados com a densidade de estados quânticos no entorno dos átomos[29].

Com respeito aos conceitos de absorção e ressonância, é importante ressaltar os seguintes fatos:

1. O efeito total da ressonância no fator de espalhamento atômico é dado por

$$
f(Q, \mathcal{E})=f(Q)+f^{\prime}(\mathcal{E})+i f^{\prime \prime}(\mathcal{E})
$$

2. A componente imaginária é proporcional à seção-de-choque de absorção de acordo com a relação

$$
f^{\prime \prime}(\mathcal{E})=\mathcal{E} \sigma_{a}(\mathcal{E}) / 4 \pi r_{e} \hbar c=\sigma_{a}(\mathcal{E}) / 2 r_{e} \lambda
$$

3. Existem relações matemáticas entre $f^{\prime}$ e $f^{\prime \prime}$ chamadas relações Kramers-Kronig que permitem determinar $f^{\prime}$ em função de $f^{\prime \prime}$ e vice-versa. Portanto, medidas do coeficiente de atenuação levam aos valores experimentais dos termos de correção do fator de espalhamento atômico, conforme ilustra o diagrama da Fig.2.8.

Os termos $f^{\prime}$ e $f^{\prime \prime}$, frequentemente chamados termos de correção da dispersão, 


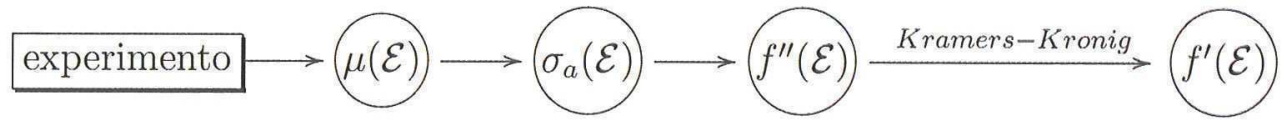

Figura 2.8: Diagrama de obtenção de correção da dispersão $f^{\prime}(\mathcal{E})$ e $f^{\prime \prime}(\mathcal{E})$.

estão dsponíveis nas tabelas da International Union of Crystallography. Os valores tabelados em geral advém de modelos teóricos para átomos isolados e são bastante acurados longe das energias de transição, ou bordas de absorção, dos átomos na amostra. Ao contrário do que acontece com os valores de $f(Q)$, cujos valores teóricos são mais acurados que os experimentais, os valores experimentais de $f^{\prime}$ e $f^{\prime \prime}$ são bem mais confiáveis porque os modelos teóricos não levam em conta a presença de átomos vizinhos, cujos efeitos podem ser bastante significativos nas proximidades das bordas de absorção.

\subsection{Geometria 3D da difração de raios X}

Se fosse necessário definir a difração de raios X em poucas palavras, certamente estas palavras seriam Lei de Bragg. Embora esta seja uma definição demasiadamente simplória e certamente subestima o potencial da grande área de cristalografia, a beleza da Lei de Bragg vem justamente da sua simplicidade em explicar algo tão útil e fundamental. Não é por menos que a ilustração da Fig.2.2 funcione como um logotipo da área de raios X pois, imediatamente ao ser vista, oferece informações diretas sobre o conceito de difração. No entanto, a informação fornecida pela Lei de Bragg, como é ilustrada na Fig.2.2, não é totalmente suficiente para a visualização de aspectos tridimensionais inerentes à geometria de difração em cristais e uma pequena extensão deste conceito se faz necessária aqui. A visualização plena de uma condição de difração no espaço direto ou angular é realizada por meio de cones de difração aqui denominados Cones de Bragg. 

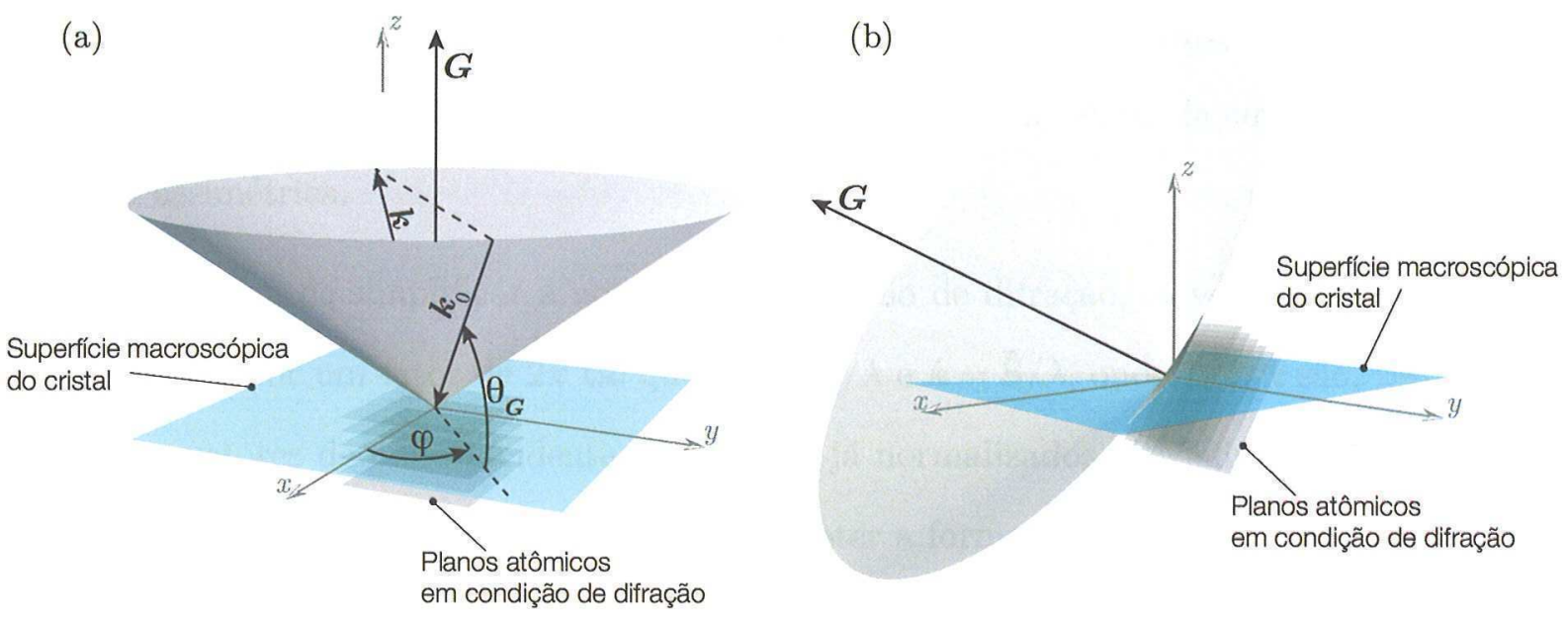

Figura 2.9: Representação tridimensional da condição de difração para (a) uma reflexão simétrica e (b) para o caso assimétrico. O feixe incidente $\boldsymbol{k}_{0}$, o qual incide num ângulo $\theta_{G}$ com os planos atômicos, satisfaz a condição de Bragg para o vetor de difração $G$. O vetor de onda $k$ representa o feixe difratado e o ângulo $\varphi$ denota rotações azimutais no cristal.

A Figura 2.9 ilustra as condições tridimensionais de difração para uma reflexão simétrica e para uma reflexão assimétrica ${ }^{1}$. A imagem do cone provém da idealização de uma revolução de $360^{\circ}$ do vetor incidente $\boldsymbol{k}_{0}$ em torno de $\boldsymbol{G}$. Uma vez que esta revolução é realizada na condição de difração, ou seja, mantendo o ângulo de Bragg $\theta_{G}$, o cone de Bragg contempla o conjunto das condições de difração para um dado vetor recíproco $G$. Em uma visão experimental, o cone de Bragg é facilmente observado alinhando-se o vetor de difração com o eixo de rotação azimutal (estágio de rotação $\varphi$ ) do goniômetro, e.g. Fig.2.9(a), neste texto representado pela direção $z$. Após o alinhamento, é possível monitorar a intensidade da reflexão durante rotações $\varphi$, o que significa uma visualização direta do cone de Bragg da reflexão. Esta é a base geométrica da técnica de varredura Renninger de raios X a qual será abordada nos próximos capítulos. Para reflexões assimétricas também é possível observar experimentalmente o cone de Bragg por meio de movimentos compostos de $\varphi$ e $\theta$. Estes tipos

\footnotetext{
${ }^{1}$ A extensão dos planos atômicos para fora da superfície do cristal (Fig.2.9(b)) visa um melhor entendimento da geometria de difração embora estes planos se limitem à superfície macroscópica do cristal.
} 
de varreduras $\theta-\varphi$ serão exploradas posteriormente na seção sobre difração Bragg-superfície e o traço diagonal lá observado refere-se a uma região do cone acima da superfície para uma reflexão assimétrica.

A fim de simplificar a notação da condição de difração, os vetores de onda serão normalizados por um fator de $2 \pi$ tal que $\boldsymbol{k}_{0}=\hat{\mathrm{S}}_{0} / \lambda$ e $\boldsymbol{k}=\hat{\mathrm{S}} / \lambda$, onde $\boldsymbol{k}_{0}$ e $\boldsymbol{k}$ são, respectivamente, os vetores de onda incidente e difratado já normalizados. Redefinidos os vetores de onda, obtem-se $\boldsymbol{k}-\boldsymbol{k}_{0}=\boldsymbol{G}$ e assim é possível obter a forma vetorial da Lei de Bragg,

$$
\boldsymbol{k}_{0} \cdot \boldsymbol{G}=\underbrace{-\frac{G \cdot G}{2}}_{-1 / 2 d_{h k \ell}^{2}}=-\underbrace{\left|k_{0}\right|}_{1 / \lambda} \underbrace{|G|}_{1 / d_{h k \ell} \mid} \sin \theta_{G} \Rightarrow \lambda=2 d_{h k \ell} \sin \theta_{G},
$$

a qual pode ser vista como a equação de um cone com geratrizes de revolução em torno de $\boldsymbol{G}$ determinam as direções dos vetores $\boldsymbol{k}_{0}$ e $\boldsymbol{k}$. Esse conceito será bastante utilizado nas próximas seções quando serão exploradas situações onde duas ou mais reflexões são excitadas simultaneamente para um mesmo vetor de onda incidente $\boldsymbol{k}_{0}$. Em tais casos, a intersecção entre dois ou mais cones será a representação geométrica de condições de difração múltipla no cristal.

De acordo com a abordagem da Seção 2.1, a condição de difração ocorre quando o vetor de espalhamento $s$ é igual ao vetor recíproco $G$. Esta afirmação é a base da construção geométrica de Ewald a qual é de suma importância na visualização tridimensional de eventos de difração no espaço recíproco; $s=G$ significa que um ponto do espaço recíproco está tocando a casca esférica de Ewald conforme ilustra a Fig.2.10. Assim como a representação dos cones de Bragg no espaço direto, a construção de Ewald também fornece uma visão tridimensional da condição de difração. O análogo no espaço recíproco da visualização dos cones de Bragg seria a realização de rotações $\varphi$ no cristal mantendo um ponto recíproco 
(neste caso o ponto vermelho da Fig.2.10) em contato constante com a casca esférica. Com base na Fig.2.10, onde é ilustrado um caso de difração de uma reflexão simétrica, uma vez alinhado o vetor de difração $G$ com o eixo $z$ do goniômetro, varreduras em $\varphi$ fornecerão um sinal constante da reflexão $G$. Quanto melhor for o alinhamento da amostra com o eixo de rotação, menor será a precessão do vetor recíproco nas varreduras $\varphi$ e mais constante será o nível de intensidade lido pelo detetor ${ }^{2}$.

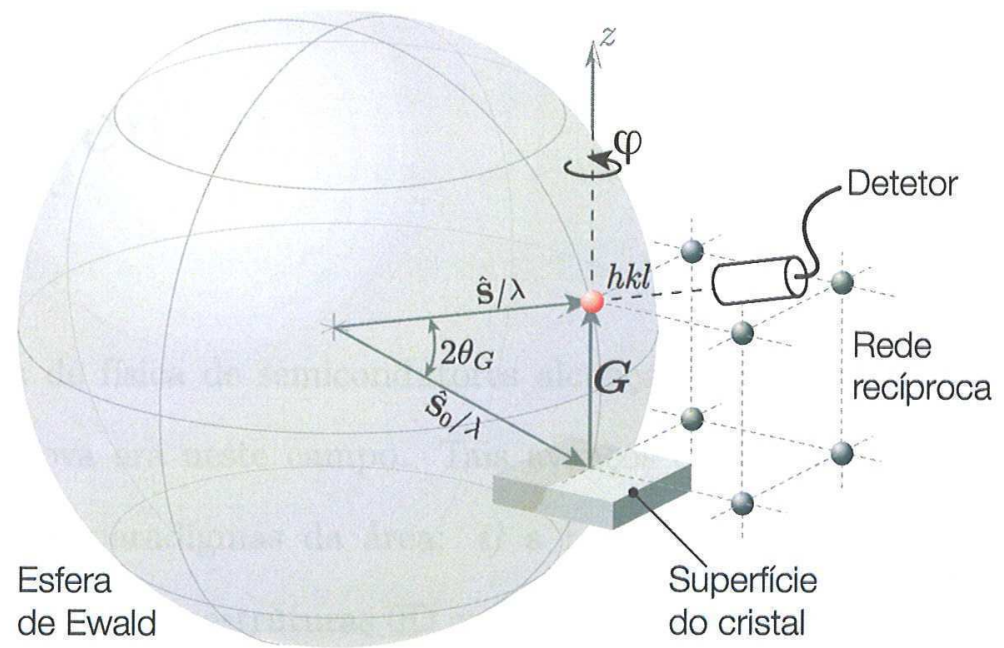

Figura 2.10: Representação no espaço recíproco da condição de difração de uma reflexão simétrica por meio da construção de Ewald. Um ponto recíproco (neste caso o ponto vermelho em destaque) é colocado em condição de difração ao tocar a casca esférica de raio $1 / \lambda$. $O$ feixe difratado sempre sairá na direção formada pela linha que liga o centro da esfera ao ponto recíproco em condição de difração, direção esta que sempre estará a $2 \theta_{G}$ do feixe incidente, sendo $\theta_{G}$ o ângulo entre o feixe incidente e os planos difratantes (ângulo de Bragg).

\footnotetext{
${ }^{2} \mathrm{~A}$ observação de um nível constante de intensidade durante as varreduras $\varphi$ também está relacionada à qualidade do cristal e nesta seção apenas o aspecto geométrico é abordado. Além disso, esta seção ainda não leva em conta os possíveis casos de difração múltipla que podem ser observados em tais varreduras $\varphi$.
} 


\section{Capítulo 3}

\section{Experimental}

Os progressos em de física de semicondutores alcançados no início dos anos 90 marcaram o início de uma nova era neste campo. Tais avanços estão fundamentalmente vinculados à quebra de alguns paradigmas da área: i) a realização experimental de estruturas 1D (fios quânticos) e ainda das estruturas 0D ou pontuais (QDs também denominados "átomos atificiais" pela natureza discreta da densidade de estados disponíveis), em contra-posição aos já conhecidos poços quânticos; ii) uso de métodos de epitaxia de nanoestruturas autoorganizadas ao invés da tradicional litografia; e iii) crescimento de heteroestruturas com descasamento de parâmetro de rede em substituição aos sistemas com parâmetros de rede casados [30]. Quase três décadas mais tarde, os dispositivos atuais ainda são frutos de tais avanços e continuam sendo um tema largamente explorado pela comunidade. O sistema nanoestruturado abordado nessa tese (QDs de InAs crescidos em GaAs) faz parte dessa "safra de $90 "$ pelo seu conceito de fabricação.

Não menos importante do que a tecnologia de fabricação dos sistemas nanoestruturados, os meios de caracterização desses sistemas são essenciais e devem, além de outras 
características, ser capazes de analisar dimensões, forma e composição dessas nanoestruturas. Estes parâmetros são críticos na definição dos níveis discretos de energia dos portadores de carga dentro dos QDs [31]. Para o caso de sistemas com QDs expostos, técnicas tradicionais de caracterização de superfície, e.g. AFM, STM e TEM, são largamente empregadas na análise da morfologia dos QDs, porém, raramente fornecem informações sobre o campo de tensão na rede e composição das ilhas expostas. Para isso, técnicas de difração de raios $\mathrm{X}$ à incidência rasante (GIXRD do inglês Grazing Incidence X-ray Diffraction) têm se mostrado o método mais eficaz na obtenção de informação do gradiente de tensão dentro das ilhas assim como, quando na configuração de GIXRD anômala, têm fornecido informações importantes sobre a composição da nanoestruturas [13, 14, 32, 33, 34]. No entanto, dispositivos opto-eletrônicos acabados necessariamente precisam ter os QDs encapsulados dentro da matriz semicondutora, ou seja, os QDs são cobertos por uma sobre-camada que tem a função de proteção e passivação dos QDs. O crescimento da sobre-camada dificulta a análise dos QDs via técnicas de pouca penetração, como GIXRD. Alternativas para análise de sistemas acabados são portanto requeridas. Esta pesquisa se focou na exploração de técnicas de difração de raios $\mathrm{X}$ que pudessem fornecer informações para análise de sistemas cobertos de QDs de InAs/GaAs(001) utilizando fontes síncrotron e fontes convencionais de raios X.

\subsection{QDs de InAs crescidos sobre GaAs}

O conjunto de amostras estudado nesse trabalho constituiu-se essencialmente de dispositivos opto-eletrônicos baseados em QDs auto-organizados de InAs crescidos em substratos de GaAs(001) por meio de epitaxia de feixe molecular (MBE do inglês Molecular Beam Epitaxy). Amostras representando as principais etapas do processo de crescimento dos dispositivos foram analisadas individualmente indo desde o substrato comercial de GaAs até o 
dispositivo final com QDs de InAs embebidos na matriz de GaAs. A Fig.3.1 ilustra as várias configurações de amostras analisadas. Todas as amostras foram crescidas sobre substrato comercial de GaAs(001) semi-isolante de espessura 600 $\mathrm{m}$ com superfície polida (Fig.3.1(a)). Sobre o substrato comercial foi crescida uma camada de GaAs de espessura típica de $2000 \AA$ denominada camada tampão (Fig.3.1(b)) cuja função é eliminar ou minimizar a presença de impurezas e defeitos superficiais na superfície de crescimento, os quais são introduzidos no procedimento de corte e polimento do wafer (em português bolacha). O crescimento das ilhas inicia-se com a deposição de poucas monocamadas de InAs (camada wet Fig.3.1(c)) quando é iniciado o processo de nucleação dos QDs (Fig.3.1(d)). O dispositivo é finalizado (Fig.3.1(e)) pela cobertura das ilhas via deposição de uma sobre-camada de GaAs.

(a)

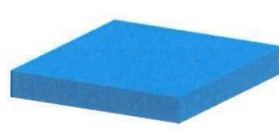

Substrato de GaAs (b)

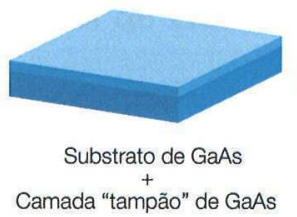

(c)

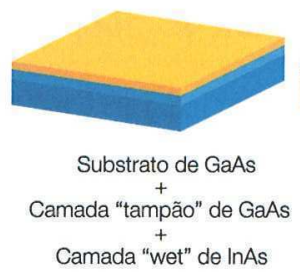

(d)

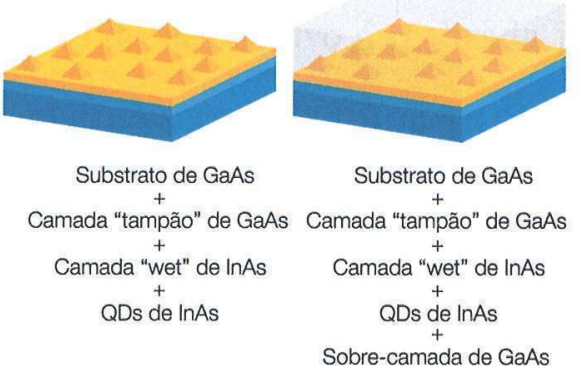

Figura 3.1: Sequência com as amostras analisadas as quais representam os principais estágios da construção do dispositivo opto-eletrônico via MBE. (a) Substrato comercial de GaAs(001), (b) crescimento da camada "tampão" de GaAs, (c) deposição da camada "wet" de InAs, (d) nucleação das ilhas de InAs e (e) adição da sobre-camada de GaAs.

O processo de formação das ilhas está intrinsicamente relacionado ao mecanismo de acomodação de tensão proveniente do descasamento das redes na interface da camada tampão com a camada wet. Os parâmetros de rede do GaAs e InAs à $300 \mathrm{~K}$ são $5,6533 \AA$ e $6,0583 \AA$, respectivamente, e proporcionam um descasamento de redes de $\sim 7 \%$. A tensão na interface é proporcional à espessura da camada wet e, portanto, o balaço da energia livre entre interface e superfície da wet é alterado à medida que sua espessura aumenta. Um valor 
crítico de tensão na camada wet é atingido para uma dada espessura $(\sim 2,4$ monocamadas de InAs), e a deposição de mais material ocasiona na formação das ilhas 3D nas quais a tensão é relaxada. Este procedimento de crescimento é conhecido como modo StranskiKrastanov (SK) e é um procedimento largamente empregado no crescimento de QDs devido à versatilidade no crescimento de grandes densidades superficiais de ilhas auto-organizadas. Em algumas situações, tal processo de relaxação das redes ocorre de forma não-coerente, introduzindo defeitos nos QDs e na camada wet e comprometendo de forma importante o desempenho óptico dos dispositivos. Especificamente no caso de QDs de InAs crescidos sobre GaAs, a direção cristalográfica da superfície do substrato exerce um papel crucial na integridade final dos QDs. O crescimento de ilhas de InAs sem defeitos de discordância de redes (chamadas ilhas coerentes) é realizado quase que exclusivamente quando os QDs são crescidos sobre substratos de $\operatorname{GaAs}(001)$ [35]. A finalização do dispositivo é realizada pela deposição de uma sobre-camada de GaAs (Fig.3.1(e)) com espessura de 300 . Esta camada final é um requisito padrão em dispositivos opto-eletrônicos pois tem um papel de passivação e proteção das nanoestruturas emissoras ou detectoras de radiação, além de fornecer uma nova superfície de crescimento para um novo conjunto de QDs.

O método de MBE é uma das ferramentas mais avançadas de crescimento epitaxial e se destaca por permitir o crescimento de camadas atômicas em taxas muito baixas de deposição, possibilitando um controle ultra preciso da composição, espessura das camadas e uniformidade do cobrimento da superfície. O aparato de MBE utilizado no crescimento das amostras (modelo GEN II da Veeco) contitui-se de uma câmara operando em ultra alto vácuo ( $\sim 10^{-11}$ Torr obtido por meio de bomba iônica) onde estão instaladas células de efusão de diversos materias (Arsênio, Gálio e Índio, dentre outros), cadinhos para evaporação ou calefação das células de efusão, porta-amostras no qual o substrato é montado e aquecido e obturadores mecânicos individuais para interrupção do feixe na célula de efusão quando 


\begin{tabular}{llllll}
\hline $\begin{array}{c}\text { Amostra } \\
\text { (\#) }\end{array}$ & $\begin{array}{c}\text { Tampão } \\
\text { (espessura) }\end{array}$ & $\begin{array}{l}\text { Camada Wet } \\
\text { (espessura) }\end{array}$ & $\begin{array}{l}\text { QDs } \\
\text { (densidade superficial) }\end{array}$ & $\begin{array}{l}\text { QDs } \\
\text { (taxa de deposição) }\end{array}$ & $\begin{array}{l}\text { Sobre-camada } \\
\text { (espessura) }\end{array}$ \\
\hline 1 & - & - & - & - & - \\
2 & $200 \mathrm{~nm}$ & - & - & - & - \\
3 & $200 \mathrm{~nm}$ & $2,4 \mathrm{MC}$ & $360 \mathrm{QDs} / \mu \mathrm{m}^{2}$ & $0,09 \mathrm{MC} / \mathrm{s}$ & - \\
4 & $200 \mathrm{~nm}$ & $2,4 \mathrm{MC}$ & $200 \mathrm{QDs} / \mu \mathrm{m}^{2}$ & $0,007 \mathrm{MC} / \mathrm{s}$ & - \\
5 & $200 \mathrm{~nm}$ & $2,4 \mathrm{MC}$ & $360 \mathrm{QDs} / \mu \mathrm{m}^{2}$ & $0,09 \mathrm{MC} / \mathrm{s}$ & $30 \mathrm{~nm}$ \\
6 & $200 \mathrm{~nm}$ & $2,4 \mathrm{MC}$ & $200 \mathrm{QDs} / \mu \mathrm{m}^{2}$ & $0,007 \mathrm{MC} / \mathrm{s}$ & $30 \mathrm{~nm}$ \\
7 & $400 \mathrm{~nm}$ & $2,4 \mathrm{MC}$ & $300 \mathrm{Ds} / \mu \mathrm{m}^{2}$ & $0,05 \mathrm{MC} / \mathrm{s}$ & $30 \mathrm{~nm}$ \\
8 & $200 \mathrm{~nm}$ & $1,0 \mathrm{MC}$ & - & - & $30 \mathrm{~nm}$ \\
\hline
\end{tabular}

Tabela 3.1: Especificações do conjunto de amostras. A amostra \#1 refere-se ao wafer comercial de GaAs o qual foi utilizado como substrato em todas as demais amostras. A amostra \#8 não contém ilhas e trata-se de uma monocamada simples de InAs coberta por uma sobre-camada de 30nm de GaAs.

necessário. Com este aparato, um conjunto amplo de amostras foi crescido pelo Laboratório de Novos Materiais Semicondutores do IFUSP (LNMS) e fornecido a esta pesquisa. A lista completa das amostras e suas principais características é fornecida na Tabela 3.1.

O monitoramento da epitaxia das camadas é realizado in situ por meio de difração de elétrons (RHEED, Reflection high-energy electron diffraction). O canhão de elétrons também é um elemento padrão em equipamentos de MBE e o experimento de RHEED se dá por meio da incidência rasante na superfície da amostra de um feixe colimado de elétrons com energia entre 10 e $20 \mathrm{keV}$. Os elétrons penetram algumas camadas atômicas e são espalhados/difratados para uma tela fosforescente. Um esquema simplificado do experimento de RHEED dentro da câmara de crescimento do MBE é ilustrado na Fig.3.2.

A sequência típica das etapas do crescimento de QDs no modo SK é ilustrada na Fig.3.3(a-d). Durante a deposição das primeiras moléculas de $\mathrm{As}_{4}$ e átomos de In, formamse aglomerados de InAs que cobrem gradativamente a superfície exposta (Fig.3.3(a)) até a formação da camada wet Fig.3.3(b). Devido ao estado crítico de tensão na wet após a deposição de poucas monocamadas, ilhas tridimensionais começam a eclodir, consumindo 


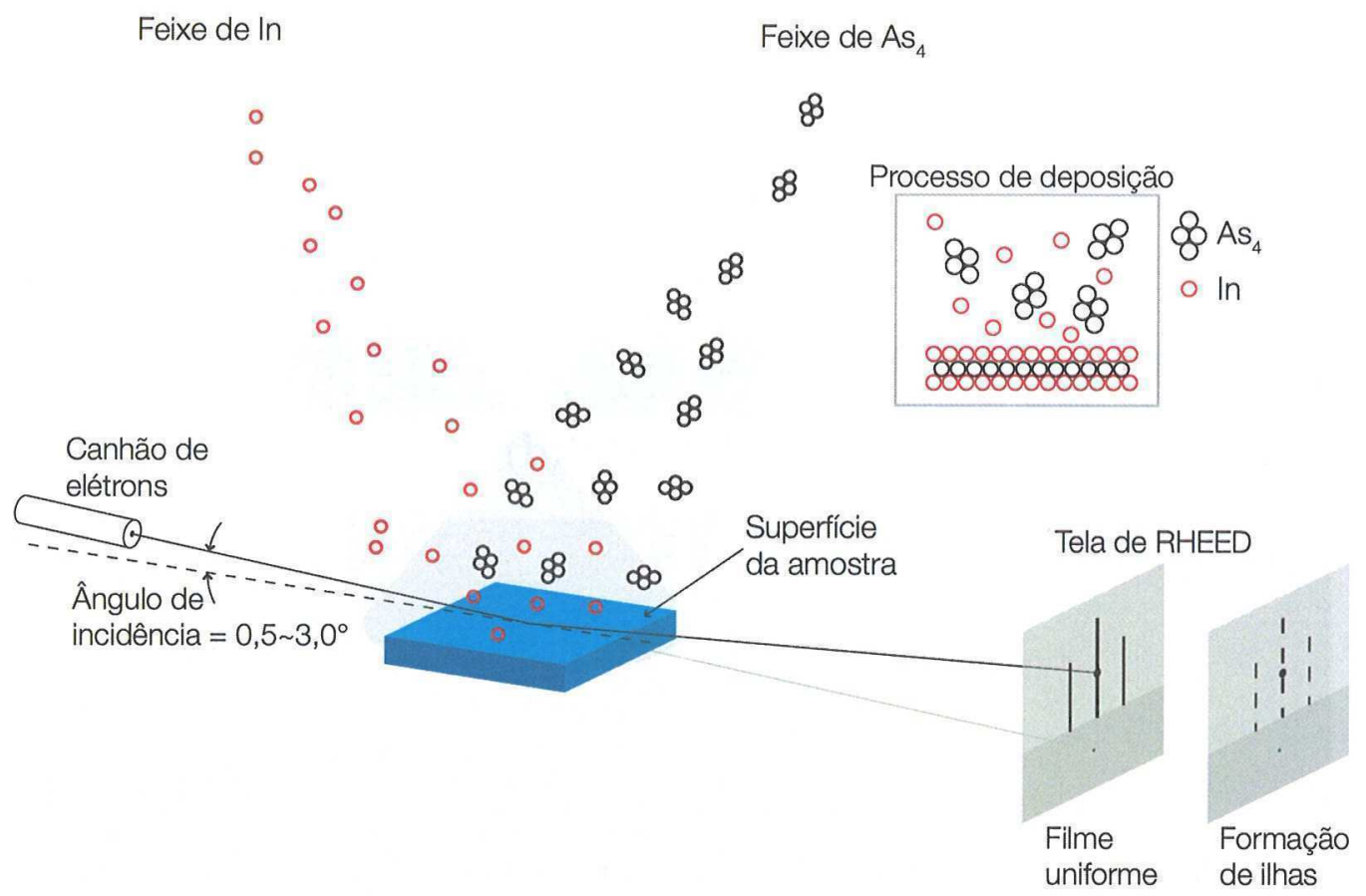

Figura 3.2: Esquema do experimento in situ de RHEED dentro do equipamento de MBE. Células de efusão de Índio e Arsênio são aquecidas a temperaturas da ordem de $1500^{\circ} \mathrm{C}$ de forma a evaporar In e $\mathrm{As}_{4}$ gerando o feixe molecular de deposição de InAs (detalhe). O feixe de elétrons do experimento RHEED é difratado pelas novas camadas de InAs e o padrão de difração é monitorado em uma tela de fósforo.

parte do material da camada wet (Fig.3.3(c)) que termina com $~ 1 \mathrm{MC}$. Esse mecanismo de formação dos QDs explica qualitativamente o teor não nulo de Ga dentro das ilhas e sugere um fenômeno de migração de Ga do substrato para o interior dos QDs [1]. A continuação da deposição de InAs resulta no aumento direto do volume das ilhas recém-crescidas além de alterar a forma das mesmas (Fig.3.3(d)). Um padrão RHEED, obtido durante a formação das ilhas de InAs de uma das amostras dessa pesquisa, é ilustrado na Fig.3.3(e-f). Linhas contínuas de intensidade e um intenso ponto especular, observados na Fig.3.3(e), sugerem a difração do feixe de elétrons por uma estrutura perfeitamente plana (2D). Já o surgimento do padrão de linhas fragmentadas (Fig.3.3(f)) indica o início da formação de saliências 3D na superfície, ou seja, representa o início da nucleação dos QDs. 


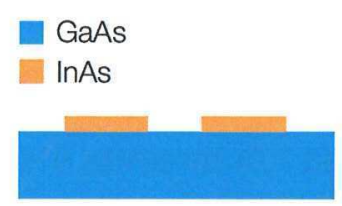

(a)

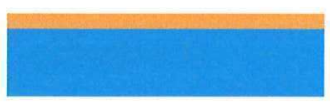

(b)

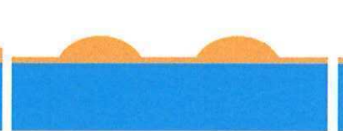

(c)

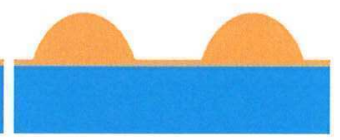

(d)

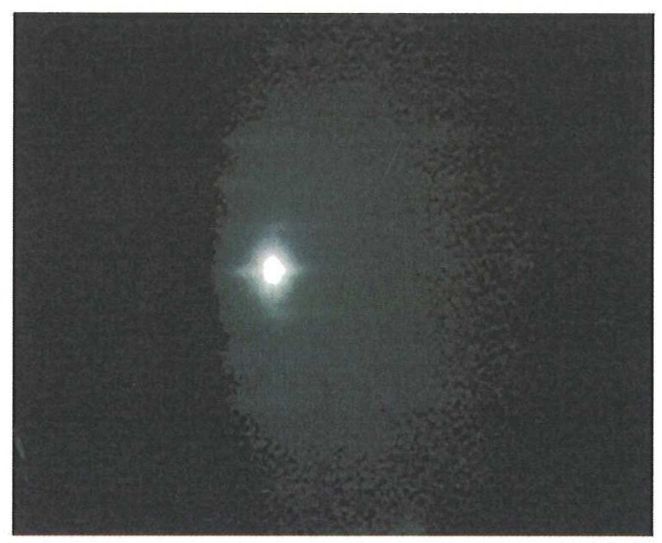

(e)

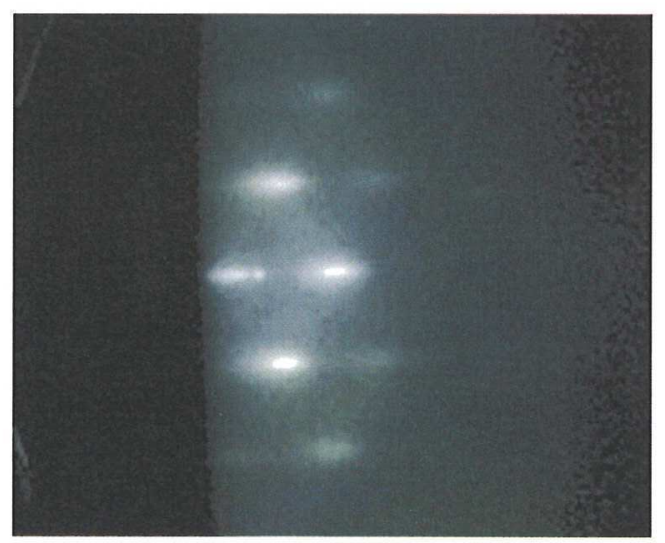

(f)

Figura 3.3: Esquema de formação das ilhas de InAs no modo de crescimento StranskiKrastanov: (a) cobertura parcial do substrato, (b) formação da camada wet, (c) nucleação das ilhas de InAs com parte do material da camada wet e (d) aumento do volume das ilhas. Imagens in situ de RHEED durante processamento do dispositivo opto-eletrônico: (e) antes e (f) depois da nucleação dos QDs de InAs.

Para uma investigação preliminar do processo de crescimento das amostras, foram tomadas curvas de varredura $\theta$ de alta resolução da reflexão 004 do GaAs em uma amostra típica com QDs cobertos (amostra \#5) e também em uma amostra com camada wet coberta (amostra \#8), conforme apresentadas na Fig.3.4. As curvas foram obtidas no arranjo experimental do X-ray Lab/UoGuelph (Sub-seção 3.2.2) com energia 8047,78eV (CuK $\alpha_{1}$ ) e a resolução necessária para visualização das franjas da sobre-camada foi obtida pelo ajuste da fenda de resolução (Fig.3.9) instalada em frente ao detector. Para análise das curvas de var- 
reduras $\theta$, foi desenvolvido um programa no qual utiliza-se um modelo cinemático de difração por 2 camadas (camada wet/QDs de InAs + sobre-camada de GaAs) para simulação das curvas de varreduras teóricas ilustradas na Fig.3.4. Neste programa, parâmetros de ajuste tais como espessura das camadas, deformação e relaxação são escolhidos via algoritmo genético, conforme é apresentado no apêndice B.

Para a amostra com a camada wet coberta, Fig.3.4(a), o modelo do algoritmo genético fornece as espessuras de $3,86 \AA$ e $288 \AA$ para a camada wet e sobre-camada, respectivamente, os quais são compatíveis com os valores nominais de $1,0 \mathrm{MC}$ de $\operatorname{InAs}(3,2 \AA$ quando $100 \%$ tensionada) e $300 \AA$ da sobre-camada de GaAs conforme a Tabela 3.1. Na amostra com QDs cobertos, Fig.3.4(b), o programa fornece a espessura de 8,2 $\AA$ para a camada wet+QDs e $281 \AA$ para a sobre-camada. As espessuras obtidas no modelo da Fig.3.4(b) fornecem indícios de que a presença dos QDs altera substancialmente a interface com a sobre-camada na comparação com a amostra sem QDs da Fig.3.4(a). O desvio logaritmico médio calculado pela Eq.B.6 é apresentado nos ajustes como $E_{a j u s t e}$ e confirma uma menor qualidade de ajuste para a Fig.3.4(b). Isto é devido à discordância de intensidades das franjas, porém, a reprodução da posição e período das franjas foi eficiente na estimativa das espessuras. Estes resultados serão discutidos com mais detalhes quando necessário e, portanto, esta seção se restringirá à esta descrição preliminar das espessuras.

A caracterização superficial dos QDs foi feita via AFM em amostras com QDs expostos. O experimento foi realizado no Laboratório de Microscopia de Força Atômica e Tunelamento (MTA) do Laboratório Nacional de Luz Síncrotron (LNLS) utilizando um microscópio de força atômica modelo Nanoscope IIIa da Veeco em modo intermitente ou semi-contato (modo tapping em inglês). Os resultados das caracterizações das amostras \#3 e \#4 são apresentados na Fig.3.5. 

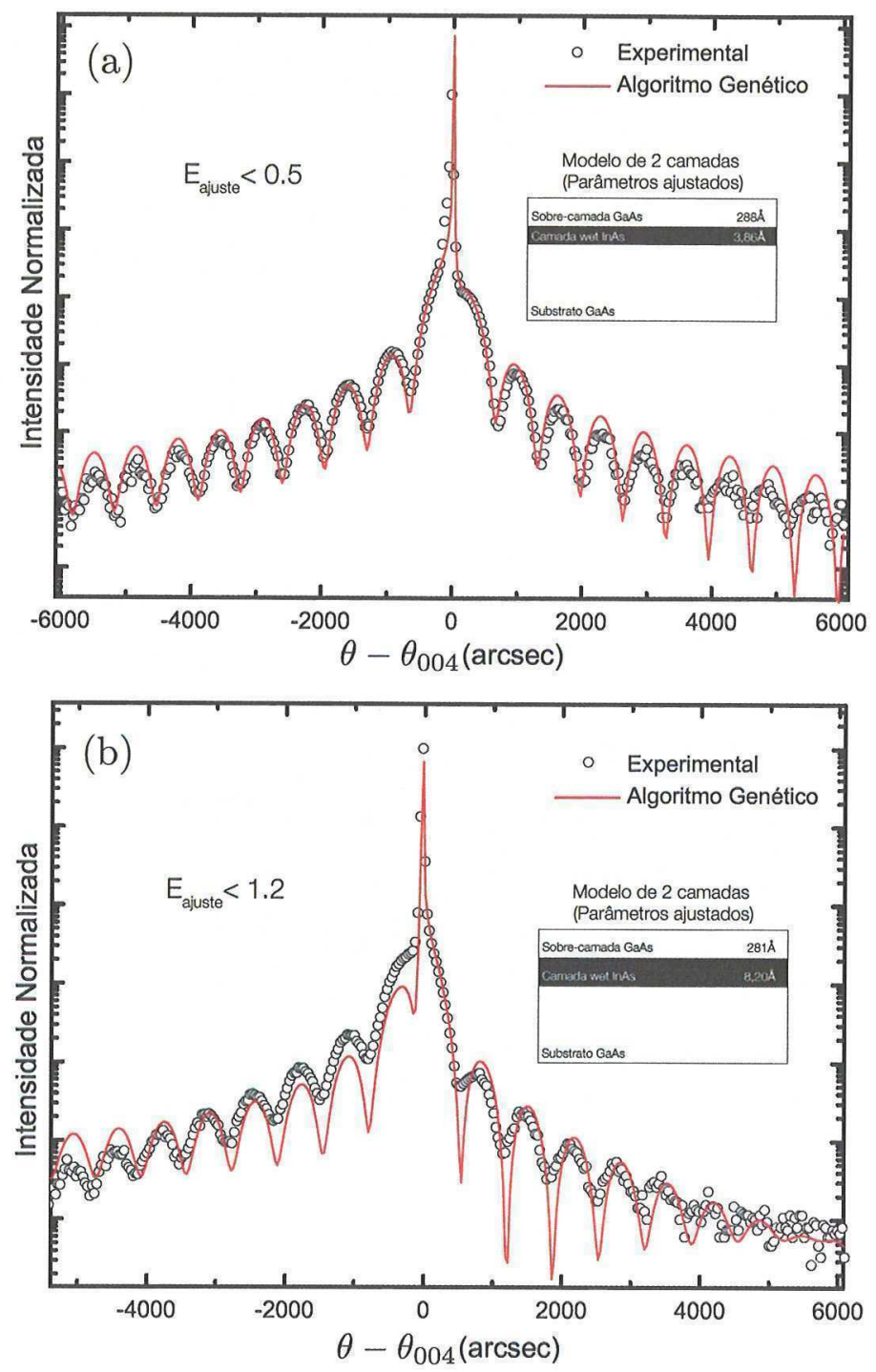

Figura 3.4: Curvas de varredura $\theta$ de alta resolução da reflexão 004 do GaAs com respectivas simulações de sistema de duas camadas para (a) amostra \#8 (camada wet com sobre-camada) e (b) amostra \#5 (QDs com sobre-camada). Os valores $E_{\text {ajuste }}$ correspondem ao desvio logaritmico médio (Eq.B.6) para os respectivos ajustes em (a) e (b).

Um exemplo de análise morfológica dos padrões de AFM é mostrado na Fig.3.6. O perfil lateral dos QDs ao longo da linha diagonal indicada na Fig.3.5(b), e a distribuição de alturas dos QDs dentro do retângulo demarcado na Fig.3.5(b) são apresentados na Fig.3.6. A análise dos resultados de AFM indicam que a amostra \#3, cujos QDs foram crescidos a uma 


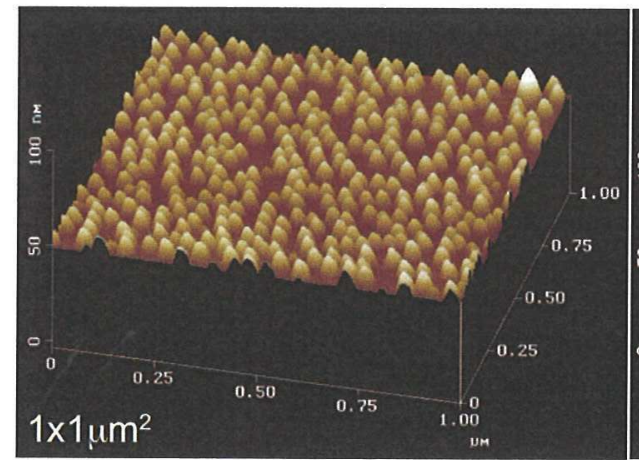

(a)

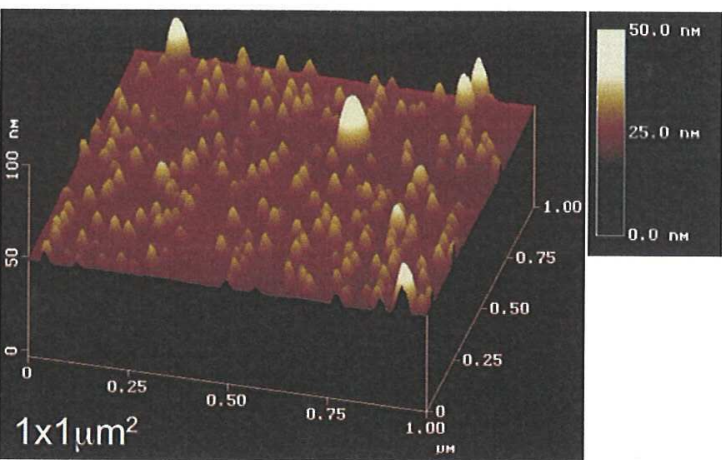

(c)

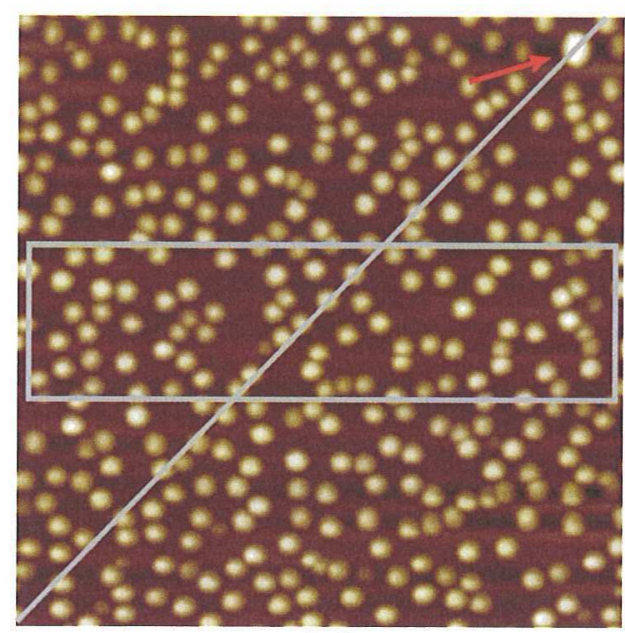

(b)

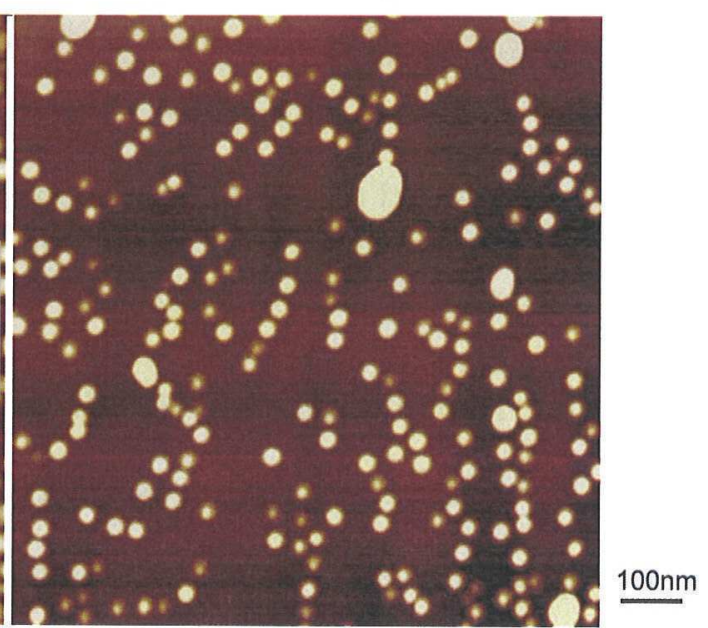

(d)

Figura 3.5: Caracterização superficial de amostras com QDs expostos via AFM. (a) e (b) imagens AFM, amostra \#3 com densidade superficial 360QDs $/ \mu m^{2}$, em perspectiva e de topo, respectivamente. (c) e (d) imagens AFM, amostra \#4 com densidade superficial 200QDs $/ \mu m^{2}$, em perspectiva e de topo, respectivamente.

taxa de $0,09 \mathrm{MC} / \mathrm{s}$, contém uma densidade superficial de $\sim 360 \mathrm{QDs} / \mu \mathrm{m}^{2} \mathrm{com}$ raio médio de 26nm e altura média de 11nm. Já a amostra \#4, com ilhas crescidas a 0,007MC/s, apresenta densidade superficial de $\sim 200 \mathrm{QDs} / \mu \mathrm{m}^{2}$ de ilhas similares às da amostras \#3 porém houve formação de algumas ilhas $\left(\sim 10 \mathrm{QDs} / \mu \mathrm{m}^{2}\right)$ com raio médio de $170 \mathrm{~nm}$ e altura média de 31 nm.

Para as amostras com QDs cobertos, foi realizada uma avaliação da eficiência de 


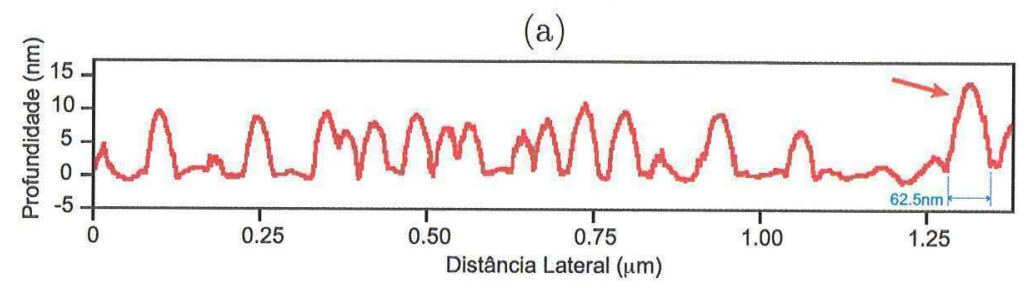

(b)

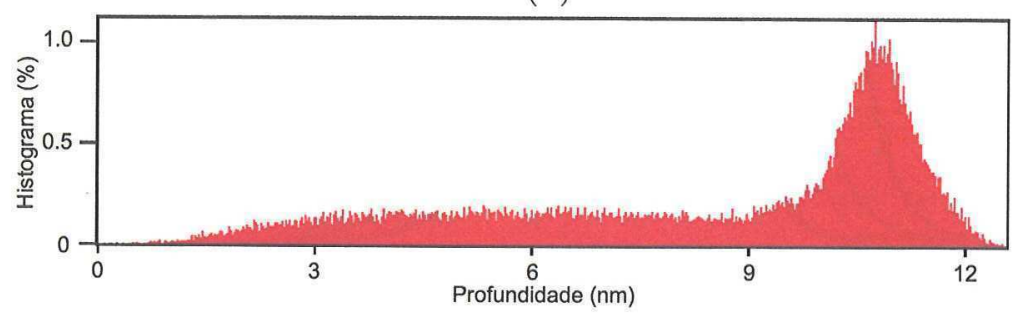

Figura 3.6: Análise das dimensões e formas dos QDs. (a) Seção transversal de QDs ao longo da linha diagonal ilustrada em Fig.3.5(b). Seta aponta para QD indicado na Fig.3.5(b). (b) histograma da altura dos QDs compreendidos no retângulo demarcado na Fig.3.5(b).

emissão das ilhas de InAs por meio de medidas de fotoluminescência (PL do inglês photoluminescence) realizadas no LNMS. A Fig.3.7 apresenta as curvas de PL para amostras com QDs crescidos com variadas taxas de crescimento dos QDs, provenientes de amostras similares, mas não exatamente aquelas listadas na Tabela 3.1.

Das curvas de PL é possível ressaltar alguns pontos importantes: i) o pico mais intenso das curvas refere-se ao sinal do estado fundamental e o menos intenso ao $1^{\circ}$ estado excitado do QD de InAs; ii) o deslocamento em energia dos perfis de emissão pode estar relacionado à variação do volume dos QDs para as diversas taxas de deposição de InAs e iii) há um expressivo alargamento das curvas à medida que se aumenta a taxa de deposição, o que indica um aumento na dispersão dimensional das ilhas (maior variedade de tamanhos de QDs). Embora exista uma correlação do desempenho de emissão das ilhas com a taxa de crescimento das mesmas, mudanças relevantes podem acontecer na operação de cobrimento dos QDs (deposição da sobre-camada de GaAs) e técnicas de análise estrutural, como a 


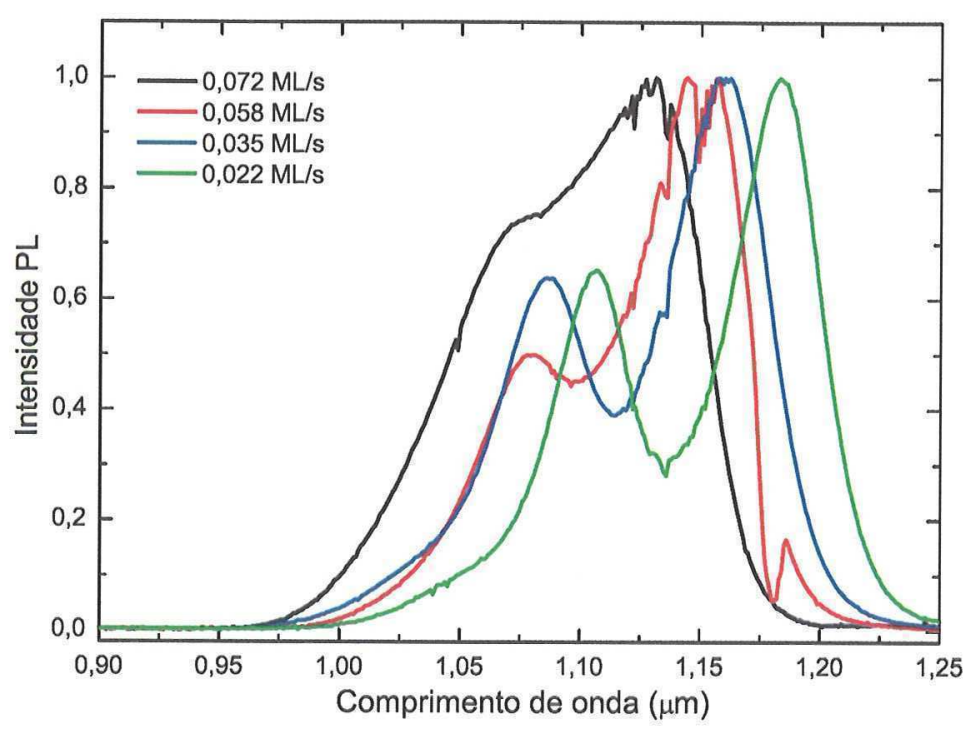

Figura 3.7: Curvas de PL para amostras com QDs de InAs cobertos crescidos com diferentes taxas de deposição de InAs.

difração de raios X, são necessárias para um melhor entendimento do mecanismo de crescimento do dispositivo acabado. A seção à seguir apresenta os aparatos utilizados na aquisição dos dados de difração de raios X.

\subsection{Arranjo experimental de difração de raios X}

A aquisição dos dados de difração de raios $\mathrm{X}$ foi realizada em três frentes distintas. Os experimentos de determinação de parâmetro de rede via varreduras Renninger de raios X foram realizadas majoritariamente na linha de luz XRD1 do LNLS. Mapas de difração BraggSuperfície foram obtidos na linha XRD1 e no laboratório de espalhamento e difração de raios X da Universidade de Guelph-Canada (X-ray Lab/UoGuelph). Experimentos de difração de raios X à incidência rasante foram realizados no X-ray Lab/UoGuelph e na linha XRD2 do LNLS. À medida que os resultados forem apresentados, o respectivo aparato experimental será citado. 


\subsubsection{Linha de difração XRD1-LNLS}

A linha XRD1 do LNLS é servida por um feixe policromático (feixe branco) proveniente de um imã defletor (bending-magnet). A monocromatização é feita por meio de um monocromador tipo cristal duplo de $\operatorname{Si}(111)$ o qual disponibiliza uma faixa operacional de energia de 4 a $12 \mathrm{keV}$. A focalização e colimação vertical é realizada por espelhos de luz branca e a focalização sagital por meio da curvatura elástica do segundo cristal monocromador. A linha oferece um fluxo médio de $\sim 5 \times 10^{10}$ fótons/s·mrad para a energia de $8 \mathrm{keV}$. Detectores tipo "cintiladores" modelo Cyberstar da FMB Oxford foram utilizados no monitoramento do sinal de raio X. O feixe é direcionado ao centro de um goniômetro de 3 eixos (ou 3-círculos) da marca Huber o qual é montado sobre uma estrutura metálica denominada "berço $\chi$ " de acordo com a ilustração da Fig.3.8. Os estágios de rotação $\theta$ e $\varphi$ operam com passos mínimos de $0,0002^{\circ}$ enquanto que o berço $\chi$ é somente destinado à seleção da polarização pois realiza rotações em torno da direção do feixe incidente. Todos os experimentos dessa tese realizados na linha XRD1 utilizaram óptica de feixe paralelo (espelho e cristal sagital focalizados no infinito) com divergência efetiva de $18^{\prime \prime}$ e $24^{\prime \prime}$ nas direções vertical e horizontal, respectivamente. A energia foi ajustada para $\mathrm{E}=9320 \mathrm{eV}(\lambda=1,3303 \AA) \operatorname{com} \Delta E / E \simeq 1 \times 10^{-4}$.

\subsubsection{Difratômetro de 4 círculos do X-ray Lab/UoGuelph - Ca- nadá}

Os experimentos realizados no X-ray Lab/UoGuelph utilizaram radiação característica CuK $\alpha_{1}$ ( $\mathrm{E}=8047,78 \mathrm{eV}$ ou $\lambda=1,540611 \AA$ ) proveniente de um gerador anôdo rotatório operando em modo de foco "ponto" de $0,2 \times 0,2 \mathrm{~mm}^{2}$. Um espelho comercial (sistema de multi-camadas da marca Osmic) foi responsável pela focalização e colimação do feixe além de maximizar 
(a)

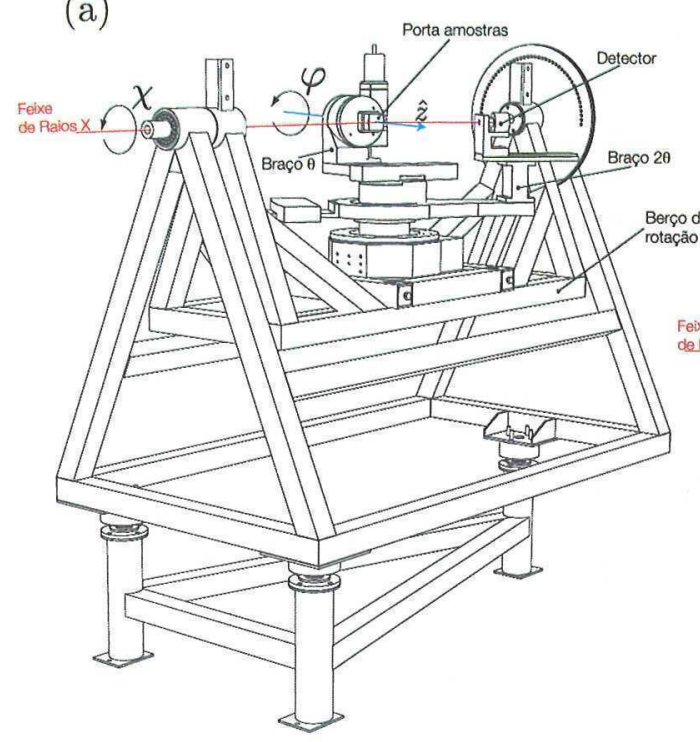

(b)

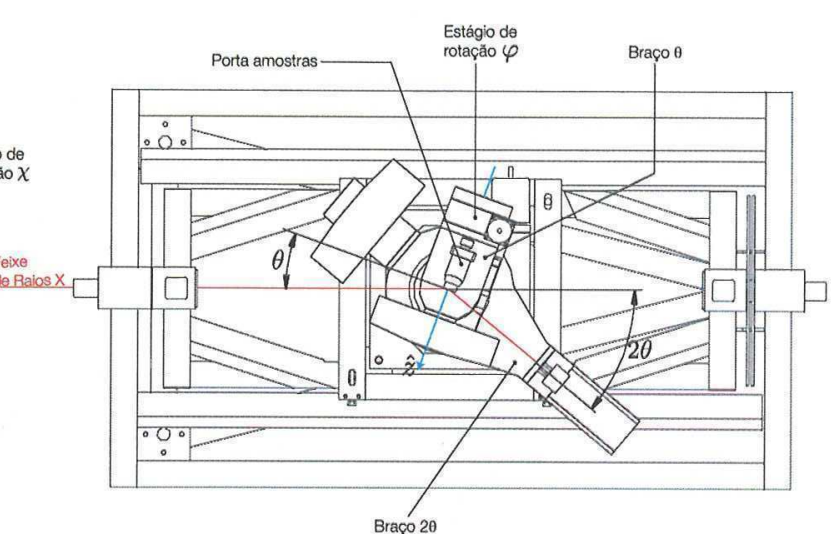

Figura 3.8: Goniômetro de 3 eixos instalado da linha de difração XRD1 do LNLS. Quarto estágio de rotação (berço $\chi$ ) permite escolha da polarização via rotação do plano de incidência em torno do feixe de raios $\mathrm{X}$.

a intensidade incidente na amostra $\left(\sim 2,5 \times 10^{7}\right.$ fótons/s para uma potência do gerador de $45 \mathrm{kV} \times 15 \mathrm{~mA}$ ). O espelho foi ajustado de forma a focalizar o feixe no infinito (óptica de feixe paralelo) e a monocromatização foi feita por meio de um cristal duplo (chanel-cut) de Ge(220). Monocromático e colimado, o feixe tinha a forma de um quadrado de 1,5×1,5mm. O feixe de raios X era apontado para um goniômetro 4-círculos da marca Huber (Fig.3.9) com resolução nos estágio $\theta, \varphi$ e $2 \theta$ de $0,0002^{\circ}$ e $0,001^{\circ}$ no círculo $\chi$. O goniômetro foi instalado sobre uma mesa automatizada com recurso de ajuste do ângulo de incidência do feixe em relação ao goniômetro (ângulo de incidência $\alpha$ ). Tal recurso permite o alinhar o círculo $\chi$ no plano perpendicular ao feixe incidente, técnica que é descrita em detalhes no Apêndice A. 


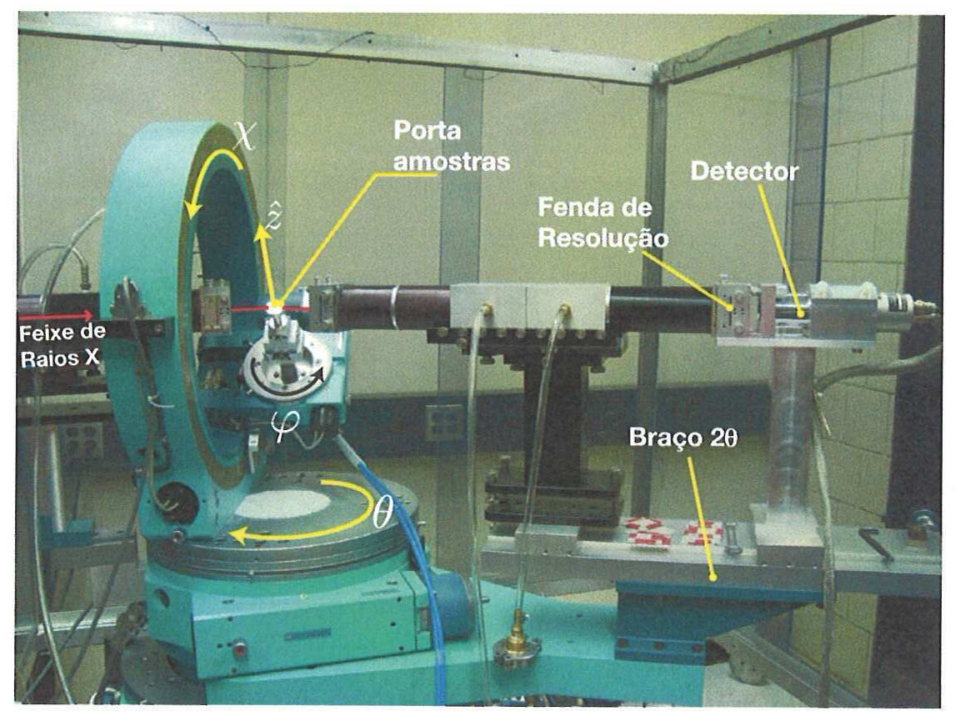

Figura 3.9: Goniômetro de 4 círculos instalado no laboratório de espalhamento e difração de raios X da Universidade de Guelph-Canadá.

\subsubsection{Linha de difração XRD2-LNLS}

Nos experimentos de difração de raios X à incidência rasante GIXRD, utilizou-se a linha de luz XRD2 do LNLS a qual utiliza radiação proveniente de imã deflector. A energia é selecionada via monocromador de duplo cristal de $\mathrm{Si}(111)$ o qual disponibiliza uma faixa de energia de 4 a 15keV. Focalização sagital é realizada por curvatura elástica do segundo cristal do monocromador. O fluxo de fótons na amostra é $\sim 2 \times 10^{10}$ fótons/s·mrad para a energia de 8keV. Utilizou-se o mesmo tipo de detector descrito na linha XRD1. A linha é equipada com um goniômetro Huber 4-círculos (Fig.3.10) o qual possui resolução nos estágios angulares similar ao 4-círculos descrito anteriormente no arranjo experimental do Xray Lab/UoGuelph. Os experimentos realizados nessa linha de luz utilizaram óptica de feixe paralelo e a energia foi ajustada para $\mathrm{E}=9320 \mathrm{eV}(\lambda=1,3303 \AA)$.

Experimentos realizados com diferentes configurações das apresentadas nesta seção serão devidamente descritos caso as modificações experimentais sejam relevantes aos resul- 


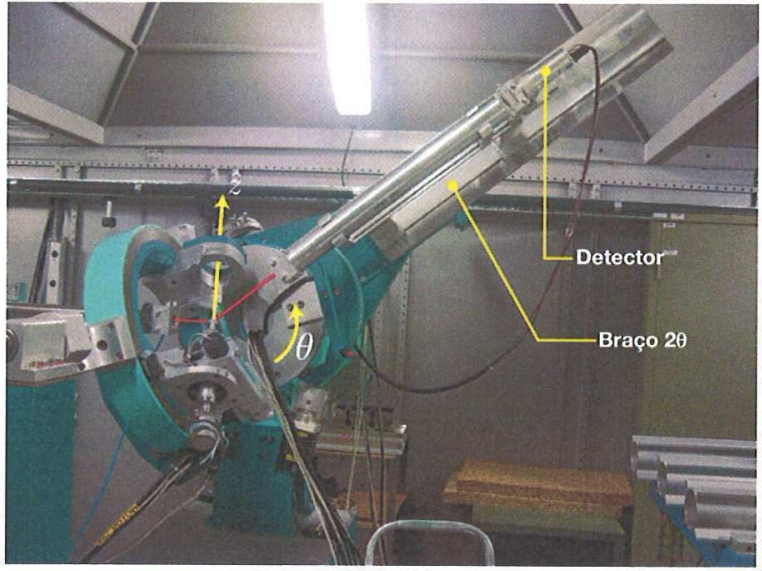

(a)

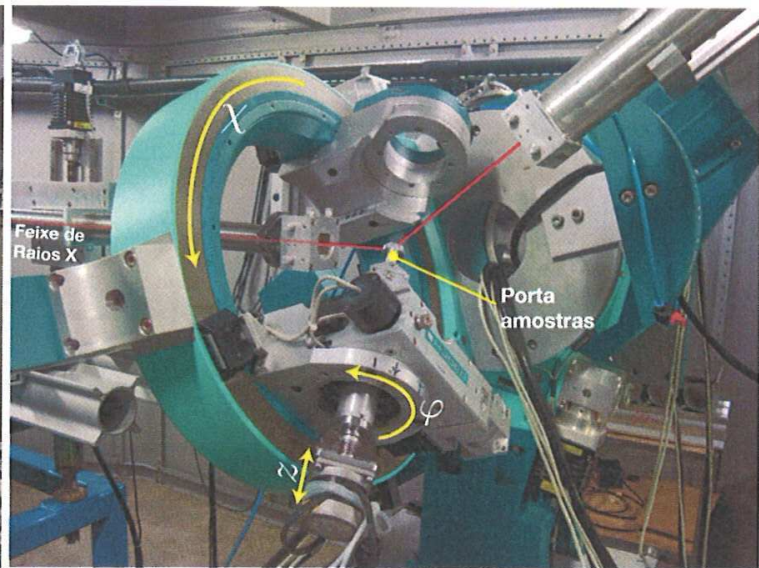

(b)

Figura 3.10: Goniômetro 4-círculos da linha de difração XRD2 do LNLS.

tados.

\subsection{Preparação de amostras}

Todas as amostras estudadas nesse trabalho foram crescidas por MBE e utilizaram wafers comerciais de GaAs como substrato. Na etapa de crescimento no sistema de MBE, a superfície do substrato que recebeu a deposição (superfície polida do wafer) foi cuidadosamente limpa de forma a evitar contaminação do sistema assim como para assegurar a perfeita epitaxia do material a se depositar. A amostra é fixada no porta-amostras por meio de uma solda de Índio a qual é aplicada na superfície traseira do substrato. Para amostras com nanoestruturas auto-organizadas, o estado de tensão superficial do substrato é de extrema relevância no crescimento das nanoestruturas. Tensões introduzidas pelo método de fixação das amostras podem influenciar nas características finais dos dispositivos epitaxiais, fato já evidenciado no crescimento de filmes finos [36]. A Fig.3.11 ilustra os resíduos da solda de In após o crescimento da amostra em MBE. 


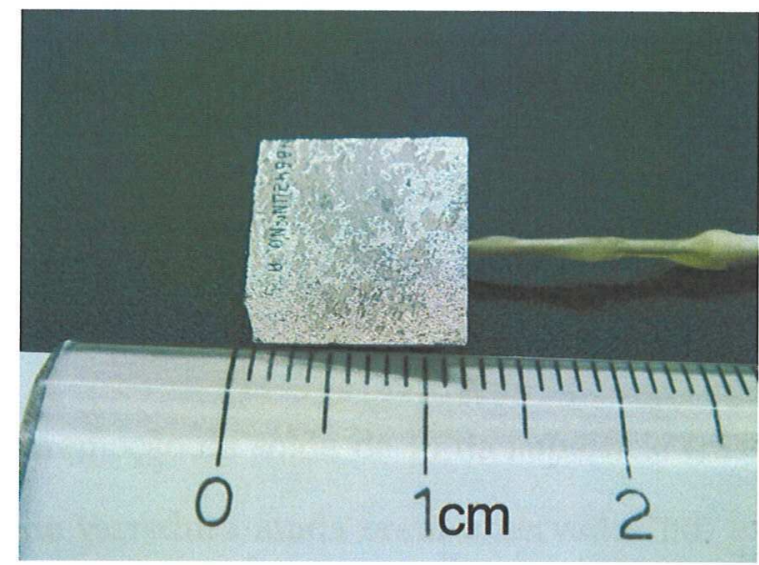

Figura 3.11: Resíduos de Índio provenientes da solda utilizada para fixação dos substratos na câmara de MBE. Os locais mais escuros correspondem ao substrato de GaAs e as manchas de cor prata correspondem aos resíduos da solda de Índio.

A solda de In apresenta-se sólida à temperatura ambiente e possui grande aderência ao substrato de GaAs, o que faz com que ela esteja presente na grande maioria das amostras preparadas por MBE. Durante os procedimentos de alinhamento de amostras para os experimentos de difração de raios $\mathrm{X}$ notou-se um alargamento inesperado das curvas de varredura (rocking curves) em várias amostras. A frequente observação deste efeito estimulou uma investigação mais detalhada. Constatou-se que a maior parte do efeito de alargamento das curvas de varredura era devido à presença dos resíduos da solda de In. A confrmação veio depois da total remoção do In realizado pelo seguinte procedimento:

1. Proteção da superfície de crescimento com cêra ou parafina;

2. Imersão da amostra em ácido clorídrico $(\mathrm{HCl})$ concentrado com agitação contínua por $\sim 30$ minutos;

3. Remoção da amostra da solução e lavagem em água corrente;

4. Remoção mecânica de forma cuidadosa dos resíduos do ataque químico com lixa ultra fina (lixa para lapidação com granulação 2500); 
5. Imersão em em solução de ácido sulfúrico nas proporções $\mathrm{H}_{2} \mathrm{SO}_{4}(1 \mathrm{x}): \mathrm{H}_{2} \mathrm{O}_{2}(1 \mathrm{x}): \mathrm{H}_{2} \mathrm{O}(5 \mathrm{x})$ por $\sim 3$ minutos;

6. Remoção da amostra da solução e lavagem em água corrente;

7. Remoção da cêra com acetona.

Mesmo após a remoção da solda de In da superfície traseira do substrato, efeitos de distorção das curvas de varredura ainda eram observados nos experimentos de difração. Como o principal objetivo da pesquisa era estudar a influência dos QDs de InAs na matriz de GaAs, restava saber se as distorções observadas eram geradas pelas nanoestruturas. Assim constatou-se uma forte influência do método de montagem no estado final de curvatura das amostras. Esta susceptibilidade à curvaturas está relacionada à pouca espessura do substrato ( $\sim 600 \mu \mathrm{m})$ o qual é facilmente curvado quando montado com procedimentos tradicionais de fixação (tais como gota de cêra e fita dupla-face). Como fruto desta investigação, foi desenvolvido um novo método de montagem para wafers finos o qual é baseado em reduzidas superfícies de contato por meio de esferas metálicas (Fig.3.12). Neste método, apenas um filme fino de cêra em torno das esferas é responsável pela aderência da amostra. A geometria de triângulo da posição das esferas otimiza o equilíbrio das forças entre os contatos.

Para a investigação do estado de curvatura das amostras, realizou-se uma série de curvas de varredura da reflexão simétrica 002 de um substrato de GaAs em diferentes azimutes. Esta técnica foi denominada aqui como Diagramas Polar, o qual se tornou uma ferramenta versátil na verificação da qualidade do procedimento de montagem. A Fig.3.13(a) mostra um diagrama polar para amostra fixada por uma pequena gota central de cêra. $\mathrm{O}$ alargamento em uma direção específica (neste caso a direção BB) sugere que o cristal sofreu uma curvatura do tipo cilíndrica. A Fig.3.13(b) apresenta o diagrama polar do mesmo substrato de GaAs montado via método de 3 contatos. 

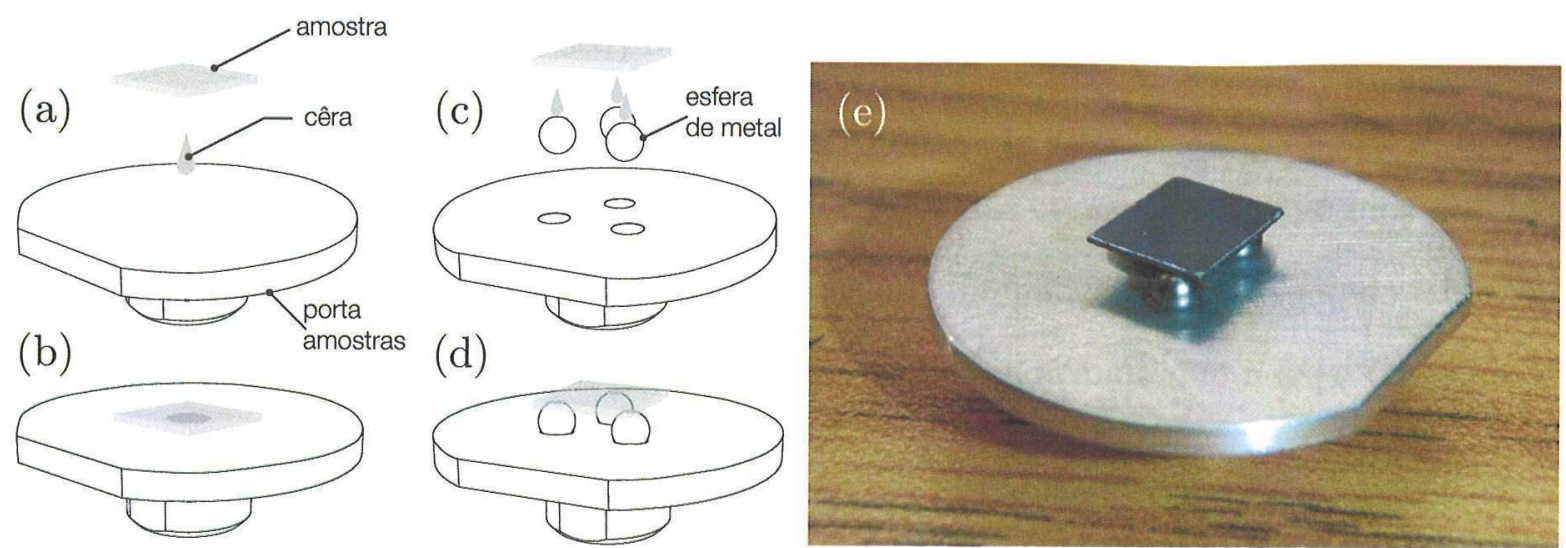

Figura 3.12: (a,b) Esquema de montagem com gota de cêra no centro da face da amostra, $(c, d)$ Esquema de montagem com esferas metálicas embebidas na cêra. (e) Foto de amostra montada com o método das esferas ou método dos 3 contatos.
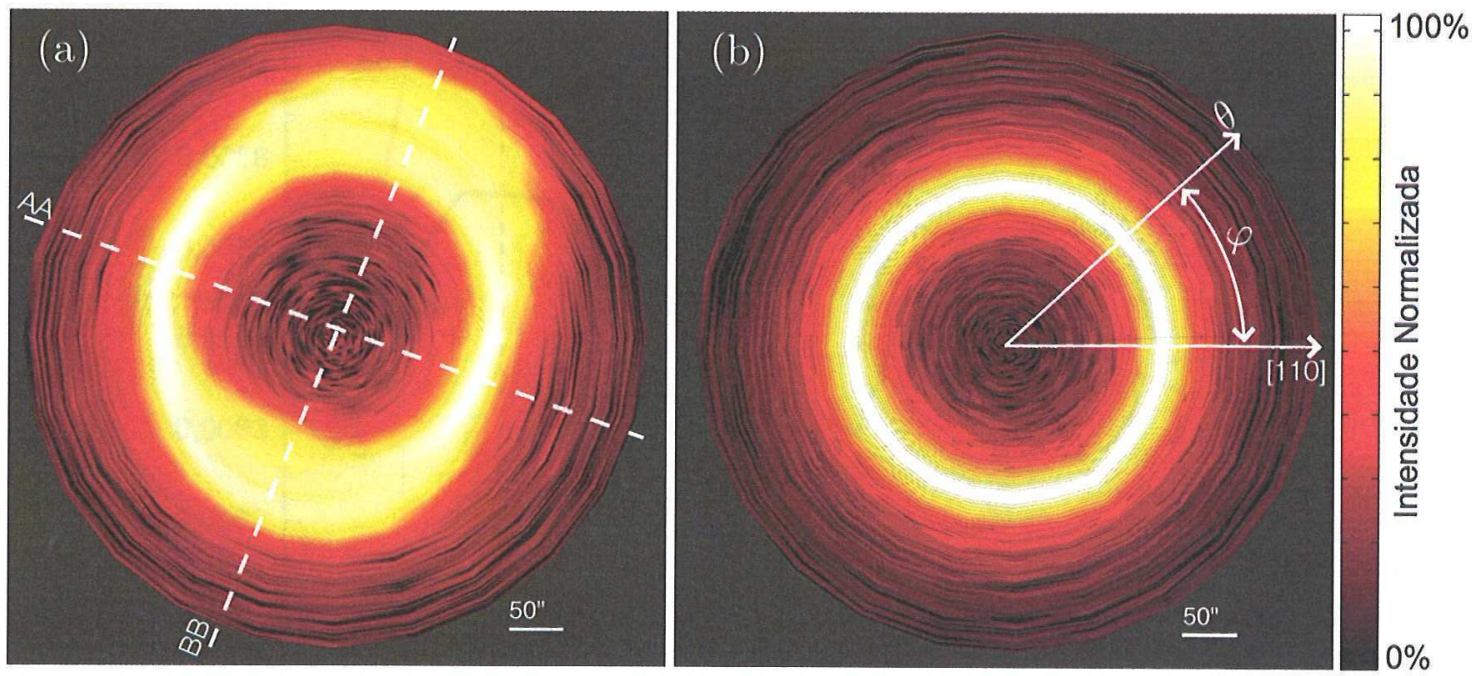

Figura 3.13: Diagramas polar da reflexão 002 de um substrato de GaAs: (a) montado de forma convencional, e.g. Fig.3.12(b). AA e BB indicam as direções plana e curvada, respectivamente; e (b) montado com o método das esferas, e.g. Fig.3.12(d) e (e).

Em algumas situações é necessária uma análise das amostras no estado em que elas foram crescidas na câmara de $\mathrm{MBE}$, ou seja, sem a limpeza dos resíduos de Índio da sua superfície traseira. Uma forma de reduzir o efeito da curvatura nos dados de raios X é diminuir a área iluminada pelo feixe por meio de fendas ${ }^{1}$. A Fig.3.14 apresenta uma análise

\footnotetext{
${ }^{1}$ Procedimento indicado em situações nas quais a perda de intensidade devido ao corte do feixe pelas
} 
das larguras à meia altura (FWHM) da reflexão 004 do GaAs montado com gota central de cêra para diferentes aberturas de fendas (tamanhos do feixe incidente). A posição $\varphi=0$ foi definida pela direção [110] da Fig.3.13(b). Os máximos das curvas estão separados por 180 em $\varphi$ reforçando a hipótese de curvatura cilíndrica. A dimunuição do tamanho do feixe de 2 para $1 \mathrm{~mm}$ causou uma perceptível redução dos máximos indicando que o feixe passou a ser menos sensível à curvatura da amostra.

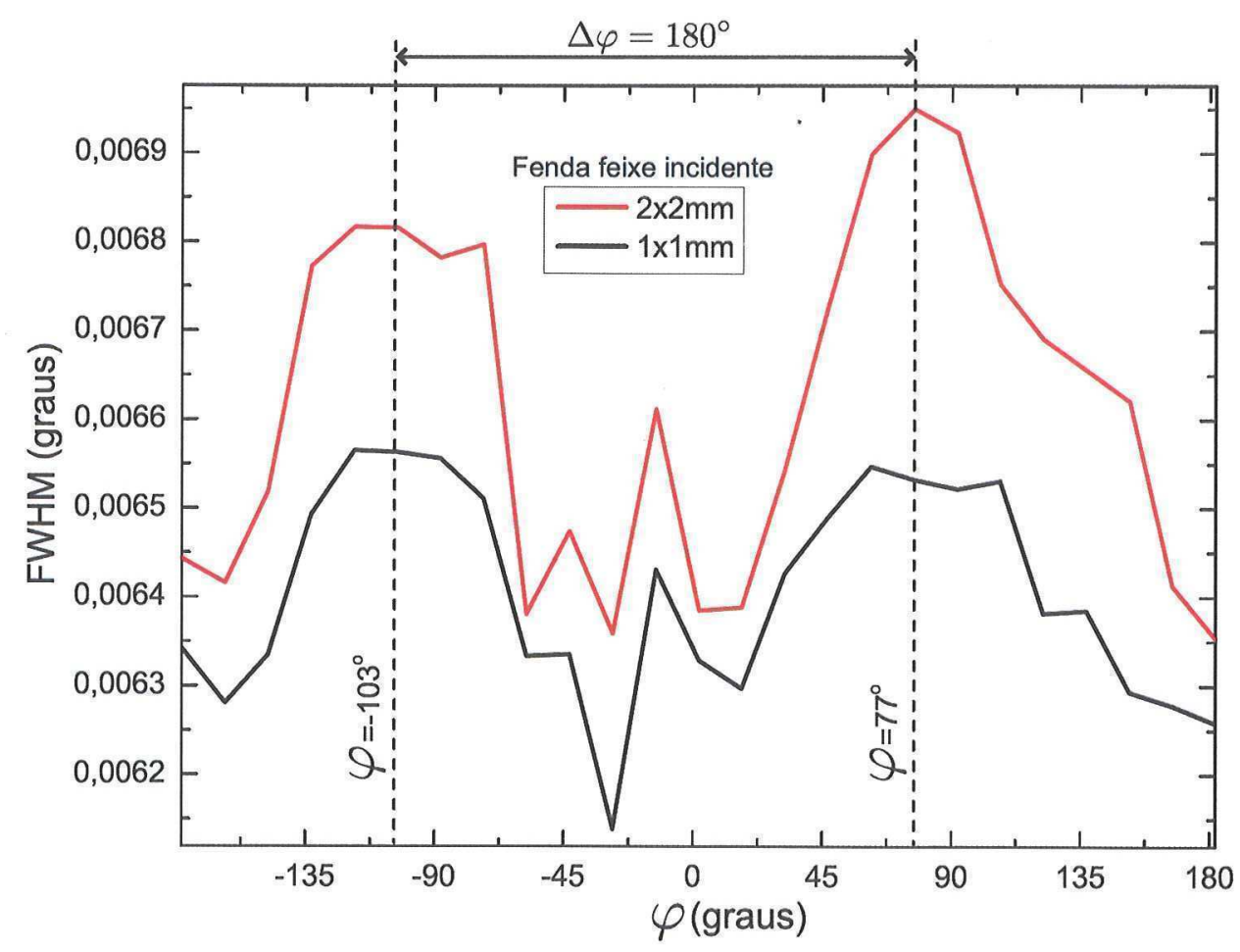

Figura 3.14: Larguras à meia altura (FWHM) da reflexão 004 do GaAs em função do azimute da amostra para dois tamanhos de feixe incidente.

fendas não compromete o experimento. 


\section{Capítulo 4}

\section{Varreduras Renninger e medidas}

\section{ultra-precisas de parâmetro de rede}

Varredura Renninger de Raios X (XRS, X-ray Renninger Scanning) é uma das técnicas mais precisas para determinação absoluta de parâmetro de rede em monocristais [37, 38, 39, 40]. No entanto, ainda existiam limitações importantes no uso generalizado da XRS no estudo de materiais com potencial tecnológico, como i) a dificuldade de usuários de técnicas típicas de difração de raios X na utilização da geometria de difração múltipla assim como na escolha das Umweganregung (Umwegs: picos de difração múltipla) apropriadas para cada tipo de estudo, ii) falta de métodos para tratamento de erros instrumentais sistemáticos os quais comprometem a acurácia das medidas, iii) inexistência de uma função de perfil de linha para ajustar a Umweg capaz de determinar a posição sem ter a precisão comprometida devido aos perfis tipicamente assimétricos das Umwegs; e iv) ausência de pacotes de aquisição e análise dos dados de XRS em laboratórios de grande escala como nas linhas de luz de laboratórios síncrotron. Este capítulo apresenta um procedimento sistemático para a investigação em 
alta resolução de variações no parâmetro de rede usando XRS. O procedimento foi aplicado no estudo do campo de deformação no-plano (tradução direta do termo em inglês in-plane) de um conjunto de amostras as quais representam os principais estágios do crescimento de dispositivos nanoestruturados baseados em QDs de InAs. Para isso, este capítulo contém uma breve introdução à geometria de difração múltipla e sua extensão ao conceito de XRS, um método para indexar e escolher casos de difração múltipla e um método de análise de dados aplicado ao estudo do parâmetro de rede do sistema nanoestruturado investigado nesta tese.

\subsection{Geometria de Difração Múltipla e Varreduras Ren- ninger}

A difração múltipla (DM)[41] ocorre quando um feixe incidente de raios X monocromático satisfaz simultaneamente a condição de Bragg para dois ou mais conjuntos de planos atômicos do cristal (amostra). No ponto de vista do espaço recíproco, isso equivale à situação onde dois ou mais pontos da rede recíproca tocam a esfera de Ewald em um mesmo instante. Como consequência, três ou mais feixes difratados são gerados dentro do cristal, conforme ilustra a Fig.4.1.

Embora tais efeitos sejam presentes em muitos experimentos de difração de raios X e nêutrons, a observação sistemática da DM somente ocorre em casos específicos onde os eventos de DM dentro do cristal resultam em feixes difratados na direção do detector. Para um caso de 3 feixes, como o ilustrado na Fig.4.1, o feixe incidente $\boldsymbol{k}_{0}$ é difratado por uma reflexão simétrica com índices $H K L$, denominada "primária" e representada pelo vetor recíproco $\mathbf{P}$, e por uma reflexão assimétrica de índices $h k \ell$, reflexão "secundária" com vetor 
recíproco S. O detector é posicionado de forma a monitorar o feixe difratado pela reflexão primária, ou seja $k_{\mathrm{P}}=\mathrm{P}+\boldsymbol{k}_{0}$. O feixe secundário $\boldsymbol{k}_{\mathrm{S}}=\mathrm{S}+\boldsymbol{k}_{0}$ é re-espalhado para o detector por meio de uma reflexão assimétrica denominada "acoplamento" (representada pelo vetor recíproco $\mathbf{C}$ ) a qual gera o feixe difratado $\boldsymbol{k}_{\mathrm{P}^{\prime}}=\mathbf{S}+\mathbf{C}+\boldsymbol{k}_{0}=\mathbf{P}^{\prime}+\boldsymbol{k}_{0}$ (Fig.4.1(a)). Em um monocristal e para um caso de 3 feixes, a ocorrência da DM implica que

$$
\mathbf{P}^{\prime}=\mathbf{S}+\mathbf{C}=\mathbf{P}
$$

O monitoramento dos feixes simultâneos $k_{\mathrm{P}}$ e $k_{\mathrm{P}^{\prime}}$ é a base fundamental de métodos investigatórios do problema da fase em cristalografia assim como de técnicas de determinação de estruturas por análise do tripleto de fases [41]. De forma a simplificar a simbologia, eventualmente este texto se referirá aos casos de MD apenas pelos índices $h k \ell$ de suas reflexões secundárias.

(a)

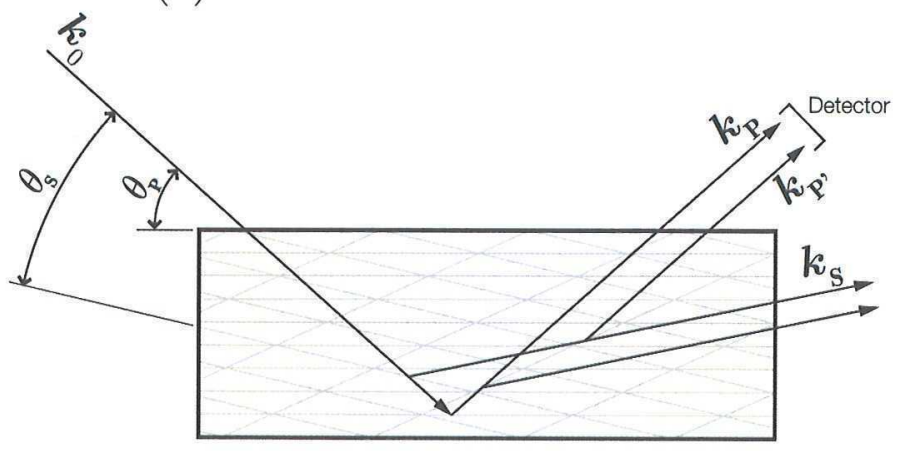

(b)

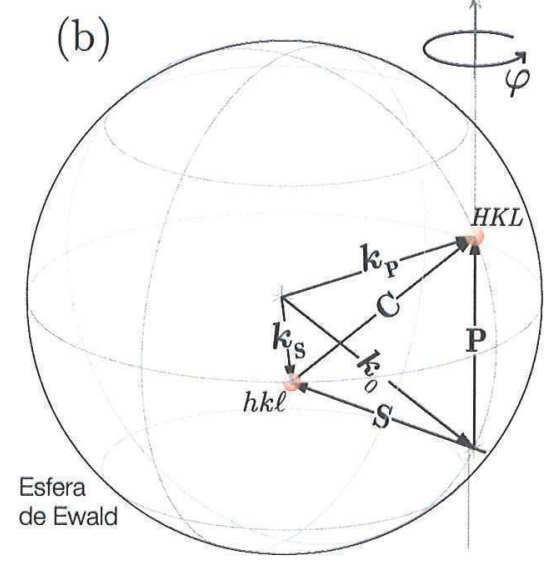

Figura 4.1: Representação geométrica da difração múltipla de 3 feixes (a) esquema planar no espaço direto (planos atômicos do cristal) e (b) no espaço recíproco (esfera de Ewald). Os ângulos $\theta_{\mathbf{P}}$ e $\theta_{\mathbf{S}}$ correspondem aos ângulos de Bragg das reflexões primária e secundária, respectivamente.

Uma maneira simples e largamente empregada para observação de picos de DM 
é realizada por meio da rotação $\varphi$, mantendo a reflexão primária em condição de difração, ou seja, o ponto recíproco $H K L$ é mantido sobre a esfera de Ewald durante a rotação. Para que isso seja possível, é necessário alinhar o vetor de difração $\mathbf{P} \operatorname{com}$ o eixo de rotação $\varphi$, indicado pela direção $z$ na Fig.4.1(b), configurando assim a base geométrica dos experimentos de XRS. Com $\mathbf{P} \| \boldsymbol{z}$, as varreduras $\varphi$ apresentam nível constante de intensidade referente a reflexão primária, sofrendo modulações à medida que condições de DM são satisfeitas, e.g. Fig.4.2. Nas condições de DM, cada reflexão possui uma fase específica em seu fator de estrutura. Efeitos de interferência entre as ondas difratadas estão constantemente presentes nos experimentos de XRS, e são responsáveis pelos perfis assimétricos dos Umwegs. Diminuição da intensidade da reflexão primária, denominadas por Wagner em 1920 como Aufhellung, foram as primeiras evidências do fenômeno de DM [42]. Por outro lado, acréscimos na intensidade da reflexão primária são denominados Umweganregung ou simplesmente Umweg, e foram observados inicialmente por Renninger em 1937 durante varreduras $\varphi$ da reflexão proibida (222) do diamante [37]. Esses fenômenos de diminuição (Aufhellung) e acréscimo (Umweganregung) na intensidade primária estão relacionados ao balanço de energia entre as reflexões que compõem o evento de DM.

A Figura 4.2 apresenta uma XRS da reflexão 002 do GaAs (reflexão primária), realizada na linha XRD1 do LNLS com fótons de raios X de energia 9316eV. A reflexão primária foi mantida excitada durante os $15^{\circ}$ de varredura $\varphi$ (fundo constante) e 6 picos de DM foram observados. As posições angulares e intensidades relativas dos picos de DM estabelecem $\varphi=180^{\circ}$ como um espelho de simetria o qual é útil na indexação desses picos de DM. Um caso de DM de 3 feixes pode ser excitado em duas posições $\varphi$ distintas: $i$ ) com o ponto recíproco secundário entrando na esfera de Ewald (casos denominados out-in) e ii) com o ponto recíproco secundário saindo da esfera (casos in-out). Isto explica a presença dos índices out-in e in-out nos picos de DM da Fig.4.2. O procedimento de indexação desses 
picos de DM é detalhado mais adiante.

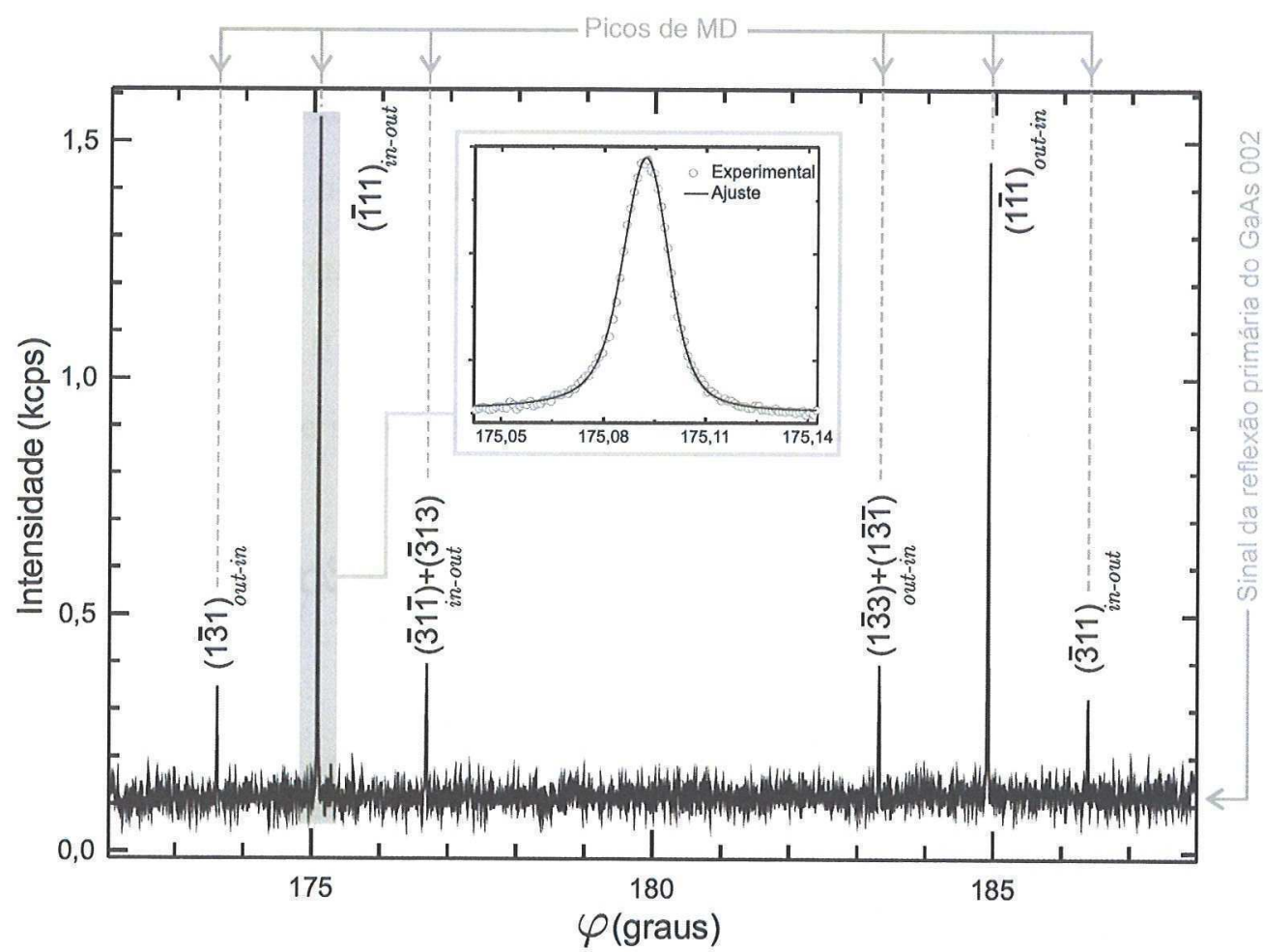

Figura 4.2: Padrão de XRS da reflexão 002 do GaAs (reflexão primária) para E=9316eV e polarização $\sigma$. Índices duplos indicam casos de 4 feixes (2 reflexões secundárias). No Detalhe, ajuste do pico de DM $\overline{1} 11_{\text {in-out }}$.

\subsection{Medidas de Parâmetro em sistemas nanoestrutu- rados baseados em QDs}

As medidas de parâmetro foram realizadas de forma a investigar a rede do GaAs, ou seja, o material que envolve os QDs de InAs. O principal objetivo da experiência foi estudar o estado de tensão residual causado pelas ilhas de InAs na matriz de GaAs por meio de técnicas avançadas de difração de raios X como XRS. No experimento de XRS, foi utilizada 
a reflexão 002 como primária $(\mathbf{P}=002)$ e como secundária reflexões da família $\{11\} 1$, onde $\{11\}=11,1 \overline{1}, \overline{1} 1$, e $\overline{1} \overline{1}(\mathbf{S}=h k 1$, sendo $h= \pm 1$ e $k= \pm 1)$. Cada reflexão secundária fornece duas condições de DM totalizando oito condições para cada medida completa de parâmetro de rede, conforme ilustra o diagrama da Fig.4.3(a). No ponto de vista dos cones de Bragg, as condições de DM ocorrem nas intersecções dos cones conforme ilustrado na Fig.4.3(b) ${ }^{1}$. A definição do azimute $\varphi=0$ foi realizada quando a direção de referência do cristal $\mathbf{M}=[110]$ encontrava-se no plano de incidência do difratômetro e apontando para a fonte de raios X.

(a)

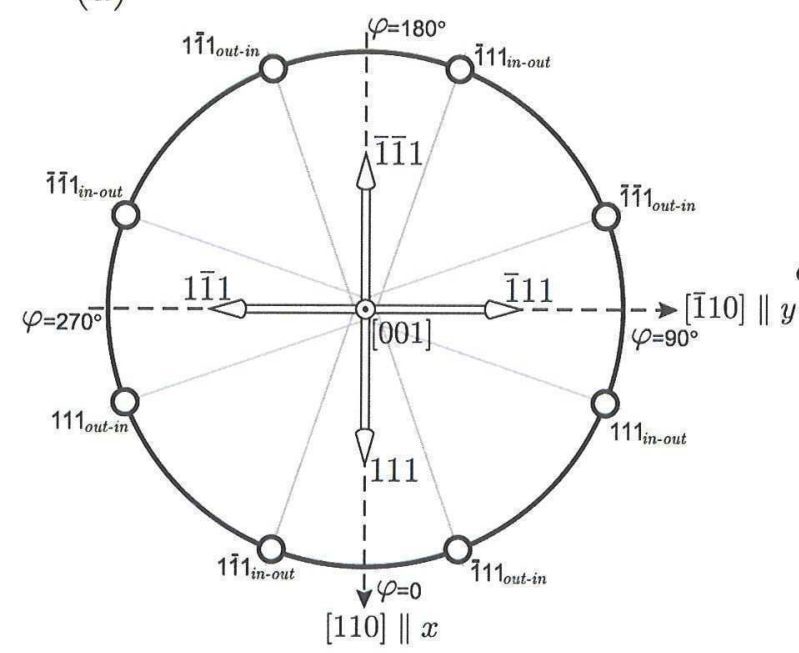

(b)

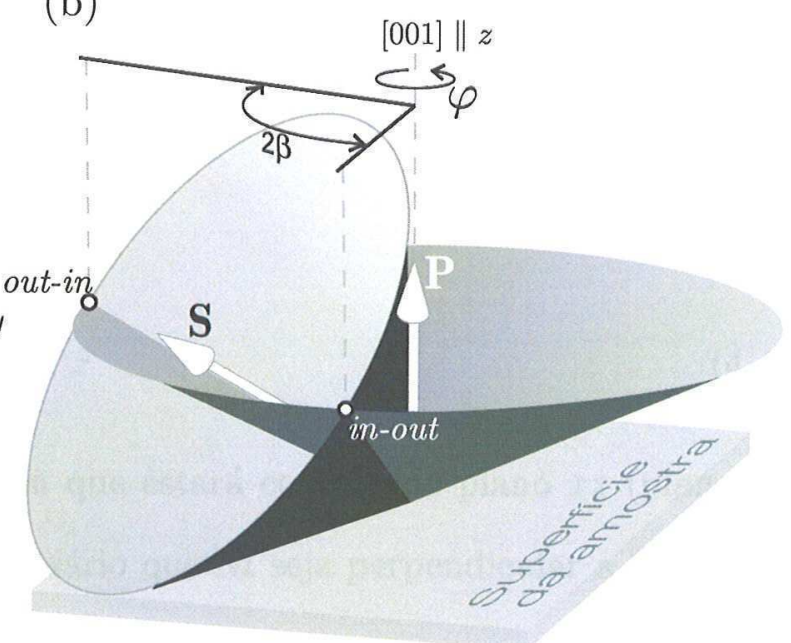

Figura 4.3: (a) Representação esquemática (vista de topo) das 8 posições de DM escolhidas para a determinação do parâmetro de rede. Cada reflexão secundária possui um par (inout/out-in) de posições $\varphi$ onde ocorre a DM. (b) Esquema de cones de Bragg das reflexões primária e secundária: a intersecção dos cones denota condição de DM.

Uma abordagem geométrica foi utilizada na indexação dos picos de DM, ou seja, na previsão das posições $\varphi$ onde ocorrem os casos de DM. Para isso foi necessário definir um sistema de coordenadas $x y z$ onde o feixe incidente $k_{0}$ pudesse ser expresso em termos dos ângulos instrumentais $\theta$ e $\varphi$, conforme ilustra a Fig.4.4. $\varphi$ é definida como a distância angular entre a projeção de $k_{0}$ no plano $x y$ e a direção $x$. $\psi$ é a distância angular entre a

\footnotetext{
${ }^{1}$ Para maior clareza, tomou-se apenas uma das reflexões secundárias como exemplo, ou seja, apenas um cone assimétrico foi desenhado para a ilustração da intersecção.
} 
projeção de $\mathbf{S}$ no plano $x y$ e a direção de referência $x$. A direção $z$ é tomada paralela ao vetor $\mathbf{P}$, de modo que quando a reflexão primária está em condição de difração, o ângulo de incidência $\theta$ é igual ao ângulo de Bragg $\theta_{P}$ da reflexão primária. $\psi$ e $\gamma$ são os ângulos de azimute e polar do vetor $\mathbf{S}$, respectivamente. Esse sistema instrumental de coordenadas é criado da seguinte forma:

$$
\begin{gathered}
\hat{z}=\frac{\mathbf{P}}{|\mathbf{P}|}, \\
\hat{y}=\frac{\mathbf{P} \times \mathbf{M}}{|\mathbf{P} \times \mathbf{M}|},
\end{gathered}
$$

e

$$
\hat{x}=\hat{y} \times \hat{z}
$$

onde $\mathbf{M}$ é uma escolhida direção cristalográfica que estará contida no plano $x z$ (plano de incidência primário) quando $\varphi=0$. Não é necessário que $\mathbf{M}$ seja perpendicular a $\mathbf{P}$.

Nesse novo sistema de coordenadas, o vetor de onda incidente $\boldsymbol{k}_{0}$ é dado como

$$
k_{0}=-\left|k_{0}\right|(\cos \theta \cos \varphi, \cos \theta \sin \varphi, \sin \theta)
$$

e o vetor secundário $\mathbf{S}$ como

$$
\mathbf{S}=|\mathbf{S}|(\sin \gamma \cos \psi, \sin \gamma \sin \psi, \cos \gamma)
$$

Com base na Eq.2.34, a qual foi deduzida para um vetor recíproco genérico $G$, é possível representar as condições de difração primária e secundária na forma vetorial, 


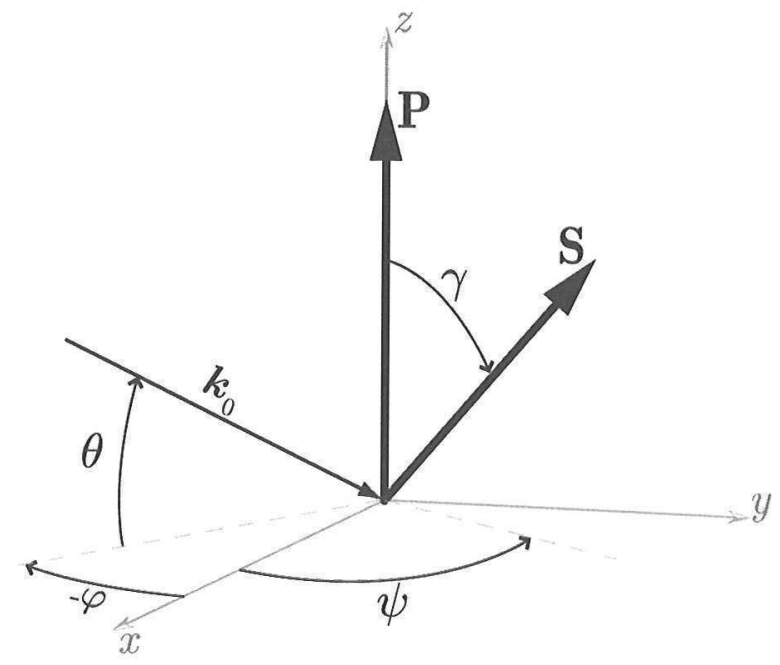

Figura 4.4: Sistema $x y z$ de coordenadas usado para descrever o feixe incidente $\boldsymbol{k}_{0}$ em função dos ângulos instrumentais $\theta$ e $\varphi$, assim como os vetores recíprocos $\mathbf{P}$ e $\mathbf{S}$.

respectivamente, como

$$
k_{0} \cdot \mathbf{P}=-\frac{\mathbf{P} \cdot \mathbf{P}}{2}=-\frac{|\mathbf{P}|^{2}}{2},
$$

$\mathrm{e}$

$$
k_{0} \cdot \mathbf{S}=-\frac{|\mathbf{S}|^{2}}{2}
$$

Aplicando as Equações 4.5 e 4.6 na 4.8 e mantendo-se os vetores de ondas normalizados por $2 \pi\left(\left|k_{0}\right|=1 / \lambda\right)$, obtem-se a expressão

$$
\begin{aligned}
k_{0} \cdot \mathbf{S} & =-\left|k_{0}\right||\mathbf{S}|(\cos \theta \cos \varphi \sin \gamma \cos \psi+\cos \theta \sin \varphi \sin \gamma \sin \psi+\sin \theta \cos \gamma) \\
& =-\frac{|\mathbf{S}|}{\lambda}(\cos \theta \sin \gamma \cos (\varphi-\psi)+\sin \theta \cos \gamma)=-\frac{|\mathbf{S}|^{2}}{2}
\end{aligned}
$$

a qual forncece 


$$
\cos (\varphi-\psi)=\cos (\beta)=\frac{\frac{\lambda|\mathbf{S}|}{2}-\sin \theta \cos \gamma}{\cos \theta \sin \gamma}
$$

$2 \beta$ corresponde à diferença entre os dois ângulos de azimute

$$
\varphi_{\text {out }- \text { in }}=\psi-\beta \quad \text { e } \quad \varphi_{\text {in-out }}=\psi+\beta,
$$

onde o ponto recíproco secundário (apontado pelo vetor $\mathbf{S}$ ) toca a esfera de Ewald. Note que essas posições somente representam as condições de DM ilustradas na Fig.4.3(b) quando $\theta=\theta_{P}\left(\theta_{P}\right.$ corresponde ao ângulo de Bragg para a reflexão $\left.\mathbf{P}\right)$ na Eq.4.10. Os padrões de XRS são indexados através das Eqs.4.10 e 4.11. Para cada reflexão S, além do módulo do vetor $\mathbf{S}$, calculam-se os ângulos $\psi$ e $\beta$ e assim as posições out-in e in-out, onde as condições de DM associadas à esta reflexão secundária ocorrem. A tabela 4.1 apresenta os ângulos calculados para várias reflexões secundárias presentes na XRS da reflexão primária 002, mostrada na Fig.4.2. O conjunto de reflexões secundárias da família $\{11\} 1$ foram utilizadas nas medidas de parâmetro de rede, e as reflexões com ângulos idênticos correspondem a casos de DM de 4 feixes. As XRS apresentam em geral uma simetria nas posições dos picos de DM, como pode ser visto na Fig.4.2. Elas são determinadas basicamente pelo eixo cristalográfico do vetor $\mathbf{P}$, e são úteis na identificação da real posição azimutal da amostra.

A primeira etapa do experimento de medidas de parâmetro é o alinhamento do vetor recíproco $\mathbf{P}$ com o estágio de rotação azimutal $\varphi$. Esse procedimento baseia-se no uso da posição do centróide de curvas de varredura $\theta$ da reflexão 002 para diferentes azimutes os quais permitam corrigir os arcos da cabeça goniométrica. Para uma amostra idealmente alinhada espera-se um mesmo valor de $\theta$ para os centróide das curvas de varredura em qualquer azimute. Como exemplo do procedimento de alinhamento, as curvas de varredura 


\begin{tabular}{ccccc}
\hline Reflexão $\mathbf{S}$ & $\psi$ & $\beta$ & $\varphi_{\text {out-in }}$ & $\varphi_{\text {in-out }}$ \\
\hline 111 & 0 & 85,08736 & 274,91264 & 85,08736 \\
$\overline{1} 11$ & 90 & 85,08736 & 4,91264 & 175,08736 \\
$\overline{1} \overline{1} 1$ & 180 & 85,08736 & 94,91264 & 265,08736 \\
$1 \overline{1} 1$ & 270 & 85,08736 & 184,91264 & 355,08736 \\
$1 \overline{3} 1$ & 243,43495 & 69,83764 & 173,59730 & 313,27259 \\
$\overline{3} 11$ & 116,56505 & 60,14060 & 56,42445 & 176,70565 \\
$\overline{3} 13$ & 116,56505 & 60,14060 & 56,42445 & 176,70565 \\
$1 \overline{3} 3$ & 243,43495 & 60,14060 & 183,29435 & 303,57555 \\
$1 \overline{3} 1$ & 243,43495 & 60,14060 & 183,29435 & 303,57555 \\
$\overline{3} 11$ & 116,56505 & 69,83764 & 46,72741 & 186,40270 \\
\hline
\end{tabular}

Tabela 4.1: Indexação parcial da XRS da reflexão 002 GaAs. Valores angulares (em graus) calculados para $\mathrm{E}=9316 \mathrm{eV}$ e $\mathbf{M}=[110]$.

nos azimutes $0^{\circ}, 90^{\circ}, 180^{\circ}$ e $270^{\circ}$ estão mostradas na Fig.4.5. Os respectivos valores dos centróides são: $\theta_{\varphi=0}=15,5132^{\circ}, \theta_{\varphi=90}=16,0993^{\circ}, \theta_{\varphi=180}=16,1335^{\circ}$ e $\theta_{\varphi=270}=15,5454^{\circ}$. As posições $\varphi=0^{\circ}$ e $\varphi=180^{\circ}$ fornecem o valor médio na direção [110], $\bar{\theta}_{[110]}=15.8233^{\circ}$, e as posições $\varphi=90^{\circ}$ e $\varphi=270^{\circ}$ fornecem o valor médio $\bar{\theta}_{[\overline{1} 10]}=15.8223^{\circ}$. Desta forma, o alinhamento foi efetivado ajustando-se os arcos da cabeça goniométrica de forma a deslocar o centróide das curvas de varredura para os valores médios nas direções [110] e [110], os quais em geral apontam para um mesmo valor. Este procedimento de alinhamento é essencial para a obtenção de XRS longas como a demonstrada na Fig.4.2, as quais são comumente utilizadas na indexação dos picos de DM para uma dada reflexão primária.

Após alinhar a amostra e identificar sua posição de azimute, ou seja, indexar os picos de DM, as medidas de parâmetro são obtidas a partir da repetição de várias XRS. Em cada XRS, os dados são coletados com alta resolução somente em torno dos umwegs escolhidos, e.g. detalhe da Fig.4.2. Neste trabalho, oito umwegs foram medidos em cada XRS, correspondendo às posições de entrada e saída das reflexões segundárias da família $\{11\} 1$. Desalinhamentos do vetor recíproco primário com o estágio de rotação azimutal proporcionam deslocamentos nas posições azimutais dos picos de DM, as quais são diretamente relacionadas às medidas de parâmetro via XRS. Devido a este fato, optou-se pela exploração 
da geometria de eixo 4 dos picos de DM (Fig.4.3(a)) de forma a eliminar a dependência das medidas de parâmetro com o procedimento de alinhamento do cristal, o que justifica a utilização dos oito picos de DM nas medidas. Afim de demonstrar o efeito do desalinhamento da amostra nas posições dos picos de DM, a determinação do ângulo $\beta$ experimental, resumida na Tabela 4.3, foi realizada com a amostra \#1 ligeiramente desalinhada (desalinhamento residual de $\sim 0,01^{\circ}$ ). Como é possível observar na Tab.4.3, os valores de $\beta$ apresentam efeitos de desalinhamentos os quais são eliminados no cálculos dos valores médios $(\bar{\beta})$ nas direções [110] e [110].

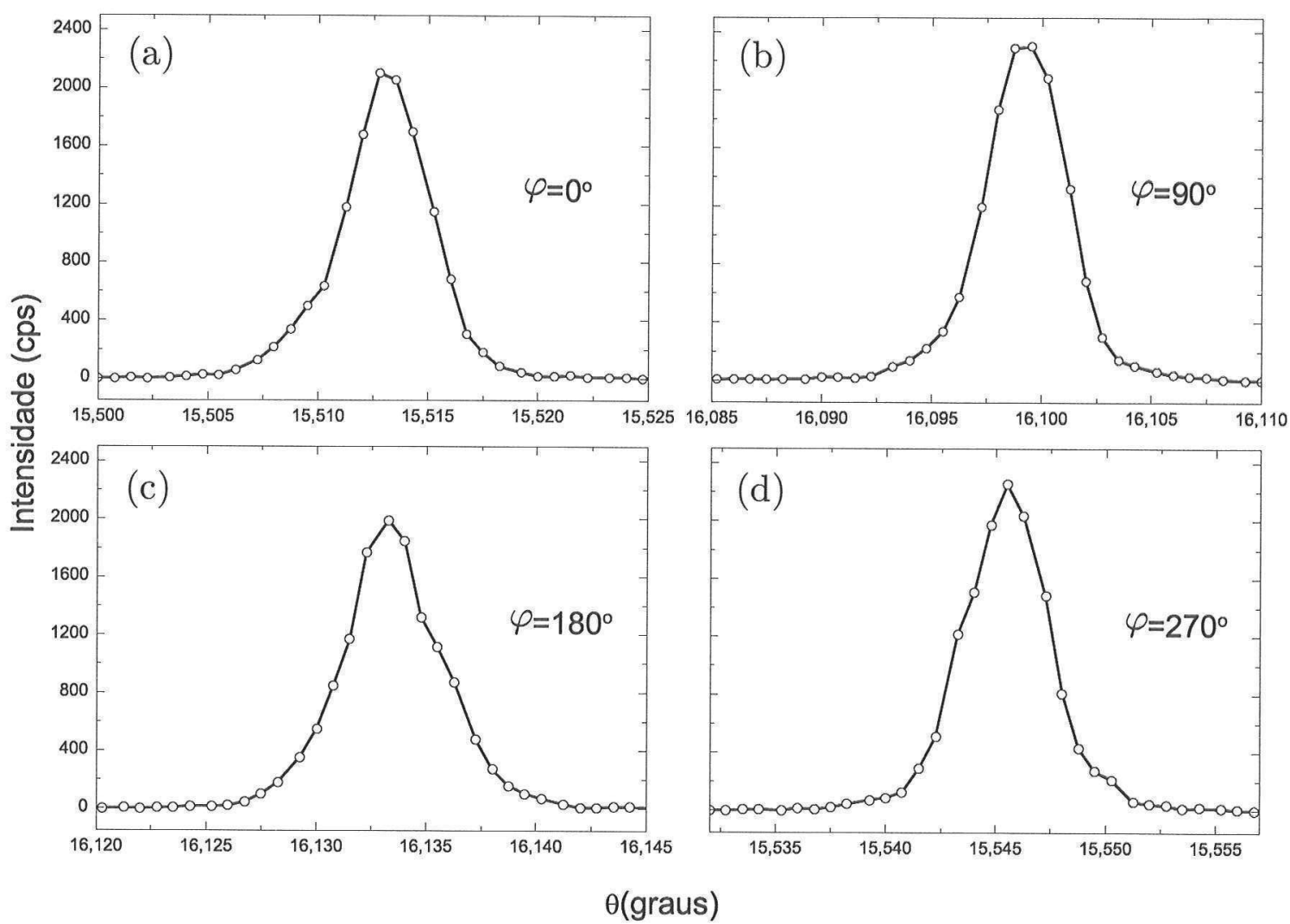

Figura 4.5: Procedimento de alinhamento da amostra \#1 via curvas de varredura $\theta$ da reflexão 002 do GaAs obtidas nos azimutes $0^{\circ}, 90^{\circ}, 180^{\circ}$ e $270^{\circ}$.

As posições $\varphi$ dos umwegs (picos de DM) são a chave para a análise do parâmetro de rede via XRS. Picos de DM possuem efeitos intrínsecos oriundos da interferência en- 
tre ondas difratadas simultaneamente, os quais são responsáveis por umwegs com perfis assimétricos. A assimetria dos perfis umwegs depende, dentre outros parâmetros, da fase relativa entre as ondas, também conhecida como "fase tripleto", $\Psi_{T}$, nos casos de DM de 3-feixes. Valores de $\Psi_{T}= \pm 90^{\circ}$ produzem picos simétricos enquanto que valores em torno de $0^{\circ}$ ou $180^{\circ}$ apresentam expressivos efeitos de assimetria. Levando em conta possíveis perfis umwegs assimétricos, a determinação da posição azimutal dos picos de DM exigiu o desenvolvimento de um procedimento específico para o ajuste das curvas de forma a fornecer uma análise sistemática do conjunto específico de umwegs. O processo de interferência entre ondas simultaneamente diffratadas em monocristais perfeitos é descrito com grande precisão e riqueza de detalhes pela teoria dinâmica da difração de N-feixes [41, 43, 44]. E nesta tese utilizou-se uma função parametrizada para o ajuste de curvas, a qual foi baseada na aproximação de segunda ordem da teoria dinâmica para DM de 3-feixes do tipo

$$
I(\varphi)=\left|D_{1}\right|^{2}+\left|D_{2}(\varphi)\right|^{2}+\varrho\left[D_{1} D_{2}^{*}(\varphi)+D_{1}^{*} D_{2}(\varphi)\right]
$$

onde $D_{1}$ representa o campo de onda da reflexão primária e $\varrho$ é um fator de peso para os termos de interferência entre os campos de onda $D 1$ e $D 2$, sendo que

$$
D_{2}(\varphi)=R \frac{\omega_{S}}{2\left(\varphi-\varphi_{0}\right)+i \omega_{S}} e^{i \Psi_{T}}
$$

é gerado pela excitação da reflexão secundária, mas seu valor efetivo também depende da reflexão de acoplamento. $R$ é um parâmetro relacionado à razão das amplitudes entre os campos, $\varphi_{0}$ é a posição azimutal e $\omega_{S}$ a largura intrínseca do perfil dos picos de DM. $\Psi_{T}$ é a diferença de fase entre as ondas, ou seja, a fase tripleto. Na comparação com a curva experimental, o perfil intrínseco, Eq.4.13, precisa ser convoluido com uma função instrumental. 
Usou-se uma função gaussiana de largura $\omega_{G}$.

Os ajustes das curvas são obtidos via algoritmo genético [45], Apêndice B, o qual otimiza os valores dos parâmetros $\omega_{S}, R, \varrho, \varphi_{0}$ e $\omega_{G}$. O Apêndice C apresenta o código fonte do programa de ajuste de curvas baseado na teoria dinâmica, denominado FITTER, já implementado com o algoritimo genético, e com a versão completa da função paramétrica, a qual inclui os vetores de polarização dos campos $D_{1}$ e $D_{2}$. Este programa foi desenvolvido nessa pesquisa especialmente para o ajuste dos perfis de difração múltipla. Um exemplo de arquivo de entrada do FITTER é apresentado na Fig.4.6.

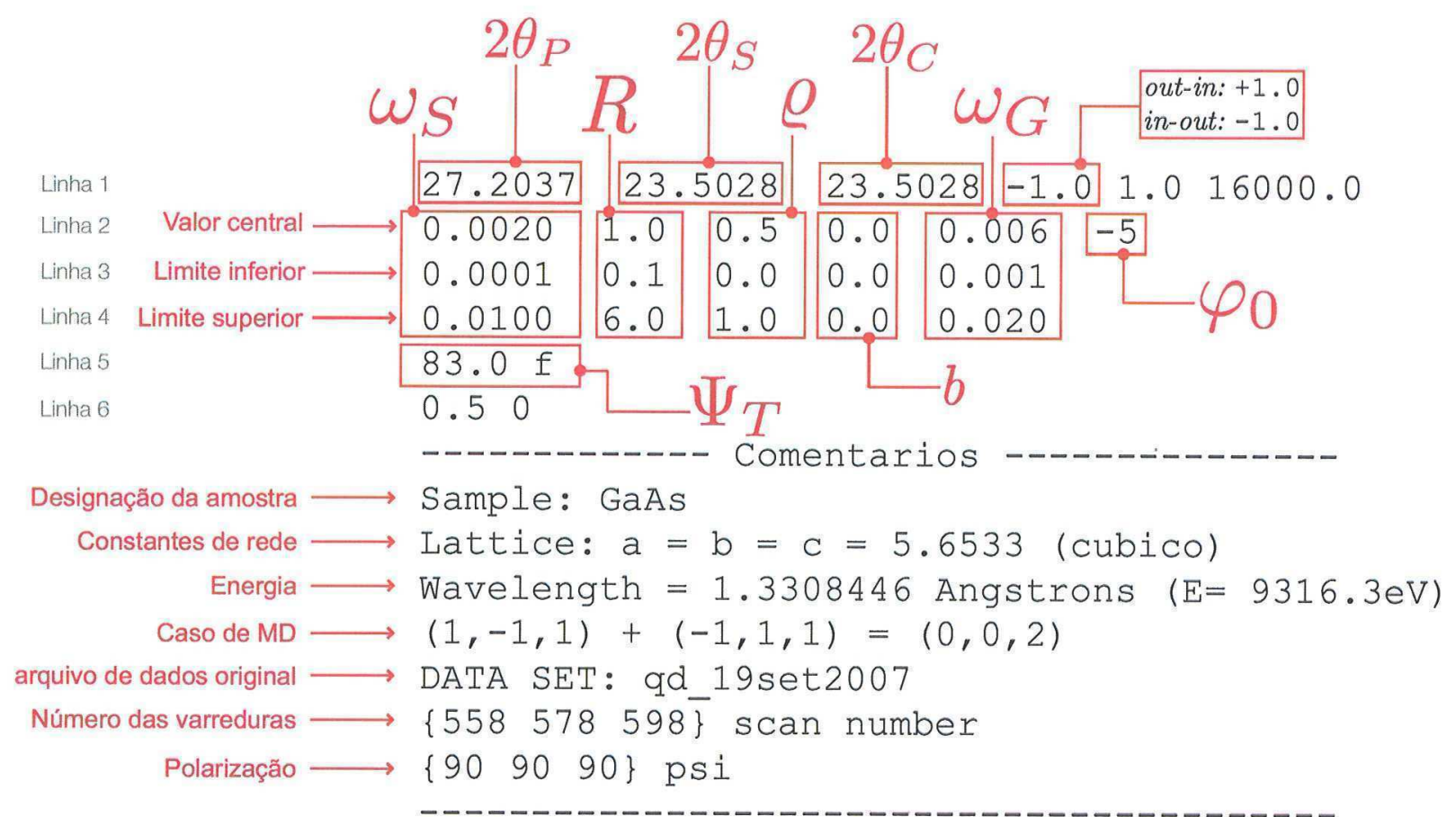

Figura 4.6: Arquivo de entrada para o programa FITTER (Apêndice C). Os parâmetros $\omega_{S}, R, \varrho, b, \omega_{G}$ e $\varphi_{0}$ são ajustados pelo algoritmo genético (Apêndice B).

Na linha 1 tem-se os valores de $2 \theta$ (2 vezes o ângulo de Bragg) para as reflexões primária, secundária e acoplamento. Esses valores são utilizados no cálculo do vetores de polarização, implícitos nos campos $D_{1}$ e $D_{2}$. Na linha 2 estão as estimativas iniciais (chutes) para os 
parâmetros ajustáveis pelo algoritmo. As linhas 3 e 4 estabelecem os limites inferior e superior dos parâmetros ajustáveis, respectivamente. No caso do parâmetro $\varphi_{0}$, que é a posição do umweg, os limites são dados pelos próprios limites da varredura experimental. Na determinação da posição do umweg, o valor da fase tripleto foi sempre $\Psi_{T}=0^{\circ}$ ou $180^{\circ}$. Esses valores ajustam perfeitamente tanto os umwegs assimétricos como os simétricos. Note que através do parâmetro $\varrho$, a assimetria introduzida pelo valor da fase é eliminado permitindo assim o ajuste de umwegs com qualquer assimetria. Um exemplo da atuação do FITTER é demonstrado na Fig.4.7 para perfis de XRS do umweg $1 \overline{1} 1+\overline{1} 11=002$ do GaAs nas energias E=9316, 10200 e $10500 \mathrm{eV}$ coletados na linha de difração XRD1 do LNLS.

Para energias abaixo da borda de absorção do $\mathrm{Ga}(\sim 10367 \mathrm{eV})$ os perfis apresentam leves traços de assimetria do tipo construtiva-destrutiva (C/D), Figs. 4.7(a) e 4.7(b), o que é esperado para valores da fase tripleto em torno de $83^{\circ}$ previsto para estas energias. Para a energia de $10500 \mathrm{eV}$, Fig.4.7(c), o perfil apresenta um grau acentuado de assimetria tipo destrutiva-construtiva (D/C), a qual encontra-se invertida quando comparada com as outras energias. Para a energia de $10500 \mathrm{eV}$, é prevista uma fase de $136^{\circ}$ a qual explica a tanto a acentuação da assimetria como a inversão do tipo de assimetria: de C/D para D/C [46]. Os perfis foram ajustados de forma a fornecer a posição do pico de DM para análise do parâmetro de rede. A Tabela 4.2 apresenta o resultado dos ajustes dos parâmetros das curvas simuladas da Fig.4.7. Mesmo para os casos com grande assimetria é possível realizar uma análise sistemática da posição relativa dos umwegs para uma mesma energia. Este procedimento foi adotado em todos os experimentos de medida de parâmetro apresentados a seguir neste capítulo. A alta simetria dos picos para energia de $9316 \mathrm{eV}$ possibilitou a utilização de um mesmo arquivo de entrada no programa, o que forneceu ajustes sistemáticos para os 8 picos de DM utilizados na determinação do parâmetro de rede. 


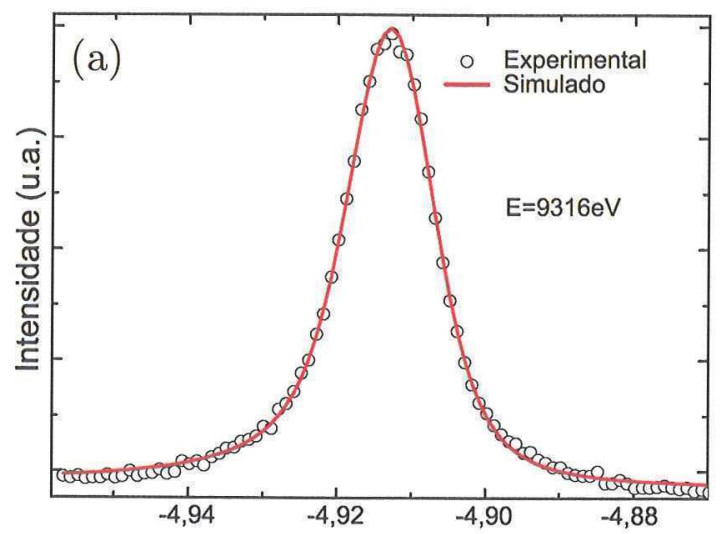

$\begin{array}{lllllll}27.2037 & 23.5028 & 23.5028 & -1.0 & 1.0 & 16000.0\end{array}$

$\begin{array}{lllllll}0.0020 & 1.0 & 0.5 & 0.0 & 0.006 & -5\end{array}$

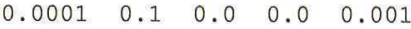

$\begin{array}{lllll}0.0100 & 6.0 & 1.0 & 0.0 & 0.020\end{array}$

$83.3 \mathrm{f}$

0.50

-..---nentarios

Sample: GaAs

Lattice: $\mathrm{a}=\mathrm{b}=\mathrm{c}=5.6533$ (cubico)

Wavelength $=1.3308446$ Angstrons $(E=9316.3 \mathrm{eV})$

$(1,-1,1)+(-1,1,1)=(0,0,2)$

DATA SET: qd 19set2007

$\{558\}$ scan number

$\{90\}$ psi

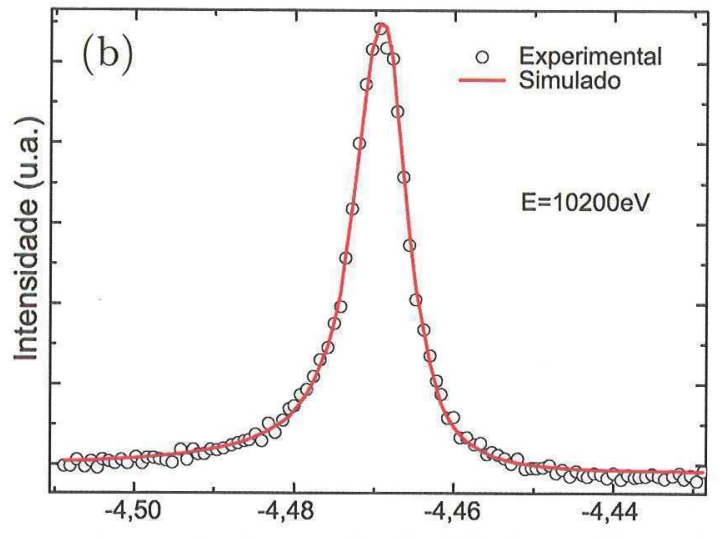

$\begin{array}{llllll}24.8323 & 21.4627 & 21.4627 & -1.0 & 1.0 & 11000.0\end{array}$

$\begin{array}{llllll}0.007 & 1.0 & 0.5 & 0.0 & 0.010 & -5\end{array}$

$\begin{array}{lllll}0.002 & 0.1 & 0.0 & 0.0 & 0.001\end{array}$

$\begin{array}{llllll}0.011 & 8.0 & 1.0 & 0.0 & 0.020\end{array}$

$82.0 \mathrm{f}$

0.51

Sample: GaAs

Lattice: $\mathrm{a}=\mathrm{b}=\mathrm{c}=5.6533$ (cubico)

Wavelength $=1.1809 \mathrm{~A}(\mathrm{E}=10200 \mathrm{eV})$

$(1,-1,1)+(-1,1,1)=(0,0,2)$

DATA SET: qd_31jan07

$\{404\}$ scan number

\{90\} psi

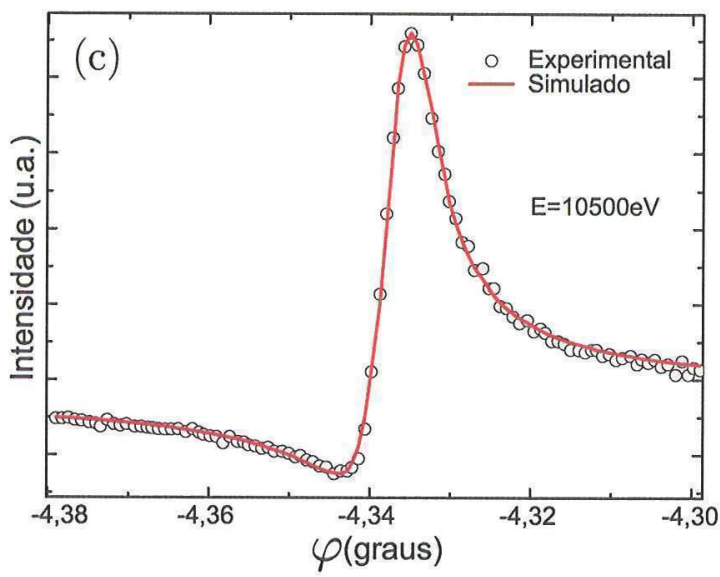

$\begin{array}{llllll}24.1119 & 20.8425 & 20.8425 & -1.0 & 1.0 & 30000.0\end{array}$

$\begin{array}{llllll}0.0020 & 1.0 & 0.5 & 0.0 & 0.006 & -5\end{array}$

$\begin{array}{lllll}0.0001 & 0.1 & 0.0 & 0.0 & 0.001\end{array}$

$\begin{array}{lllll}0.0100 & 4.0 & 1.0 & 0.0 & 0.020\end{array}$

$136.5 \mathrm{f}$

0.50

-...- Comentarios

Sample: GaAs

Lattice: $\mathrm{a}=\mathrm{b}=\mathrm{c}=5.6533$ (cubico)

Wavelength $=1.1809 \mathrm{~A} \quad(\mathrm{E}=10500 \mathrm{eV})$

$(1,-1,1)+(-1,1,1)=(0,0,2)$

DATA SET: qd $31 j a n 07$

$\{473\}$ scan number

\{90\} psi

Figura 4.7: Perfis umwegs experimentais (círculos) e ajustados (linhas) pelo FITTER. Energias: (a) $9316 \mathrm{eV}$, (b) $10200 \mathrm{eV}$ e (c) $10500 \mathrm{eV}$. Ao lado das figuras encontram-se os respectivos arquivos de entrada do programa FITTER.

Voltando ao contexto das condições de DM fornecidas pelas reflexões secundárias 111 com a relfexão primária 002 , os 8 perfis de DM foram ajustados de forma a fornecer 


\begin{tabular}{ccccccc}
\hline Energia & $\omega_{S}$ & $R$ & $\varrho$ & $\omega_{G}$ & $\varphi_{0}$ & $\delta$ \\
\hline $9316 \mathrm{eV}$ & 0,0083 & 3,0872 & 0,1023 & 0,0092 & $-4,9125687$ & 83,3 \\
$10200 \mathrm{eV}$ & 0,0065 & 3,7471 & 0,2036 & 0,0032 & $-4,4689639$ & 82,0 \\
$10500 \mathrm{eV}$ & 0,0053 & 2,7759 & 0,9331 & 0,0039 & $-4,3367580$ & 136,50 \\
\hline
\end{tabular}

Tabela 4.2: Resultado do ajuste dos parâmetros para as energias $9316 \mathrm{eV}, 10200 \mathrm{eV}$ e $10500 \mathrm{eV}$.

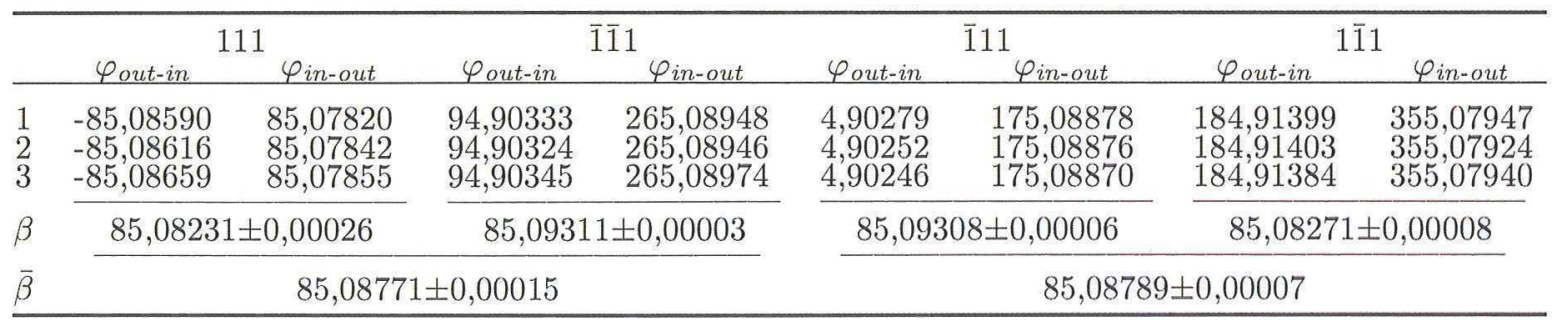

Tabela 4.3: Posições $\varphi$ dos umwegs com reflexões secundárias 111, $\overline{1} 11, \overline{1} 11$, e $1 \overline{1} 1$ obtidas em XRS na amostra \#1. Cada posição $\varphi$ foi medida 3 vezes (linhas 1, 2 and 3) como detalhado no texto. $\beta=\left(\varphi_{\text {in-out }}-\varphi_{\text {out-in }}\right) / 2, \bar{\beta}$ são valores médios sem efeitos de desalinhamentos residuais. Todos os valores angulares são dados em graus.

a posição das intersecções dos cones primário e secundário para análise do parâmetro de rede. As linhas 1,2 e 3 da Tabela 4.3 apresentam as posições centrais dos perfis de XRS obtidos da amostra \#1, as quais foram extraídas do ajuste realizado pelo programa descrito anteriormente. A diferença entre as posições dos picos $\varphi_{\text {in-out }}$ e $\varphi_{\text {out-in }}$ fornece a projeção no-plano da abertura do cone $2 \beta$. O valor de $\bar{\beta}$ é obtido da média nas direções [110] e [110] e são intrinsicamente livres de efeitos de desalinhamentos residuais.

A distribuição dos QDs de InAs acontece de forma aleatória e isotrópica na superfície do GaAs durante o crescimento. Espera-se, portanto, que as deformações na rede do GaAs resultem em células unitárias tetragonais. Em uma abordagem tridimensional e considerando um material isotrópico, deformações em uma determinada direção produzem deformações ao longo das outras duas direções. A Fig.4.8 ilustra um esquema de forças $\sigma_{i} \mathrm{e}$ respectivas deformações $\epsilon_{i}$ na célula unitária.

A generalização tridimensional da lei de Hooke é dada pelas 3 equações a seguir: 


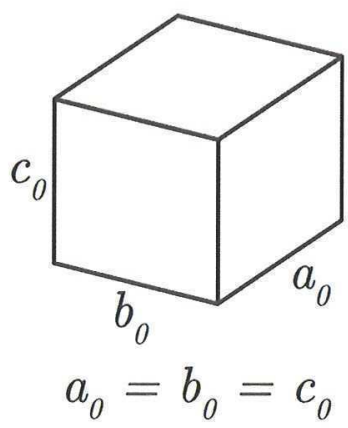

(a)

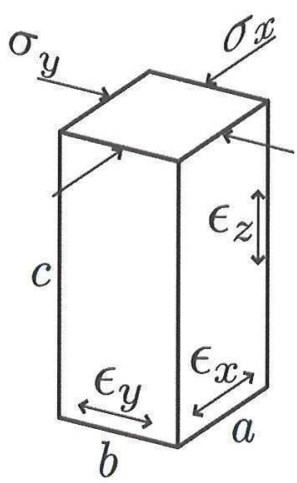

$a=b \neq c$

(b)

Figura 4.8: Célula unitária do GaAs: (a) cúbica relaxada e (b) tetragonal tensionada.

$$
\begin{aligned}
& \epsilon_{x}=\frac{1}{E_{Y}}\left[\sigma_{x}-\nu\left(\sigma_{y}+\sigma_{z}\right)\right] \\
& \epsilon_{y}=\frac{1}{E_{Y}}\left[\sigma_{y}-\nu\left(\sigma_{x}+\sigma_{z}\right)\right] \\
& \epsilon_{z}=\frac{1}{E_{Y}}\left[\sigma_{z}-\nu\left(\sigma_{x}+\sigma_{y}\right)\right]
\end{aligned}
$$

sendo $\epsilon_{i}$ a deformação e $\sigma_{i}$ a tensão aplicada nas respectivas direções $i=x, y$ ou $z$. $E_{Y}$ e $\nu$ correspondem ao módulo de Young e razão de Poisson do material, respectivamente. No caso da deformação tetragonal,

$$
\sigma_{x}=\sigma_{y} \equiv \sigma_{\|} \quad \text { e } \quad \sigma_{z}=0 .
$$

Substituindo esses valores nas Eqs.4.14, 4.15 e 4.16, obtem-se 


$$
\begin{gathered}
\epsilon_{x}=\epsilon_{y} \equiv \epsilon_{\|}=\frac{\sigma_{\|}}{E_{Y}}(1-\nu), \\
\epsilon_{z} \equiv \epsilon_{\perp}=-\frac{2 \nu}{E_{Y}} \sigma_{\|},
\end{gathered}
$$

e portanto

$$
\epsilon_{\perp}=-\frac{2 \nu}{(1-\nu)} \epsilon_{\|}
$$

A Eq.4.17 permite escrever os parâmetros da rede tensionada em função apenas da deformação no plano, ou seja

$$
\begin{aligned}
& a=b=a_{0}\left(1+\epsilon_{\|}\right) \\
& c=a_{0}\left(1+\epsilon_{\perp}\right)=a_{0}\left(1-\frac{2 \nu}{(1-\nu)} \epsilon_{\|}\right) .
\end{aligned}
$$

Com os parâmetros da rede tetragonal dados em função da deformação no plano, pode-se agora calcular o valor de $\beta$ em função dessa deformação, o que leva a

$$
\beta\left(\epsilon_{\|}\right)=\beta_{0}+\epsilon_{\|}\left(\frac{\partial \beta}{\partial \epsilon_{\|}}\right)_{\epsilon_{\|=0}},
$$

onde $\beta_{0}$ pode ser um valor nominal ou um valor experimental, o qual será usando como valor de referência na determinação das deformações no-plano em um conjunto de amostras. O valor $\left(\partial \beta / \partial \epsilon_{\|}\right)_{\epsilon_{\|}=0}=23,406^{\circ}$ é obtido para a razão $a_{0} / \lambda=4,2479$ e $\nu_{G a A s}=0,311$ (razão de Poisson do GaAs em 300K). Desta forma foram obtidos os valores de deformação apresentados na Tabela 4.4 .

A Fig.4.9 apresenta uma síntese das medidas de parâmetro de rede no-plano das 


\begin{tabular}{ccccc}
\hline Amostra & $\bar{\beta}_{[110]}$ & $\bar{\beta}_{[\overline{1} 10]}$ & $\epsilon_{\|_{[110]}} \times 10^{-5}$ & $\epsilon_{\|_{[\overline{1} 10]}} \times 10^{-5}$ \\
\hline$\# 1$ & $85,08771 \pm 0,00015$ & $85,08789 \pm 0,00007$ & $1,52 \pm 0,64$ & $2,28 \pm 0,30$ \\
$\# 2$ & $85,08725 \pm 0,00033$ & $85,08746 \pm 0,00037$ & $-0,45 \pm 1,41$ & $0,45 \pm 1,58$ \\
$\# 3$ & $85,08753 \pm 0,00012$ & $85,08784 \pm 0,00022$ & $0,75 \pm 0,51$ & $2,07 \pm 0.94$ \\
$\# 4$ & $85,08751 \pm 0,00013$ & $85,08750 \pm 0,00016$ & $0,66 \pm 0,56$ & $0,62 \pm 0,68$ \\
$\# 5$ & $85,15225 \pm 0,00028$ & $85,15198 \pm 0,00030$ & $277,26 \pm 1,20$ & $276,10 \pm 1,28$ \\
$\# 6$ & $85,08833 \pm 0,00011$ & $85,08824 \pm 0,00010$ & $4,16 \pm 0,47$ & $3,78 \pm 0,43$ \\
\hline
\end{tabular}

Tabela 4.4: Valores experimentais de $\bar{\beta}$ e da deformação no-plano, $\epsilon_{\|}$, para as amostras de \#1 a \#6 especificadas na Tabela 3.1.

\begin{tabular}{ccc}
\hline Amostra & $a_{[110]}$ & $a_{[\overline{1} 10]}$ \\
\hline$\# 1$ & $5,653386 \pm 0,000036$ & $5,653429 \pm 0,000017$ \\
$\# 2$ & $5,653275 \pm 0,000080$ & $5,653325 \pm 0,000089$ \\
$\# 3$ & $5,653342 \pm 0,000029$ & $5,653417 \pm 0,000053$ \\
$\# 4$ & $5,653337 \pm 0,000031$ & $5,653335 \pm 0,000039$ \\
$\# 5$ & $5,668974 \pm 0,000068$ & $5,668909 \pm 0,000072$ \\
$\# 6$ & $5,653536 \pm 0,000026$ & $5,653514 \pm 0,000024$ \\
\hline
\end{tabular}

Tabela 4.5: Parâmetros de rede no-plano do GaAs medidos nas direções [110] e [1110].

amostras de \#1 a \#6 especificadas na Tabela 3.1. Nessa análise, a medida de parâmetro da amostra \#2 (camada tampão) foi tomada como referência, a qual é demarcada pela linha horizontal vermelha referente à média das medidas das direções [110] e [110]. A amostra \#2 apresenta uma leve compressão no parâmetro comparada ao substrato comercial de GaAs (amostra \#1). Tal diferença pode estar relacionada a possíveis defeitos introduzidos no processo de polimento do substrato, os quais são minimizados com o crescimento dos $2000 \AA ̊$ de camada tampão. Uma tendência de expansão no parâmetro de rede é observada nas amostras com QDs. Para amostras com QDs expostos (amostras \#3 e \#4), um leve acréscimo é observado e basicamente se deve ao descasamento de $7 \%$ entre os parâmetros de rede do InAs e GaAs. A amostra com maior densidade de QDs (\#3) apresentou maior expansão média quando comparada à amostra \#4. Valores mais acentuados de expansão do parâmetro de rede são observados nas amostras com QDs cobertos (amostras \#5 e \#6) e isto pode ser devido à propagação da tensão de deformação ao longo da sobre-camada. O valor fora de escala observado na amostra \#5 fornece indícios de que outros fatores podem afetar o perfil de DM e, como será evidenciado no próximo capítulo, para tais casos o modelo de 


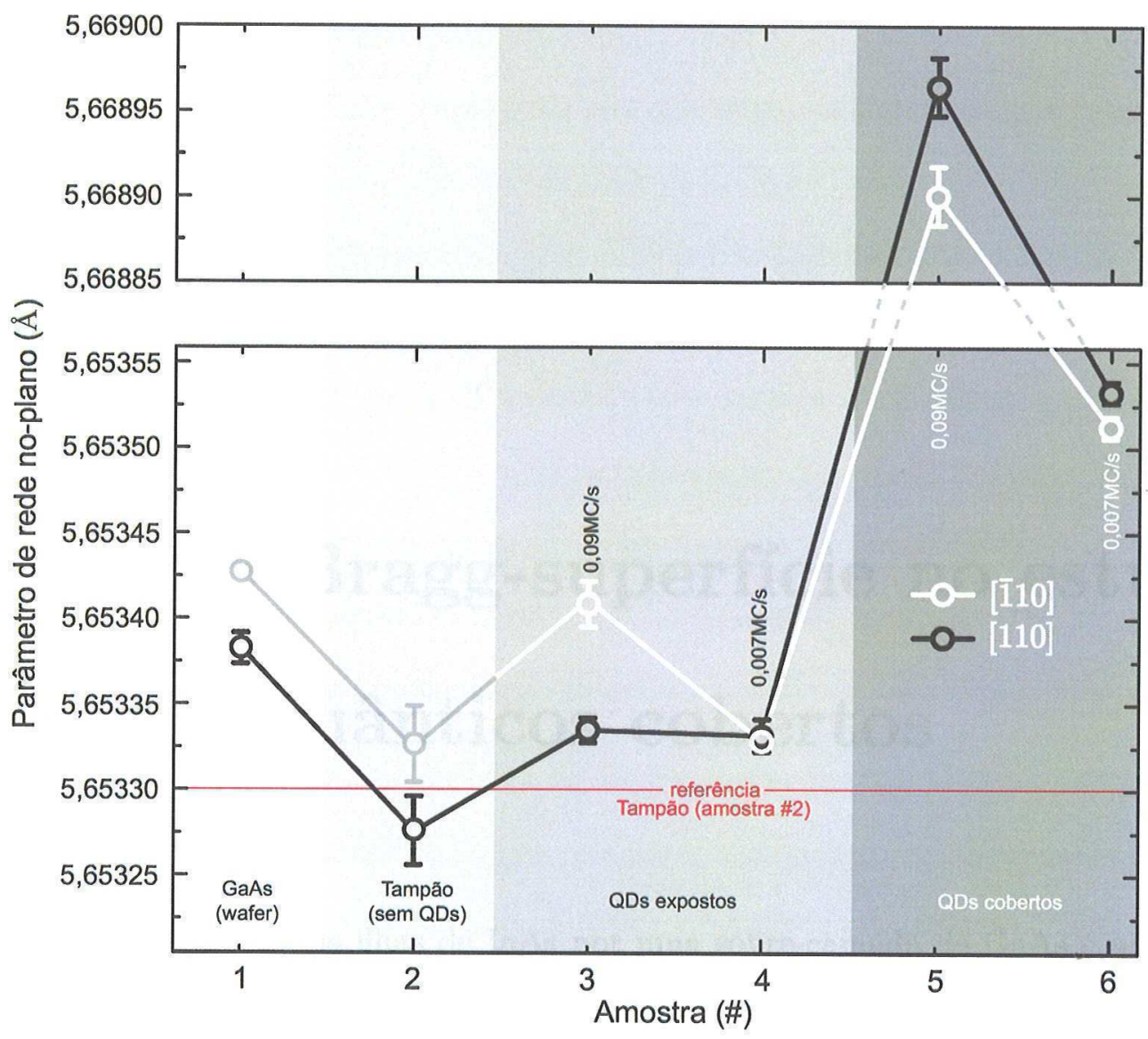

Figura 4.9: Resumo das medidas de parâmetro de rede nas amostras de \#1 a \#6 da Tabela 3.1 .

deformação tetragonal não é adequado. Neste contexto, o próximo capítulo apresenta um estudo mais amplo das proximidades da região do umweg (mapas $\theta-\varphi$ ) aplicado ao mesmo conjunto de amostras da Tabela 3.1. 


\section{Capítulo 5}

\section{A difração Bragg-superfície no estudo de pontos quânticos cobertos}

O processo de cobrimento das ilhas de InAs por uma sobre-camada de GaAs é uma etapa crítica na construção de dispositivos optoeletrônicos. Além de determinar a atividade óptica final dos QDs, a sobre-camada disponibiliza uma nova superfície para o crescimento de mais ilhas, como é feito no caso de dispositivos baseados em super-rede de QDs. Outra função importante da sobre-camada é proteger a superfície das nanoestruturas, as quais são passivadas com o processo de cobrimento. No entanto, o processo de cobrimento possui uma cinética complexa de crescimento a qual exerce forte influência na composição e na forma final das ilhas [47]. Além disso, o campo de tensão dentro dos QDs - uma propriedade natural de nanoestruturas formadas no modo SK - tem forte impacto no transporte de massa durante a deposição da sobre-camada. Análises realizadas por X-TEM utilizando marcadores de alumínio [48] revelaram uma expressiva redistribuição de material de forma a causar depressões na sobre-camada na região exatamente acima dos QDs. O mesmo efeito foi obser- 
vado em micrografias de AFM realizadas na superfície da sobre-camada [49] em um sistema também baseado em QDs de InAs. Esse efeito tem sido explorado no crescimento de sistemas baseados em QDs empilhados, ou seja, super-redes de QDs de InAs/GaAs [50]. Mecanismos de acomodação das discordâncias de rede, interdifusão e redistribuição de material durante o processo de cobrimento são efeitos previstos no entorno das ilhas e a ocorrência de defeitos do tipo micro-twin ou defeitos planares na rede da sobre-camada é um fenômeno já observado $[48,51,52]$. Dada a importância do processo de cobrimento no estado final dos dispositivos, técnicas de análise não-destrutíveis as quais sejam capazes de obter informação estrutural da interface de conjuntos representativos de ilhas são essenciais para o melhor entendimento e aprimoramento dos métodos de fabricação desses dispositivos.

Difração Bragg-Superfície (BSD do inglês Bragg-Surface Diffraction) é o termo utilizado para os casos particulares de DM de três feixes nos quais uma reflexão extremamente assimétrica, difratando paralelamente à superfície macroscópica do cristal, é excitada junto com uma reflexão Bragg simétrica. Como ilustrado na Fig.5.1, o feixe incidente 1 é difratado simultaneamente pelas reflexões $\mathbf{P}$ e $\mathbf{S}$ sendo a última responsável pelo feixe de superfície 2. Devido ao caráter ultra rasante do feixe de superfície, qualquer defeito presente na superfície da amostra pode favorecer o re-espalhamento do feixe de superfície, fato que tem sido usada na investigação de acabamentos superficiais, alterações estruturais causadas por implantação de íons em materiais semicondutores $[53,54]$ e, mais recentemente, no estudo de deformações estruturais em interfaces de filmes finos epitaxiais com resolução atômica em profundidade [18]. Mapas $\theta-\varphi$ em torno da BSD fornecem um padrão de distribuição de intensidade característico onde é possível identificar traços dos cones primário e secundário, como mostrado no detalhe da Fig.5.1. O traço horizontal de intensidade é gerado pela reflexão primária enquanto o traço diagonal provem da reflexão secundária. Assim, duas características básicas podem ser consideradas nos mapas: i) a orientação relativa do traço 
diagonal e ii ) a distribuição de intensidade ao longo do mesmo. A primeira é essencialmente regida pela orientação dos planos difratantes 111 na superfície da amostra enquanto que a segunda depende do regime, cinemático ou dinâmico, de acoplamento feixe de superfície. No regime cinemático ocorre um acoplamento de intensidade, i.e. sem coerência de fase entre ondas difratadas. Qualquer defeito na superfície da amostra, tais como mosaicidade e/ou espalhamento difuso, podem modificar a distribuição de intensidade nos mapas $\theta-\varphi$ com relação àquela esperada no caso de um acoplamento dinâmico (cristal perfeito). Devido a sensibilidade da geometria BSD na análise de superfícies e interfaces $[18,19,20]$, este capítulo apresenta uma investigação do processo de crescimento de dispositivos baseados em QDs de InAs/GaAs via mapas $\theta-\varphi$ ou mapas BSD. Dentro de outras propriedades analisadas, o estudo da orientação do traço secundário em mapas BSD de amostras dos vários estágios do crescimento dos dispositivos traz novas pistas sobre os mecanismos de acomodação de tensão nas imediações das ilhas.

A orientação do traço secundário com relação ao primário (variável $\zeta$ ) está relacionada com o ângulo de inclinação entre as bordas dos cones de Bragg $\mathbf{P}$ e $\mathbf{S}$ nas proximidades da intersecção. Assim, o ângulo $\zeta$ pode ser teoricamente derivando-se a 4.10 em relação aos ângulos $\theta$ e $\beta$, tal que

$$
\frac{\partial \cos \beta}{\partial \beta} \Delta \beta=\frac{\partial \cos \beta}{\partial \theta} \Delta \theta
$$

Desde que $\varphi=\psi \pm \beta$ e, portanto, $\Delta \varphi= \pm \Delta \beta$, o coeficiente angular do traço diagonal é obtido a partir da expressão

$$
\frac{\Delta \theta}{\Delta \varphi}= \pm \frac{\sin (\theta+\beta) \tan \gamma}{\cos \theta}
$$

onde se definiu $\zeta=\arctan \left(\frac{\Delta \theta}{\Delta \varphi}\right)$ para os casos in-out e $\zeta=\pi-\arctan \left(\frac{\Delta \theta}{\Delta \varphi}\right)$ para os casos 
out-in. Para $a_{G a A s}=5.6533 \AA, \lambda=1.33084 \AA, \mathbf{P}=002$ e $\mathbf{S}=111$, obtém-se os valores $\zeta_{\text {in }- \text { out }}=$ 55, $44^{\circ}$ e $\zeta_{o u t-i n}=124,56^{\circ}$, como pode ser visto no detalhe da Fig.5.1. Tal abordagem geométrica pode ser aplicada a outros casos de DM de 3 feixes e pode auxiliar na indexação de picos de DM em situações onde a posição azimutal dos mesmos não seja suficiente para sua identificação. A Eq.5.2 forneçe apenas uma estimativa teórica da orientação do traço diagonal baseada na simples geometria dos cones de Bragg, sem correções de efeitos dinâmicos. O valor referência de inclinação adotado na análise foi aquele dado pelo mapa BSD do substrato de GaAs, como detalhado mais adiante.

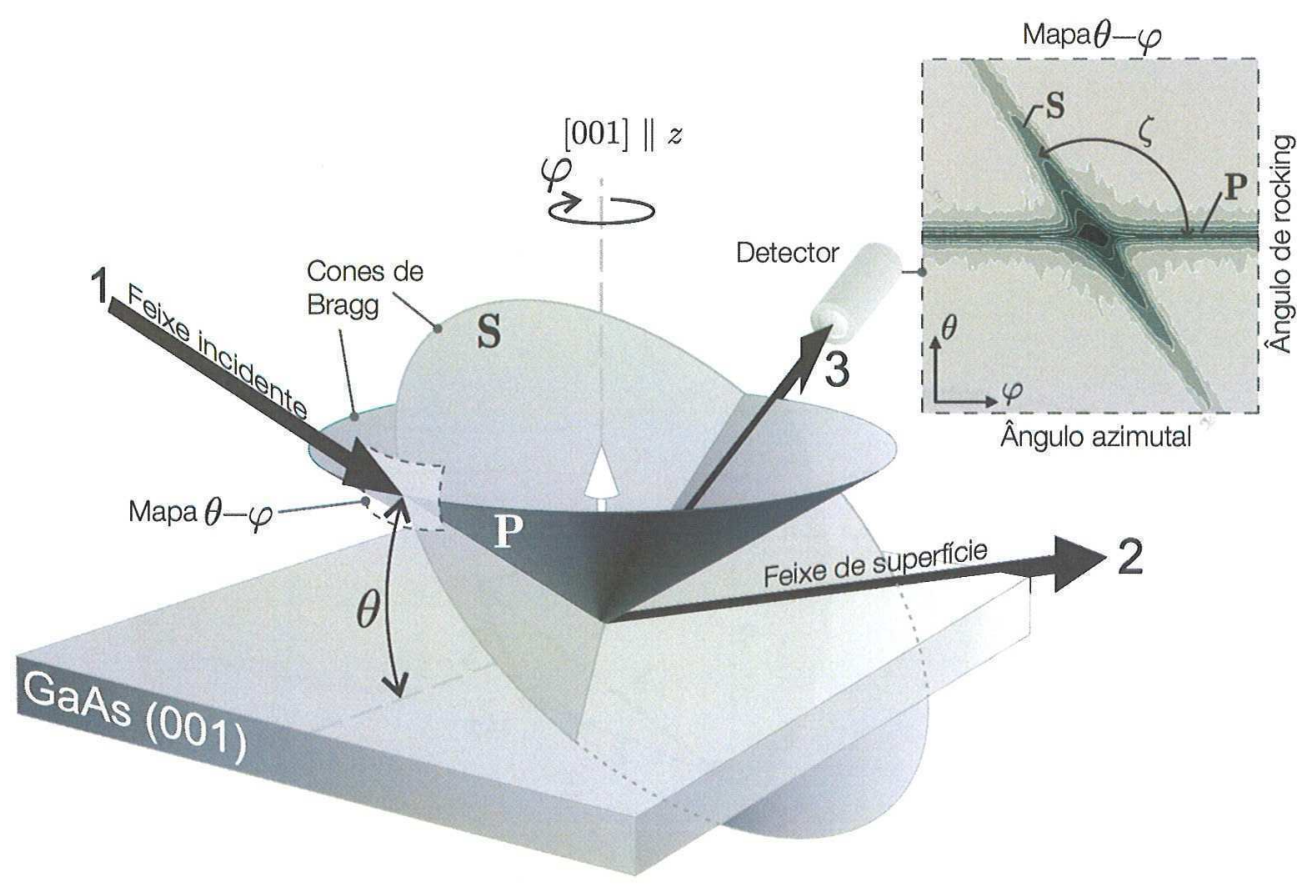

Figura 5.1: Geometria da BSD num substrato de GaAs (001). O feixe incidente 1 satisfaz a condição de Bragg para as reflexões $\mathbf{S}$ e $\mathbf{P}$, gerando simultaneamente os feixes $\mathbf{2}$ e $\mathbf{3}$, respectivamente. No detalhe, típico mapa $\theta-\varphi$ com indicação do ângulo $\zeta$ entre os traços das reflexões primária e secundária.

No espaço recíproco, a condição de DM ocorre quando dois ou mais pontos da rede recíproca tocam a esfera de Ewald simultaneamente. A BSD é um caso particular de DM de 3-feixes onde o ponto da rede recíproca secundário (extremidade do vetor $\mathbf{S}$ ) toca 
a esfera em seu equador, conforme ilustra a Fig.5.2. Quando satisfazendo uma condição de difração simétrica, como a reflexão $\mathbf{P}$, o plano do equador da esfera é paralelo à superfície do cristal, o que torna $k_{\mathrm{S}}$ um feixe difratado de superfície. O detector é posicionado de forma a monitorar o feixe difratado $k_{\mathrm{P}}$, ou seja a reflexão primária, e o feixe de superfície é observado indiretamente pelo detetor via reflexão acoplamento C. De maneira generalizada, os casos de DM são aqueles que satisfazem a Eq.4.1 para qualquer vetor da rede recíproca. Tomando os índices de Miller $H K L, h k l$ e $h^{\prime} k^{\prime} l^{\prime}$ como representando as reflexões $\mathbf{P}, \mathbf{S}$ e $\mathbf{C}$, respectivamente, os casos de BSD podem ser visualizados no espaço recíproco de acordo com a Fig.5.2.

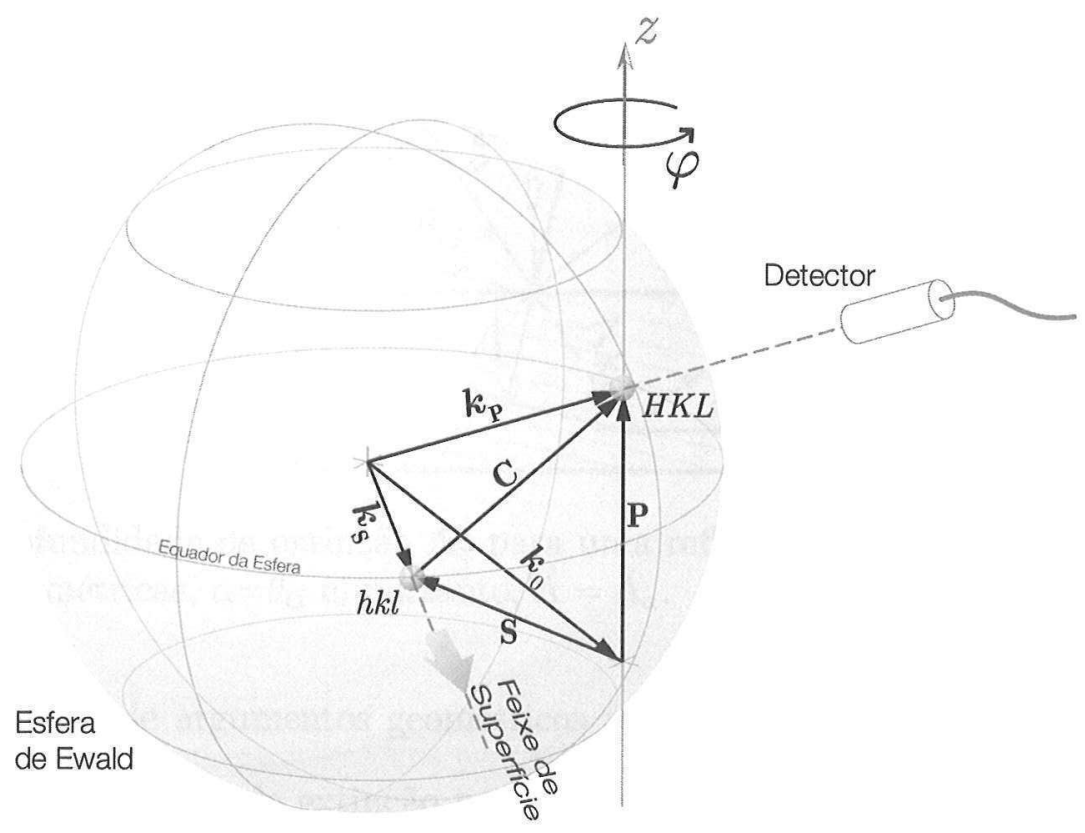

Figura 5.2: Geometria da BSD no espaço recíproco. Sendo $\mathbf{P}$ uma reflexão simétrica e $\mathbf{S} \cdot \mathbf{P}=|\mathbf{P}|^{2} / 2$, o feixe difratado $\boldsymbol{k}_{\mathrm{S}}$ é paralelo à superfície macroscópica da amostra.

O caso de BSD investigado neste trabalho tem a reflexão Bragg simétrica 002 do GaAs $(\mathbf{P}=002)$ como primária e como secundária as reflexões assimétricas da família $\{11\} 1$ ( $\mathbf{S}=h k 1$ sendo $h= \pm 1$ e $k= \pm 1$ ), as quais são responsáveis pela geração da onda ou feixe 
de superfície. A principal razão dessa BSD ser sensível ao estado da superfície advém do fato das reflexões 111 serem das mais intensas, implicando numa reduzida profundidade de extinção $\Lambda$ do feixe secundário. De acordo com a teoria dinâmica da difração de raios $\mathrm{X}$ $[55,56]$, a profundidade de extinção ${ }^{1}$ para uma reflexão simétrica é definida por

$$
\Lambda=\frac{V_{c}}{4 d r_{e}|F(\mathbf{G})|}
$$

sendo $V_{c}$ o volume da célula unitária, $r_{e}=2,818 \times 10^{-6} \mathrm{~nm}$ o raio clássico do elétron, $d$ a distância interplanar e $F$ o fator de estrutura da reflexão $\mathbf{G}$.

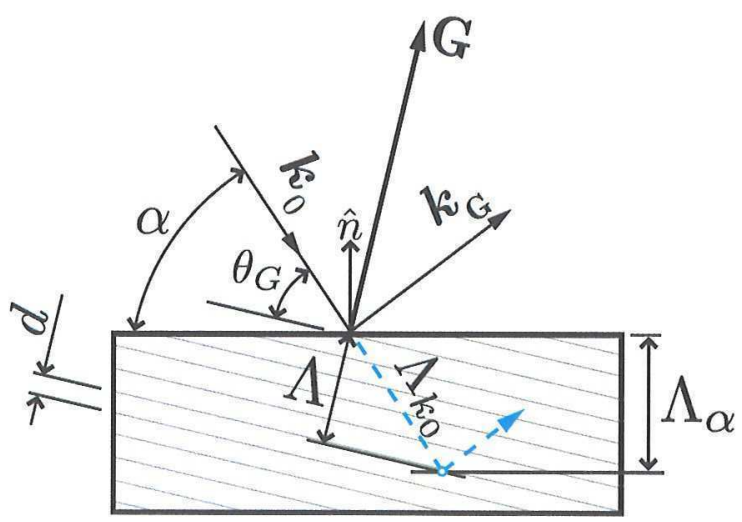

Figura 5.3: Profundidade de extinção $\Lambda_{\alpha}$ para uma reflexão Bragg assimétrica genérica $\mathbf{G}$. Para reflexões simétricas, $\alpha=\theta_{G}$ e, portanto, $\Lambda=\Lambda_{\alpha}$.

Por meio de argumentos geométricos relativamente simples, é possível extender o conceito de profundidade de extinção para reflexões assimétricas como esquematizado na Fig.5.3, de onde conclui-se que $\Lambda_{k 0}=\Lambda / \sin \theta_{G}$ e $\Lambda_{\alpha}=\Lambda_{k 0} \sin \alpha$ e, portanto,

$$
\Lambda_{\alpha}=\Lambda \frac{\sin \alpha}{\sin \theta_{G}} .
$$

\footnotetext{
${ }^{1} \mathrm{~A}$ profundidade de extinção $\Lambda$ é definida para uma atenuação de $1 / e$ na intensidade do feixe incidente $[55]$.
} 
$\theta_{G}$ é o ângulo de Bragg da reflexão $\mathrm{G}$ e $\alpha$ o ângulo entre a direção de $k_{0}$ e a superfície do cristal. Para $a_{G a A s}=0,56533 \mathrm{~nm}, \mathbf{G}=111$ e $E=9316 \mathrm{eV}$, tem-se $V_{c}=0,1807 \mathrm{~nm}^{3}, \theta_{111}=11,7634^{\circ}$, $d_{111}=0,32639 \mathrm{~nm}$ e $|F(\mathbf{G})|=146,3$. Na condição da BSD, $\alpha$ corresponde ao ângulo de Bragg da reflexão 002, i.e. $\alpha=\theta_{002}=13,6158^{\circ}$, e daí segue que $\Lambda_{\alpha}=387,60 \mathrm{~nm}$. Além disso, uma pequena correção neste valor é necessária devido ao fato da reflexão 002 também estar difratando junto com a 111. A reflexão 002 do GaAs possui módulo do fator de estrutura $|F(002)|=8,3$ para a energia utilizada e, portanto, com um cálculo similar ao realizado para a reflexão 111, de modo que $\Lambda_{k_{0}}^{002}=29022,16 \mathrm{~nm}$. A partir de $\Lambda_{k 0}$ é possível definir um coeficiente de atenuação efetivo, tal que $\exp \left(-\mu_{e f} \Lambda_{k 0}\right)=1 / e$. Sendo a distância linear percorrida pelo feixe $x=t / \sin \alpha$, define-se um coeficiente de atenuação $\mu^{*}=\mu_{e f} / \sin \alpha=1 / \Lambda_{\alpha}$, para a penetração. Assim $\mu_{002}^{*}=1 / \Lambda^{002}=203 \mathrm{~nm}^{-1}$ e $\mu_{111}^{*}=1 / \Lambda^{111}=3577 \mathrm{~nm}^{-1}$. A profundidade de extinção do feixe de superfície, corrigida pelo fato da reflexão 002 também estar excitada na condição da BSD, fica sendo $\Lambda^{B S D}=\left(1 / \Lambda^{002}+1 / \Lambda^{111}\right)^{-1}=366,8 \mathrm{~nm}$. A Fig.5.4 apresenta a profundidade de extinção $\Lambda_{\alpha}^{111}$ em função do ângulo de incidência ${ }^{2} \alpha$. Na condição exata da BSD, a profundidade de extinção decresce devido à refletividade dos planos (002) difratando simultaneamente aos planos (111).

No contexto de aplicações da BSD no estudo de dispositivos com QDs, a Fig.5.5 compara a profundidade de extinção (penetração) da radiação na condição da BSD com as dimensões das nanoestruturas. Nos casos de dispositivos com sobre-camada de $30 \mathrm{~nm}$, a penetração de $366,8 \mathrm{~nm}$ implica que $11 \%$ da intensidade do feixe de superfície advém da região nanoestruturada, permitindo assim a análise da sobre-camada, interface com os QDs e camada tampão. Comparada à penetração da reflexão primária 002, em torno de7 $\mu$ m, o sinal da BSD contem muito mais informação sobre as camadas epitaxiais vizinhas às

\footnotetext{
${ }^{2}$ Para todos os mapas $\theta-\varphi$ desta tese, o ângulo $\theta$ é definido para uma geometria Bragg simétrica, ou seja, é definido em função da superfície do cristal. Assim, o ângulo de incidência $\alpha$ equivale aos valores $\theta$ dos mapas nesta argumentação da profundidade de extinção.
} 


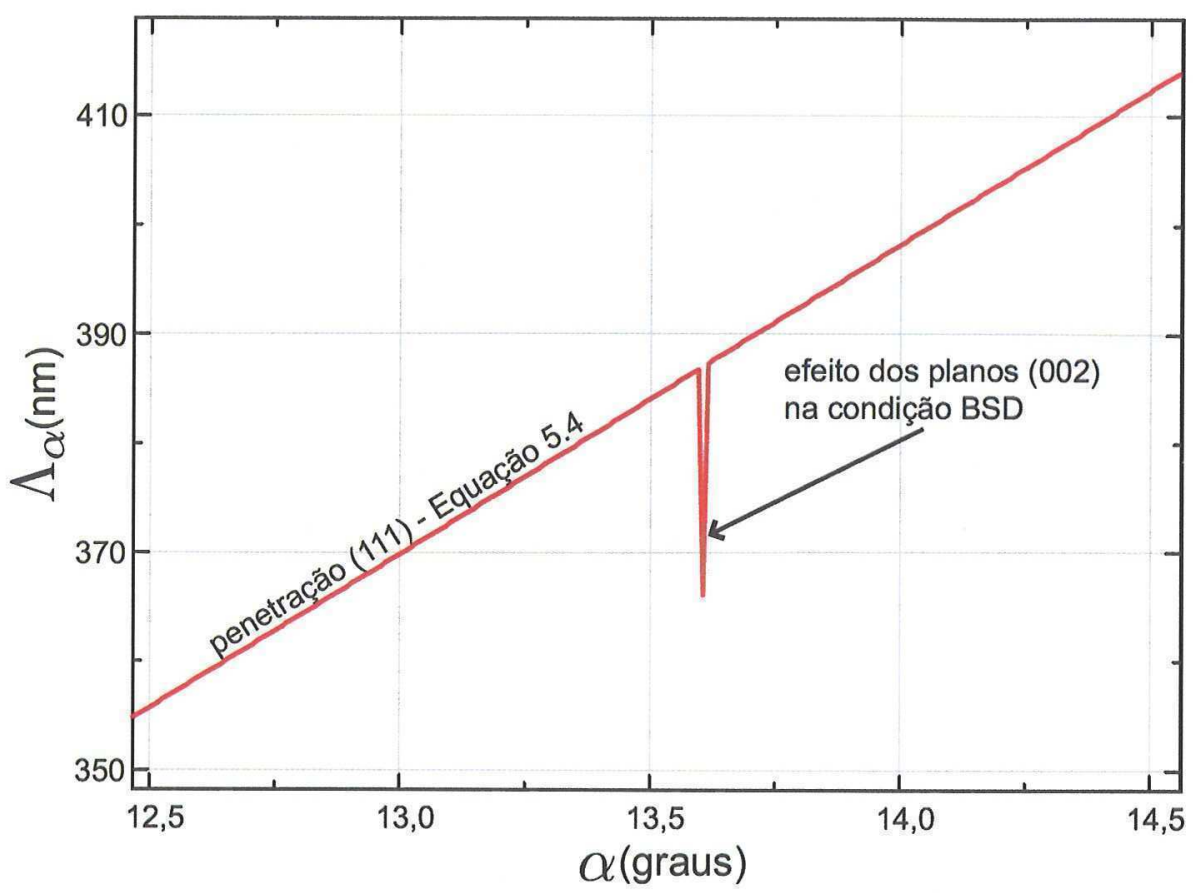

Figura 5.4: Profundidade de extinção em função do ângulo de incidência. A redução da penetração em $\alpha=13,61^{\circ}\left(\theta_{002}\right)$ ocorre devido à contribuição da (002) no processo de reflexão da onda incidente.

nanoestruturas do que o sinal da 002, que possui essencialmente informações sobre o bulk. Uma vez apresentados o modelo geométrico de previsão da orientação do traço diagonal (Eq.5.2) e a estimativa de penetração dos raios $\mathrm{X}$ nas proximidades da condição de BSD (Fig.5.5), um método de análise do traço secundário nos mapas $\theta-\varphi$ foi desenvolvido.

Mapas $\theta-\varphi$ das várias amostras da Tabela 3.1 foram obtidos de forma a investigar mudanças na orientação do traço secundário nos diversos estágios da construção dos dispositivos. Os mapas foram obtidos no arranjo experimental da linha de difração XRD1 do LNLS (Sub-seção 3.2.1) para $E=9316 \mathrm{eV}$ os quais são apresentados na Fig.5.6. Cada mapa é constituído de 40 varreduras $\varphi$ para diferentes $\theta$ em torno da condição de BSD, resultando em uma malha de $0,2^{\circ} \times 0,24^{\circ}(\theta \times \varphi)$. Mapas $\theta-\varphi$ do substrato de GaAs foram medidos de forma a servir como referência às demais amostras, conforme ilustram as Figuras 5.6(a), 


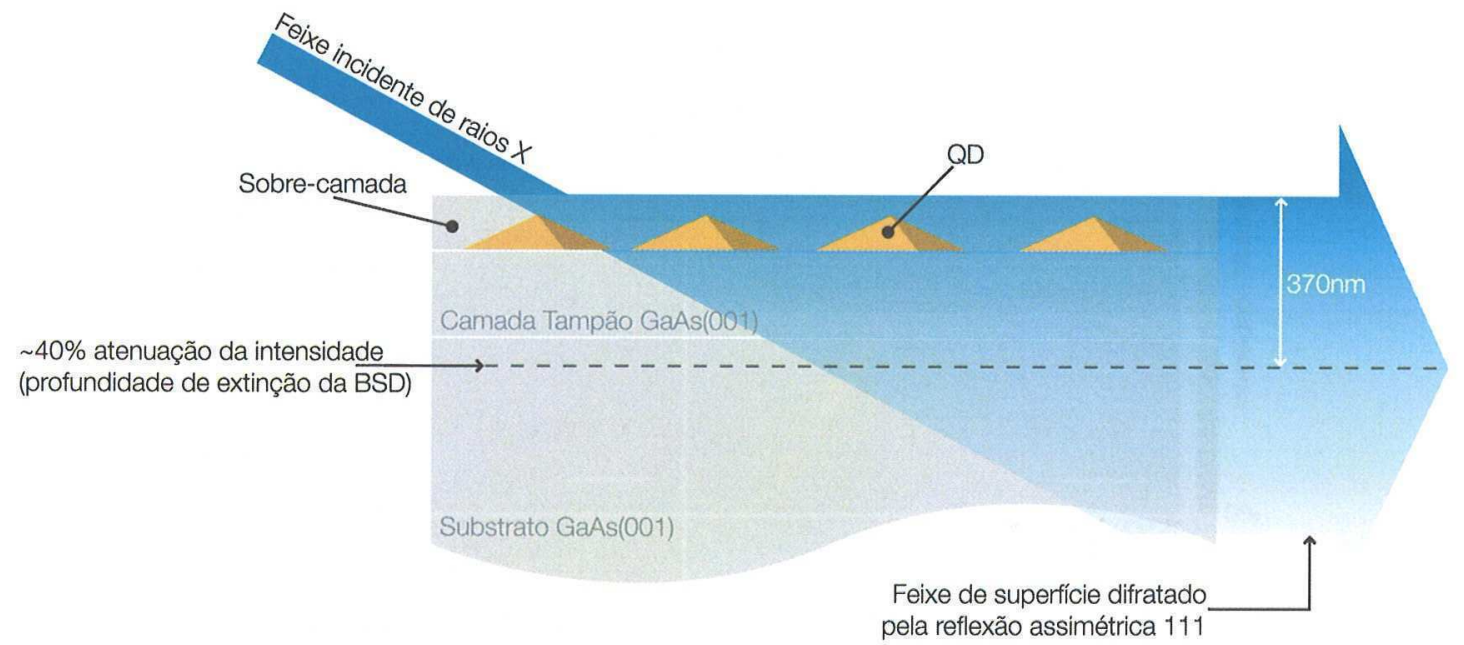

Figura 5.5: Esquema da profundidade de extinção na condição da BSD (E=9316eV) na escala dos dispositivos analisados.

para o substrato com polimento comercial, e 5.6(b), para o mesmo substrato após ataque químico. A presença de defeitos superficiais no substrato de GaAs (antes do ataque químico) é revelada pela alongada distribuição de intensidade do traço diagonal para a região abaixo do traço horizontal (reflexão primária). A presença dos efeitos é minimizada pelo ataque químico, conforme sugere a comparação nas Figs.5.6(a) e 5.6(b). Nota-se que neste último mapa, Fig.5.6(b), a intensidade ao longo do traço diagonal aparece mais simetricamente distribuida abaixo e acima do traço horizontal e, apesar da evidente mudança na distribuição de intensidade, nenhuma diferença na orientação do traço foi observada. Isto sugere que os defeitos superficiais causados pelo polimento mecânico apenas acentuam o re-espalhamento do feixe de superfície para o caso em que ele emerge do cristal, ou seja, quando $\Delta \theta=\theta-\theta_{P}<0$, sendo $\theta_{P}$ o ângulo de Bragg para a reflexão primária. As Figuras 5.6(c)-5.6(f) apresentam os mapas BSD para as amostras com QDs expostos e cobertos. Para amostras com QDs expostos, figuras 5.6(c) e 5.6(e), foi observada uma sutil variação da inclinação do traço diagonal $(\zeta)$, comparada à referência do substrato, e também um pequeno aumento do espalhamento difuso na região (indicada por setas) de menor intensidade entre os traços. 

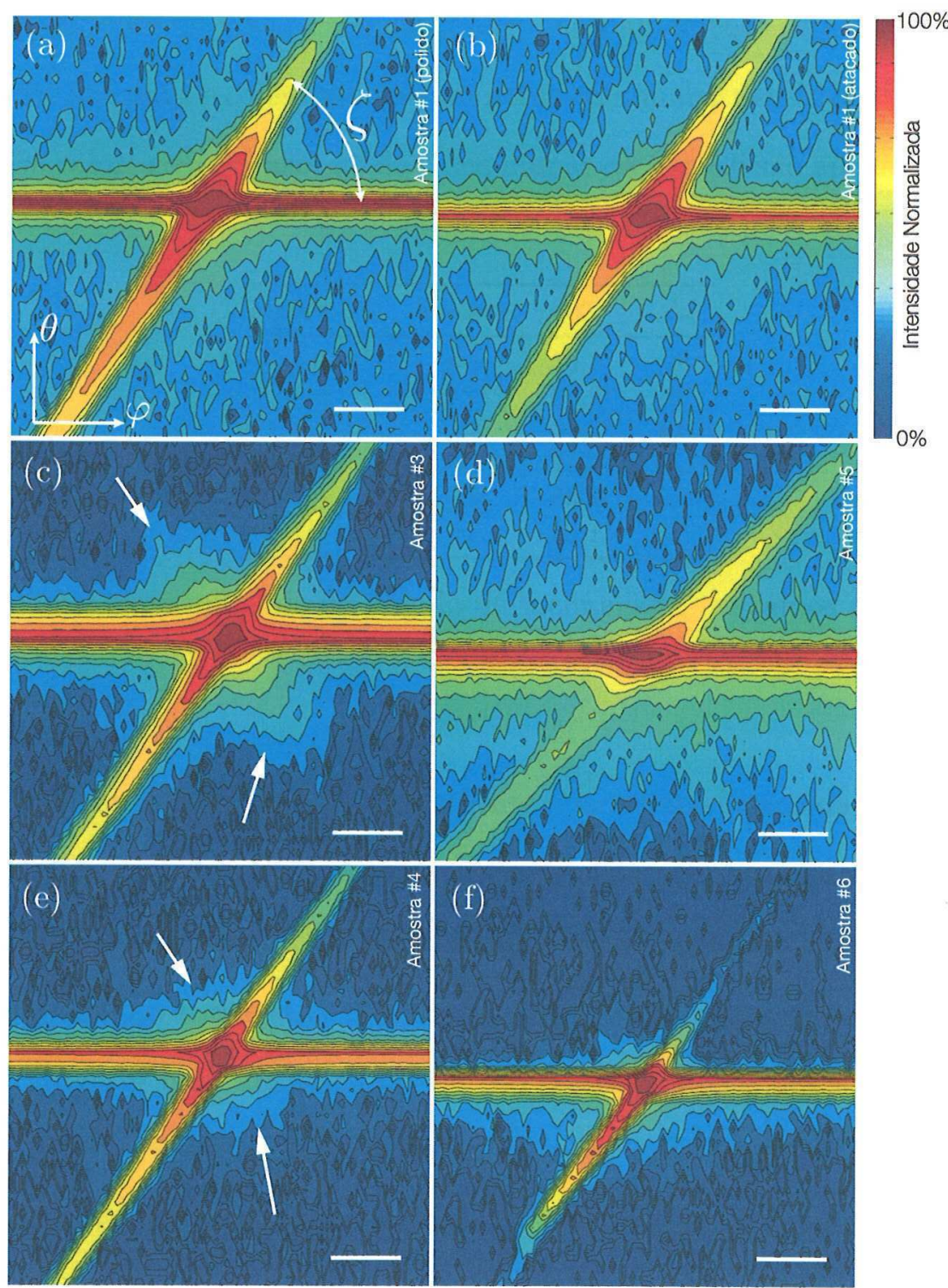

Figura 5.6: Mapas $\theta-\varphi$ na série de amostras da Tabela 3.1. (a) Substrato comercial de GaAs (amostra \#1) com indicação do ângulo $\zeta$ entre os traços das reflexões primária (horizontal) e secundária (diagonal). (b) Substrato comercial submetido a ataque químico em sua superfície. QDs crescidos à taxa de deposição 0,09MC/s (c) antes e (d) depois da deposição de 30nm de Sobre-camada de GaAs. QDs crescidos à taxa de deposição 0,007MC/s (e) antes e (f) depois da deposição da Sobre-camada. Barra de escala 100".

Para uma abordagem prática, o ângulo de inclinação do traço do substrato é tomado como referência para comparação com as demais amostras. De acordo com os mapas, 
a variação da inclinação do traço e a quantidade de espalhamento difuso nas vizinhanças da condição de BSD são mais expressivas nas amostras com maior densidade superficial de QDs (Fig.5.6(d)). Os valores experimentais de $\zeta$ dos mapas da Fig.5.6 são apresentados na Tabela 5.1.

\begin{tabular}{cccc}
\hline Figura 5.6 & Amostra & $\zeta$ & $\Delta \zeta$ \\
\hline (a) & $\# 1$ & $56,2^{\circ}$ & $0^{\circ}$ \\
(b) & $\# 1^{*}$ & $56,2^{\circ}$ & $0^{\circ}$ \\
(c) & $\# 3$ & $54,4^{\circ}$ & $1,8^{\circ}$ \\
(d) & $\# 5$ & $45,3^{\circ}$ & $10,9^{\circ}$ \\
(e) & $\# 4$ & $55,1^{\circ}$ & $1,1^{\circ}$ \\
(f) & $\# 6$ & $52,1^{\circ}$ & $4,1^{\circ}$ \\
\hline
\end{tabular}

Tabela 5.1: Valores experimentais do ângulo de inclinação $\zeta$ extraídos dos mapas $\theta-\varphi$ apresentados na Fig.5.6. $\Delta \zeta$ corresponde à inclinação relativa à amostra referência \#1. *Ataque químico.

A variação da inclinação do traço está nitidamente relacionada à densidade de QDs de acordo com os mapas BSD apresentados. Após a deposição da sobre-camada de 30nm de GaAs, figuras 5.6(d) e 5.6(f), os mapas BSD apresentam uma expressiva mudança na orientação do traço comparada ao substrato. Para a amostra com menor densidade superficial de QDs (Fig.5.6(f)) houve uma mudança de $4,1^{\circ}$ no traço enquanto que a amostra com maior densidade superficial (Fig.5.6(d)) apresentou uma variação de 10,9 com relação à referência, portanto, os planos difratantes (111) responsáveis pela massiva alteração no traço secundário estão essencialmente na sobre-camada.

Assumindo uma deformação tetragonal nos QDs sem relaxação $\left(a_{\|}=a_{G a A s}\right)$ e aplicando a razão de Poisson do InAs $\left(\nu_{I n A s}=0,350\right)$, obtem-se um parâmetro perpendicular (fora-do-plano) de $0,6494 \mathrm{~nm}$. A inclinação do traço diagonal dos mapas $\theta$ - $\varphi$ está diretamente relacionada à inclinação dos planos 111 e, portanto, tal deformação tetragonal fornece a condição máxima de inclinação do traço secundário. Nessa situação, a inclinação do traço encontra-se a $3,74^{\circ}$ do traço previsto pelo substrato de GaAs e não é capaz de explicar as 


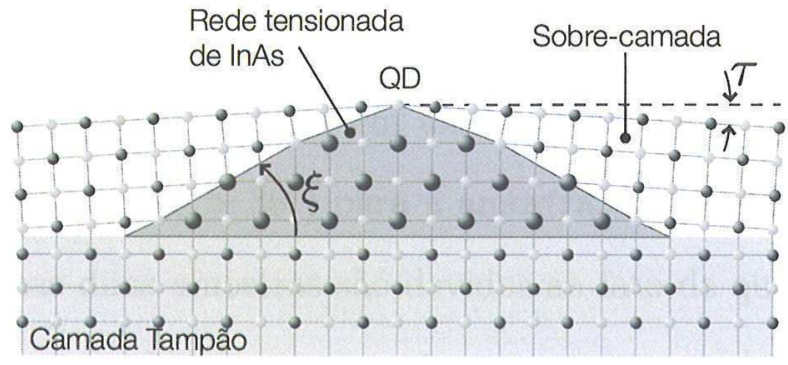

(a)

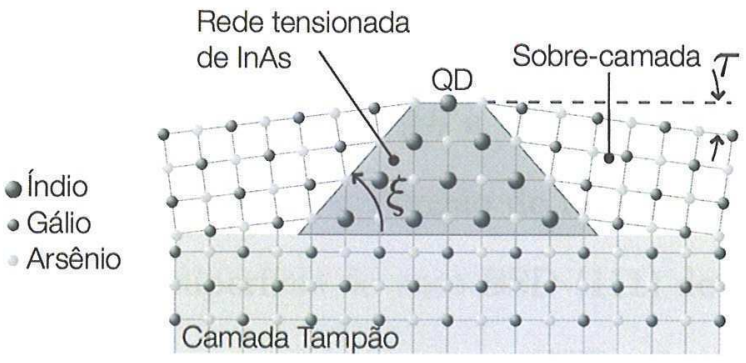

(b)

Figura 5.7: (a) Modelo de discordância de redes na interface QD/Sobre-camada para QD com formato (a) "lente" e (b) "pirâmide". A discordância perpendicular é elasticamente acomodada via inclinação da rede da Sobre-camada pelo ângulo $\tau$, o qual depende da inclinação $\xi$ das faces dos QDs.

variações $\Delta \zeta$ observadas nas amostras com QDs cobertos. A acomodação elástica de redes heteroepitaxiais descasadas sobre interfaces inclinadas (QDs) resulta, de maneira geral, em camadas epitaxiais com redes enclinadas. Um modelo de acomodação é ilustrado na Fig.5.7. Assumindo uma rede totalmente deformada para os QDs e definindo $\xi$ como o ângulo de inclinação das faces, é possível obter a relação

$$
\sin (\xi-\tau)=\left(a_{G a A s} / a_{\perp}\right) \sin \xi
$$

onde $a_{G a A s}$ é o parâmetro original do GaAs e $\tau$ é o ângulo de inclinação da rede da sobrecamada com relação à superfície da amostra (plano horizontal do cristal). Da relação é possível estimar $\tau$ conforme o esquema da Fig.5.7. Para QDs com faces inclinadas a $\xi=30^{\circ}$ e $\xi=60^{\circ}$ estimam-se os respectivos valores $\tau=4,199^{\circ}$ e $\tau=11,074^{\circ}$ e estes resultados de inclinação da superfície são compatíveis com os resultados experimentais das variações observadas na inclinação do traço secundário nas amostras \#6 e \#5, conforme apresentados na Tabela 5.1. Nestas duas amostras também é possível notar que o padrão de distribuição de intensidade ao longo do traço secundário nos mapas $\theta-\varphi$ são claramente distintos. No 
contexto do modelo de defeitos planares via inclinação da rede da sobre-camada, o qual indica a presença de QDs em forma de pirâmide $\left(\xi \simeq 60^{\circ}\right)$ para a amostra \#6 e QDs em forma de lente $\left(\xi \simeq 30^{\circ}\right)$ para a amostra \#5, os diferentes padrões de distribuição de intensidade nas duas amostras são devidos ao fato de que a onda de superfície do caso BSD (111) deve ser acoplada, em um regime cinemático, pela haste de truncamento cristalino (CTR, Cristal Truncation Rod), da reflexão (1̄11) e, portanto, apenas uma parcela dos planos desorientados (111) da sobre-camada são capazes de contribuir no sinal difratado, uma vez que a magnitude do ângulo de inclinação da rede $(\tau)$ assim como a direção das faces inclinadas dos QDs podem alterar o padrão de intensidade ao longo do traço secundário. A energia de deformação acumulada no entorno das ilhas, região onde a rede inclinada da sobre-camada encontra uma superfície plana, é maior nos casos onde as faces dos QDs possuem maiores ângulos de inclinação (Fig.5.7(b)). Alguns mecanismos podem atuar durante ou depois do processo de cobrimento das ilhas de forma a minimizar tal energia de deformação, e.g. difusão térmica de In resultando em intermistura dos compostos, os quais podem atuar de forma a suavizar o descasamento de redes nas interfaces $[15,57]$ e planificação dos QDs via segregação de In. Análises de BSD da amostra \#5 12 meses após os resultados apresentados nesta tese indicam um processo de minimização de tensão na rede à temperatura ambiente [58] e os fenômenos de intermistura e segregação podem servir como base na interpretação dessas mudanças ao longo do tempo.

Durante a tomada de dados dos mapas $\theta-\varphi$, observou-se que a distribuição de intensidade do traço diagonal se extendia muito além da região apresentada na Fig.5.6, região esta que foi suficiente para o estudo da orientação do traço diagonal, porém, incompleta para uma análise mais detalhada da distribuição de intensidade. Nas Figs. 5.8 e 5.9 estão mostrados mapas longos da BSD, obtidos de uma amostra com QDs cobertos (amostra \#7, Tabela 3.1). Um detalhe imediato que se pode observar da Fig.5.8 é a presença de franjas ao 


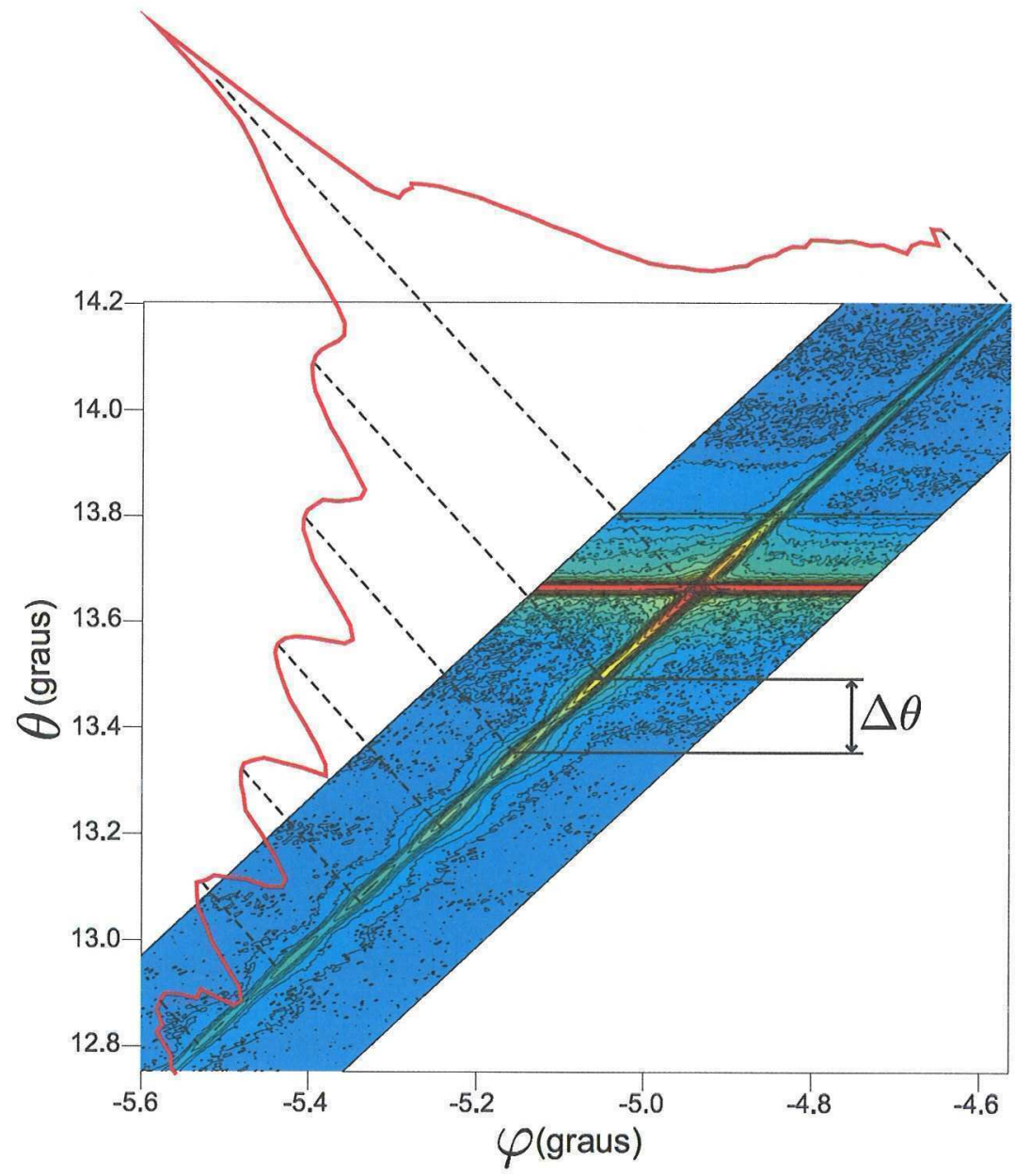

Figura 5.8: Mapa $\theta-\varphi$ de amostra com QDs cobertos. O período $\Delta \theta$ das franjas é determinado pela espessura de $30 \mathrm{~nm}$ da sobre-camada.

longo do traço diagonal de intensidade. Analisando a distância entre as franjas na direção $\theta$ é possível obter um valor médio $\Delta \theta \simeq 0,135^{\circ}$. Sendo $q=(4 \pi / \lambda) \sin \theta \Rightarrow \Delta q=(4 \pi / \lambda) \cos \theta \Delta \theta$, o valor médio $\Delta q \simeq 0,0216 \AA^{-1}$ para $\theta_{002}$. A espessura $t$ da camada que gera as franjas pode ser estimada pela relação $t \simeq 2 \pi / \Delta q \simeq 290 \AA$, cujo valor está de acordo com os dados do crescimento $(t=30 \mathrm{~nm})$ e confirma que a profundidade analisada ao longo do traço vai além da interface com os QDs. O rápido decréscimo da intensidade para $\theta>\theta_{002}$ (região acima do traço horizontal) se deve ao fato do feixe de superfície ser difratado para dentro do cristal 
nesta região e assim efeitos de re-espalhamento dentro do cristal atenuam fortemente a saída do feixe de acoplamento para o detector. Tais franjas não são visíveis na reflexão 002 e foram observadas somente em geometria de incidência rasante com a normal fora do plano de incidência, como é apresentado mais adiante nas varreduras $L$ da 111 da Fig.5.13. Ainda na etapa de análise da orientação do traço das várias amostras, foi observado um caso com indícios de duplicação do traço secundário (Fig.5.6(f)), fato que motivou uma investigação mais ampla com a aquisição de mapas mais longos e com maior resolução. Além disso, nos mapas das amostras \#5 e \#6, esperava-se observar os traços do substrato e da camada. A Fig.5.9 exibe um mapa BSD de alta resolução da amostra \#7 no qual é possível notar a presença de dois traços distintos separados angularmente por $\sim 1,7^{\circ}$ (região ampliada no detalhe inferior da figura). A relação das intensidades dos dois traços (detalhe superior) indica uma expressiva diferença na quantidade de material que gera os dois traços, ou seja, dois domínios de inclinação do GaAs, um deles bem menor que o outro: razão de área dos picos de $9,2 \%$. Um outro aspecto interessante é o padrão de espalhamento difuso nas proximidades das franjas do traço o que pode ser devido a presença de mosaicidade na rede analisada.

De acordo com o regime cinemático, a BSD pode ser dividida em duas condições de difração distintas: i) difração à incidência de alto ângulo para a reflexão secundária S e ii) difração à incidência rasante para a reflexão acoplamento C. A Fig.5.10(a) ilustra a condição no ponto de vista dos planos atômicos onde o feixe incidente $k_{0}$ é difratado simultaneamente pelas reflexões $\mathbf{P}$ e $\mathbf{S}$. O Sinal da reflexão $\mathbf{P}$ vai diretamente ao detector enquanto que o feixe difratado $\boldsymbol{k}_{\mathbf{S}}$, gerado pela reflexão $\mathbf{S}$, viaja paralelamente á superfície do cristal. O feixe de superfície $\boldsymbol{k}_{S}$ é difratado em condição de incidência rasante pela reflexão $\mathrm{C}$ cujo feixe difratado $\boldsymbol{k}_{C}$ segue para o detector, junto com o sinal primário $\boldsymbol{k}_{\mathrm{P}}$. No espaço recíproco os dois eventos de difração podem ser representados por duas esferas de Ewald: uma 


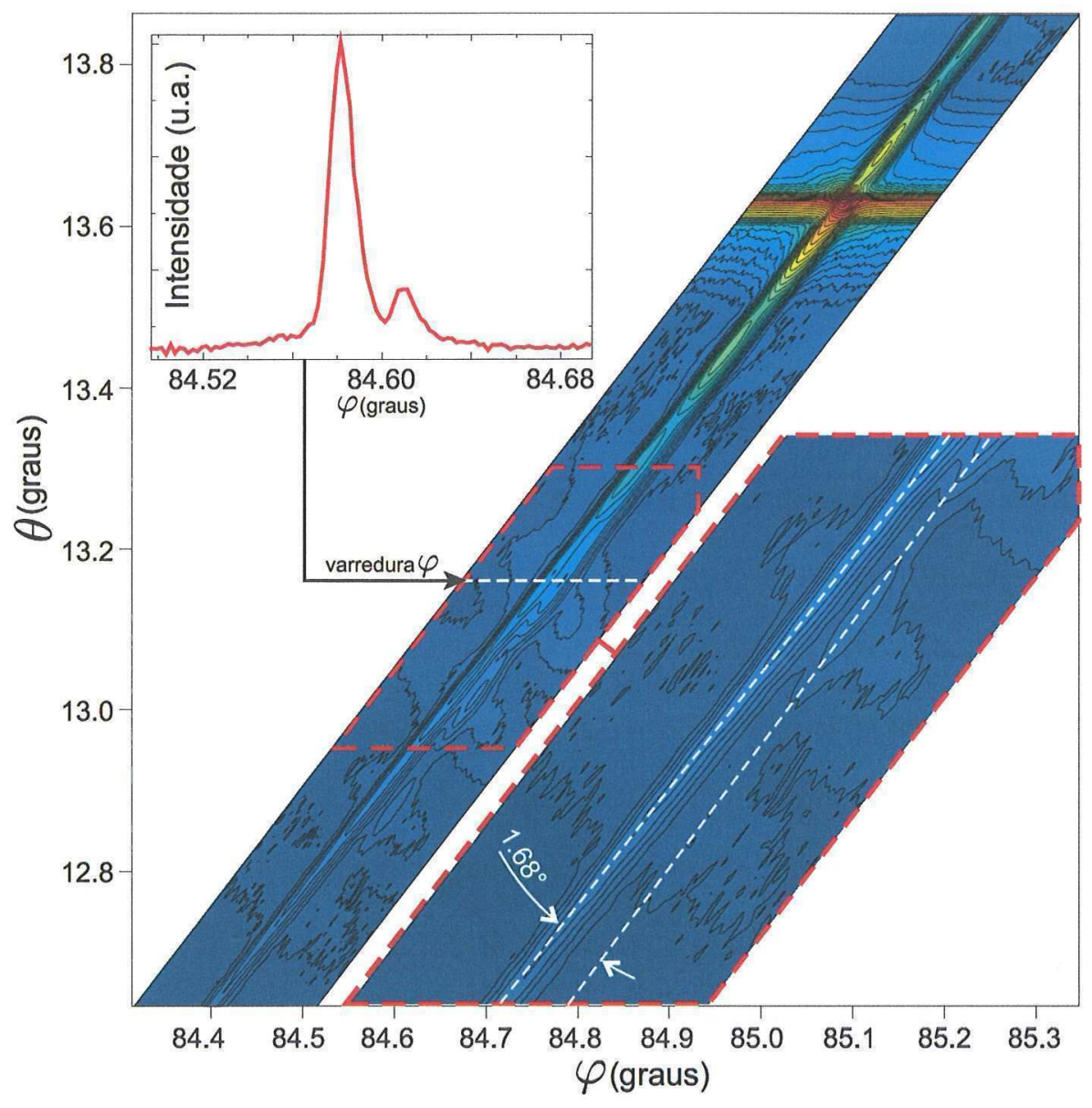

Figura 5.9: Observação de traço secundário extra em mapa BSD de amostra com QDs cobertos. Detalhe superior: varredura $\varphi$ para $\theta \simeq 13,16^{\circ}$. Detalhe inferior: ampliação parcial do mapa com indicação do ângulo entre os traços.

associada ao feixe incidente $\boldsymbol{k}_{0}$ (esfera $\boldsymbol{k}_{0}$ ), e a outra ao feixe de superfície $\boldsymbol{k}_{S}$ (esfera $\boldsymbol{k}_{S}$ ), como mostrado na Fig.5.10(b). Da esfera $\boldsymbol{k}_{0}$ saem dois feixes difratados (duas reflexões simultâneas $\mathbf{P}$ e $\mathbf{S}) . \boldsymbol{k}_{P}$ segue diretamente para o detetor, enquanto $\boldsymbol{k}_{S}$ percorre a superfície do cristal. A contribuição deste último somente é detectada (pelo mesmo detetor posicionado para a reflexão simétrica $\mathbf{P}$ ) quando difratado pela reflexão de acoplamento $\mathbf{C}$, ou seja, quando o vetor recíproco $\mathbf{C}$ toca a esfera $\boldsymbol{k}_{S}$. Esta descrição da BSD pelo modelo de acoplamento cinemático permite tratar fenômenos de re-espalhamento do feixe de superfície por redes 
distintas, tal como acontece nos casos de reflexões híbridas [59], ou mais especificamente no caso deste trabalho, quando o feixe de superfície gerado no substrato sobre acomplamento pelas redes da sobre-camada e dos QDs. Defeitos na superfície do cristal, por exemplo, como os induzidos pelo acabamento da superfície [53] e por implantação iônica [20], também favorecem o acoplamento cinemático do feixe de superfície $k_{S}$.

O acoplamento dinâmico da BSD, como de qualquer DM, ocorre em redes cristalinas coerentes: substratatos monocristalinos perfeitos e estruturas epitaxiais com quantidades ínfimas de defeitos. Na condio de DM (3-feixes), o campo de onda primário se modifica devido à excitação de uma onda secundária dentro do cristal [44]. No caso particular da BSD com reflexão primária fraca, essa modificação se traduz numa ampliação do campo de onda primário, o qual esta sujeito ás mesmas condições de contorno da reflexão primária. Isso significa, por exemplo, que franjas de espessura obdecem o padrão imposto pela geometria da reflexão primária, mas a intensidade das franjas pode ser bastante aumentada na condição da BSD.

Nessa etapa do trabalho, além de investigar a distribuição bidimensional da intensidade em torno da BSD, a intensidade ao longo do traço secundário também foi investigada. As várias BSD's da família 111 diferem pelo fato dos feixes de superfície se propagarem em diferentes direções no plano, conforme esquematizado na Fig.5.11. A direção do feixe de superfície é dada por $\boldsymbol{k}_{\mathrm{S}}=\mathrm{S}+\boldsymbol{k}_{0}$. No sistema de coordenadas instrumentais, Fig.4.4, e de acordo com as Eqs. 4.5 e 4.6, obtem-se que

$$
k_{\mathrm{S}}=\left(|S| \sin \gamma \cos \psi-\left|\boldsymbol{k}_{0}\right| \cos \theta \cos \varphi,|S| \sin \gamma \sin \psi-\left|\boldsymbol{k}_{0}\right| \cos \theta \sin \varphi, 0\right)
$$




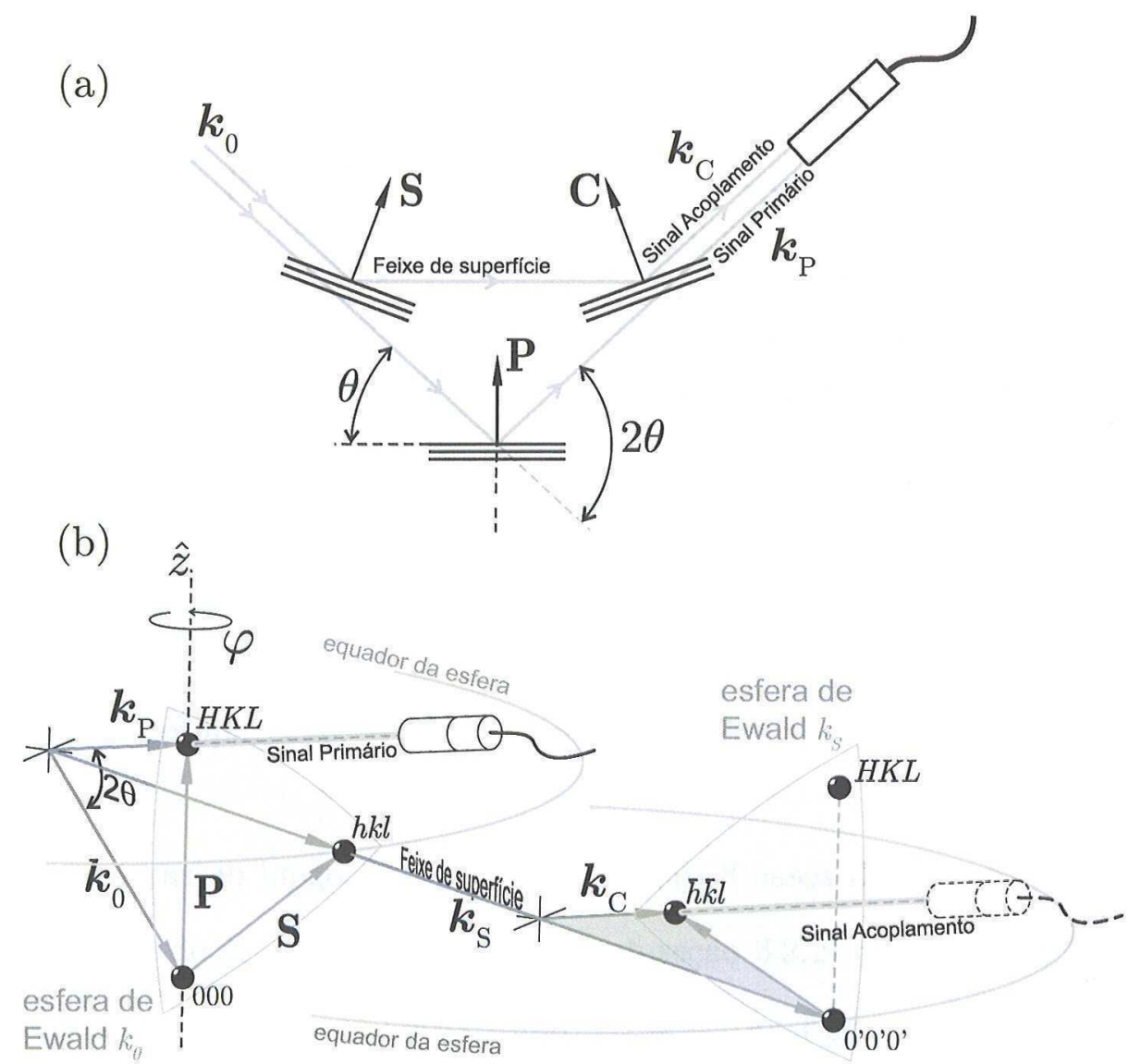

Figura 5.10: Geometrias BSD: (a) vista em corte dos planos atômicos e (b) esquema no espaço recíproco conforme modelo de acoplamento cinemático. Os detetores visto separados em (b) representam um mesmo detetor no espaço real, e.g. detetor em (a).

Para qualquer BSD representada nesse sistema de coordenadas, $|S| \cos \gamma-\left|k_{0}\right| \sin \theta=0$ de modo que $k_{S}$ possui somente componentes no-plano como esperado para um feixe de superfície. Tomando como exemplo $\mathbf{P}=002, \mathbf{S}=111$ e $\lambda=1.3308 \AA$, é possível obter $\boldsymbol{k}_{\mathrm{S}}$ para a condição de $\mathrm{BSD}$, onde $\theta=\theta_{002}=13,6158^{\circ}, \varphi=\varphi_{\text {in-out }}=85,0874^{\circ}$ (ver Tabela 4.1 ), $\gamma=$ $\gamma_{111}=54,7356^{\circ}$ e $\psi=\psi_{111}=0^{\circ}$. As componentes no-plano de $\boldsymbol{k}_{\mathrm{S}}$ indicam um ângulo de $75,5^{\circ} \mathrm{com}$ o eixo de referência $\hat{x}=[110]$ ou $\sim 14,5^{\circ}$ com o eixo $\hat{y}=[110]$. A simetria de eixo-4 da direção cristalográfica [001] permite concluir que os feixes de superfície nos 8 casos de BSD são dispostos conforme a Fig.5.11(b). 

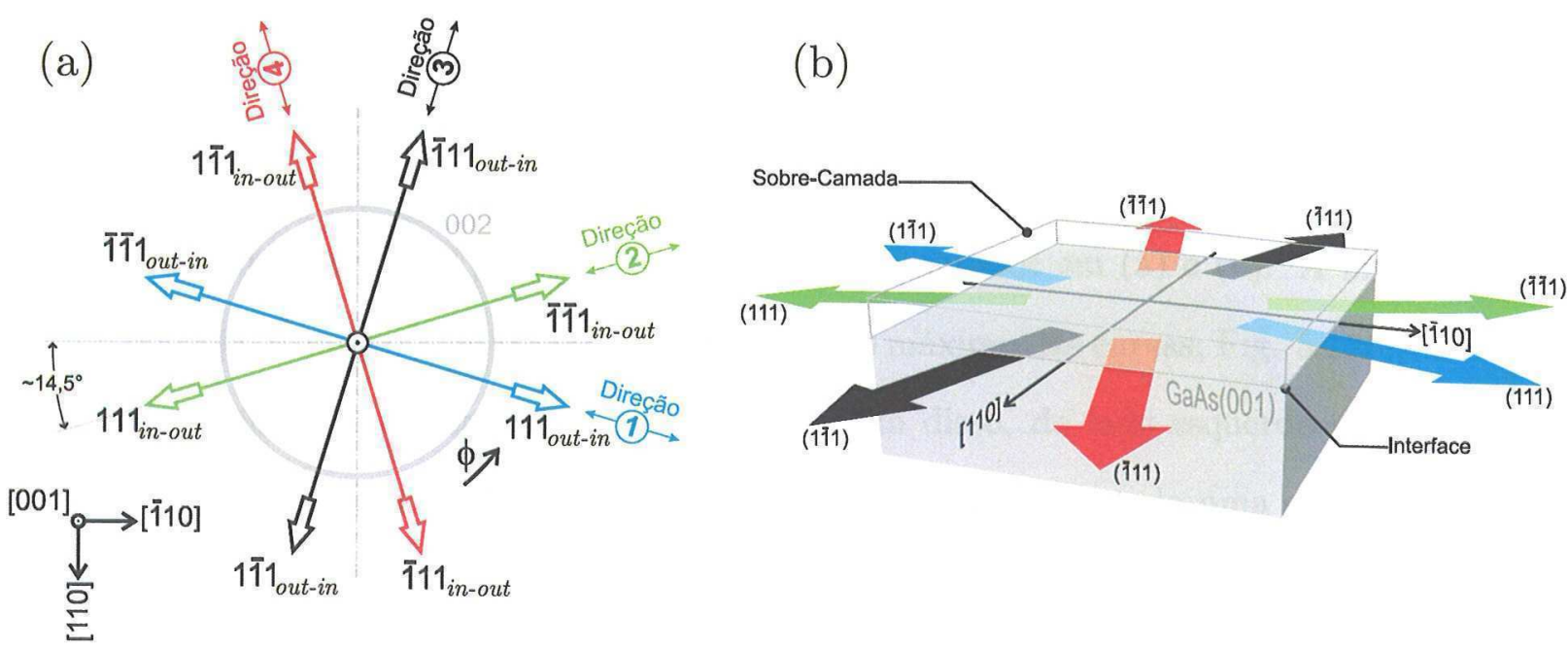

Figura 5.11: (a) Diagrama dos feixes de superfície quando vistos de topo com definição das quatro direções de propagação. (b) Vista em perspectiva dos feixes de superfície para as 8 BSD's.

Varreduras ao longo do traço diagonal dos 8 casos de BSD foram realizadas na estação de difração do X-ray Lab/UoGuelph (sub-seção 3.2.2) com E=8047,78eV (CuK $\alpha_{1}$ ) para um substrato comercial de GaAs (amostra \#1). As Figuras 5.12 (a) e (b) ilustram as varreduras para o substrato com acabamento comercial (polimento mecânico): (a) com curvatura residual do processo de montagem da amostra e (b) no modo plano (montagem pelo método dos 3 contato apresentado na seção 3.3). A Fig.5.12(c) apresenta as varreduras para o mesmo substrato montado no modo plano, porém após a superfície sofrer um desbaste químico. Os detalhes das figuras apresentam ampliações das curvas com a devida identificação das direções em acordo com o diagrama na Fig.5.11(b).

Na Fig.5.12(a), as 8 varreduras formam 4 pares de curvas sendo que cada par está associado a uma das 4 direções dos feixes de superfície. Com o substrato plano, Fig. 5.12(b), pode-se notar apenas uma maior separação entre as curvas de cada par, ficando um pouco menos evidente a associação do perfil da curva com a direção do feixe de superfície. 
Já na Fig.5.12(c) nota-se claramente que o desbaste químico produziu mudanças expressivas comparadas às demais varreduras. Houve uma inversão na posição do ombro de intensidade e uma evidente alteração no padrão de agrupamento das curvas, as quais passaram a apresentar apenas 2 agrupamentos de perfis ao invés dos 4 apresentados em (a) e (b). A inversão do ombro, ou seja, o aumento da intensidade à direita do máximo das curvas, Fig. 5.12(c), indica uma melhor qualidade cristalina da superfície. Além disso, do lado esquerdo do máximo, as curvas mostram uma tendência a formar um único grupo indicando uma superfície mais isotrópica com relação às direções no-plano. Contudo, apesar dessa tendência, as curvas associadas às direções 1 e 2 são mais intensas (no intervalo em destaque) que as 3 e 4 . A provável causa é uma superfície ligeiramente mais defeituosa em torno da direção [1]10]. Antes do desbaste químico, Figuras 5.12(a) e 5.12(b), o agrupamento das curvas sugere a direção [010] como a mais defeituosa.

Uma visualização prática das duas condições as quais compõem o sinal de BSD pode ser obtida por meio de varreduras no espaço recíproco da reflexão 111 nas condições de incidência a alto ângulo e incidência rasante. A Fig.5.13 apresenta uma série de varreduras $\ell$ de uma amostra com QDs cobertos (amostra \#7) em vários ângulos de incidência, indo desde uma incidência a alto ângulo próxima do ângulo de Bragg da reflexão 111 (para $\mathrm{E}_{\text {foton }}=9320 \mathrm{eV}$ ) até o caso de incidência completamente rasante, simulando o feixe de superfície do caso BSD. As varreduras foram realizadas na linha de difração XRD2 do LNLS em um difratômetro de 4 círculos conforme descrito na sub-seção 3.2.3. As varreduras em alto ângulo apresentam as franjas referente à sobre-camada de 30nm de GaAs sobre os QDs e a ótima definição das franjas (Fig.5.13(b)) indica uma interface bem definida entre a camada wet de InAs e a sobre-camada. À medida que o ângulo de incidência se aproxima da condição rasante as franjas são atenuadas assim como a penetração do feixe diminui, resultando em um sinal proveniente das primeiras camadas epitaxiais da sobre-camada. 

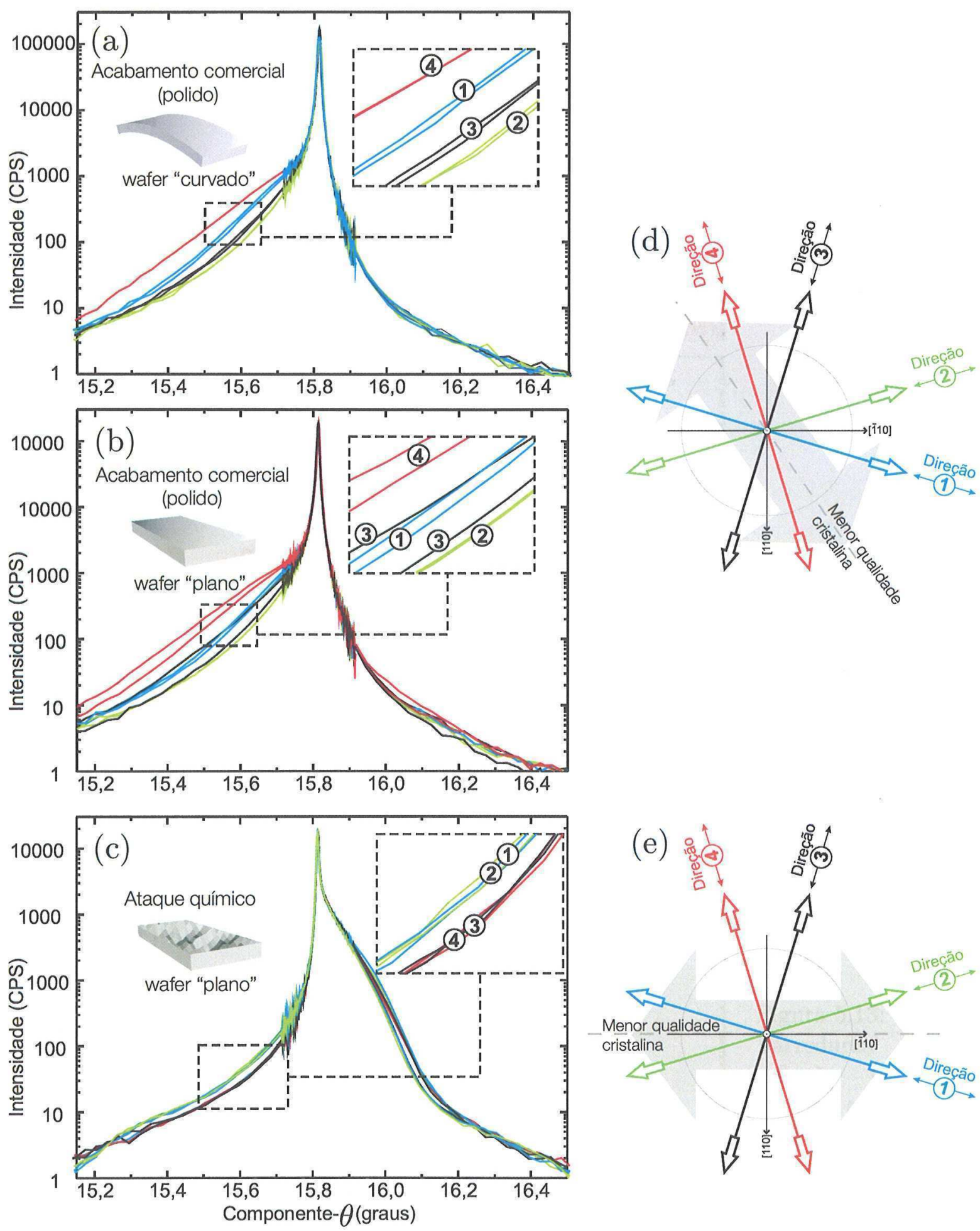

Figura 5.12: Perfis de intensidade ao longo do traço para as 8 BSD's da família 111. (a) um Substrato comercial (polido) com curvatura induzida pelo processo de montagem da amostra. (b) Substrato comercial plano. (c) Substrato comercial após desbaste químico da superfície. Nos detalhes, ampliação das curvas e indicação das direções definidas na Fig.5.11(b). (d) e (e), indicação da direção com menor qualidade cristalina de acordo com os perfis mostrados em $(a, b)$ e $(c)$, respectivamente. 


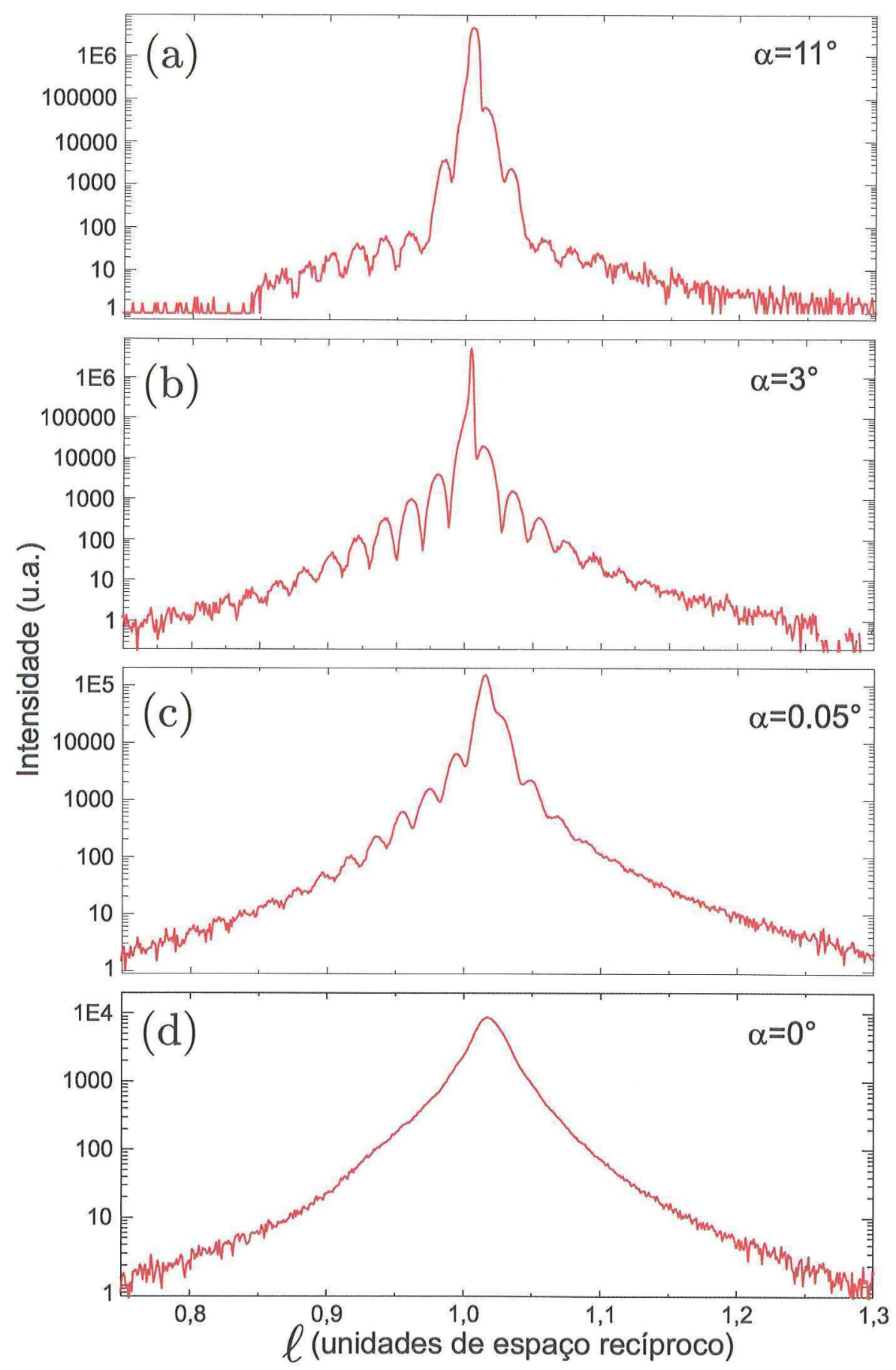

Figura 5.13:

Varreduras $\ell$ da reflexão $\operatorname{GaAs}(111)$ de uma amostra com QDs cobertos em vários ângulos de incidência $\alpha$. 


\section{Capítulo 6}

\section{Conclusões da pesquisa}

Duas frentes principais de estudo predominaram neste trabalho: i) a investigação estrutural de dispositivos optoeletrônicos baseados em QDs de InAs crescidos sobre substratos de $\operatorname{GaAs}(001)$; e ii) o desenvolvimento de novos métodos de análise capazes de acessar informações da região dos QDs quando cobertos, informações estas dificilmente obtidas com técnicas usuais de análise por raios X e microscopia.

O primeiro estágio da pesquisa focou o uso da XRS no estudo do parâmetro de rede da região das ilhas, mais precisamente no material do entorno dos QDs. Embora a XRS já era estabelecida como uma técnica de alta precisão no estudo do parâmetro de rede de monocristais, essa pesquisa explorou um caso específico de DM no qual a penetração do campo de onda é favorável a sondar a região da interface com os QDs. A pesquisa apresenta um método inédito de medida relativa de parâmetro rede onde desalinhamentos residuais são intrisicamente cancelados pela simetria das posições azimutais dos umwegs (medição das 8 posições umweg), os quais foram ajustados por uma função paramétrica a qual leva em conta possíveis assimetrias dos picos e a escolha dos parâmetros foi realizada por um algoritmo 
genético. As varreduras possibilitaram a observação de variações do parâmetro de rede noplano do GaAs com acurácia da ordem de $10^{-5}$ em duas direções distintas no-plano ([110] e [110]). As amostras com QDs expostos apresentam parâmetros de rede similares à amostra referência (camada tampão), porém, nota-se uma leve tendência de expansão da rede devido a presença das ilhas, o que pode estar naturalmente associado aos $\sim 7 \%$ de descasamento entre as redes. As alterações mais expressivas foram observadas nas amostras com QDs cobertos. A densidade superficial das ilhas também se mostrou importante na propagação da tensão para a sobre-camada e camada tampão, ou seja, maiores densidades de QDs (maiores taxas de deposição) apresentaram maiores deformações expansivas. É importante lembrar que, embora as amostras apresentem diferentes densidades superficiais de QDs, a mesma quantidade de InAs foi depositada em cada amostra. Portanto, os resultados indicam que as variações de parâmetro de rede observadas estão relacionadas às características morfológicas das ilhas (forma e volume). O valor fora de escala para a deformação no-plano observado na amostra com maior densidade de QDs cobertos (amostra \#5) sugere a existência de um mecanismo de acomodação da sobre-camada não compatível com o modelo de deformação tetragonal e serviu de motivação para a realização de um estudo mais amplo da região de DM, como a realização dos mapas $\theta-\varphi$, os quais evidenciaram a existência de defeitos planares na sobre-camada relacionados à forma dos QDs.

No contexto dos cones de Bragg, a DM é observada na intersecção dos cones primário e secundário. Portanto, a XRS é a visualização de uma estreita faixa da condição de DM sobre o cone primário. Nos dados de XRS, observou-se sutis diferenças nos perfis, tais como simetria e largura, as quais não afetaram as medidas de parâmetro, porém, davam indícios de que outras informações estruturais poderiam estar contidas na região do entorno da intersecção dos cones. Esta foi a motivação para realização de mapeamentos amplos da região de DM, os chamados mapas $\theta-\varphi$. A condição de DM escolhida (BSD) permitiu 
alcançar profundidades de análise grandes o bastante para sondar a interface com os QDs, porém, rasas o suficiente de forma a minimizar a contribuição do bulk. Dos mapas $\theta-\varphi$ foi possível evidenciar a) o espalhamento difuso no entorno da BSD, b) a distribuição da intensidade ao longo do traço da reflexão secundária (traço diagonal) e c) a inclinação do traço diagonal com relação ao traço da reflexão primária. O estudo da orientação do traço diagonal nos mapas BSD revelou pequenas variações para amostras com QDs expostos quando comparadas ao substrato de GaAs, no entanto, observa-se um padrão de espalhamento difuso em torno da BSD o qual está relacionado a presença de QDs. Expressivas mudanças na orientação do traço diagonal foram observadas nas amostras com QDs cobertos, onde mediu-se variações de até $10,9^{\circ}$ com relação ao substrato de GaAs. Ambos espalhamento difuso e inclinação do traço revelaram-se mais acentuados na amostra com maior densidade superficial de QDs, repetindo a tendência observada nas medidas de parâmetro via XRS. A geometria BSD indica que a orientação do traço secundário refere-se à orientação relativa dos planos atômicos da família 111 e então, baseado neste fato, utilizou-se um modelo de desorientação da rede da sobre-camada para a interpretação da inclinação dos traços. Segundo o modelo, os ângulos observados para a inclinação dos traços são compatíveis aos ângulos de inclinação das faces das ilhas e assim presume-se a presença de ilhas em forma de lente e pirâmide, respectivamente, para as amostras com densidades superficiais 200QDs $/ \mu \mathrm{m}^{2}$ e 360QDs $/ \mu \mathrm{m}^{2}$. A distribuição da intensidade ao longo do traço mostrou-se fortemente sensível ao estado cristalino da superfície da amostra conforme revelaram os mapas $\theta-\varphi$ do substrato comercial polido e o mesmo substrato após desbaste químico. Nessas mesmas amostras foi realizada uma análise mais detalhada da distribuição de intensidade ao longo do traço diagonal dos 8 casos de BSD onde foi possível identificar uma direção específica na qual os ombros de intensidade são acentuados e, portanto, trata-se de uma direção com menor qualidade cristalina superficial. 
Como motivação para a continuidade dessa pesquisa, a observação da duplicação do traço diagonal nos mapas $\theta-\varphi$ reforça o modelo de inclinação da rede da sobre-camada no entorno das ilhas e aponta para a presença de dois domínios distintos de redes inclinadas. Uma abordagem estritamente cinemática onde se definiu a BSD como uma convolução da haste de truncamento cristalino da reflexão secundária com a acoplamento foi testada e apresentou resultados insatisfatórios na explicação da duplicação do traço. Além disso, as franjas de interferência referentes à sobre-camada de 30nm, as quais não são visualizadas na reflexão primária 002, são reveladas pelo traço diagonal em uma amostra com QDs cobertos. Tal combinação de fatores indica que os modelos devem levar em conta efeitos dinâmicos em suas abordagens. A investigação preliminar das espessuras das sobre-camadas via varreduras $\theta$ de alta resolução (capítulo 3) revelou um detalhe importante: a espessura efetiva vista pelo raio X é expressivamente alterada pela presença dos QDs. O modelo de duas camadas mostrou-se insuficiente na explicação plena da curva de varredura, embora reproduziu o período do padrão de franjas da sobre-camada e o deslocamento do mesmo devido a espessura da camada wet. Uma modelagem estrutural, como por elementos finitos, na qual se leve em conta efeitos no-plano assim como a realização de varreduras de reflexões assimétricas podem fornecer informações mais precisas sobre a interface sobre-camada/QDs. Tais estudos podem ser realizados em instalações com raios X convencionais como a do Lab/UoGuelph.

Em síntese, essa pesquisa forneceu detalhes importantes sobre sistemas nanoestruturados baseados em QDs cobertos e avançou na viabilização do uso quantitativo da DM no estudos desses sistemas. Neste contexto, procedimentos completos para aquisição e análise dos dados de XRS e mapas $\theta-\varphi$ são disponibilizados com detalhamento suficiente para a extensão a outros sistemas. A descrição plena dos casos de BSD ainda é um caso aberto no ramo de difração de cristais perfeitos, porém, os dados experimentais inéditos e as discussões apresentadas promovem avanços relevantes neste capítulo da cristalografia. 


\section{Apêndice A}

\section{Alinhamento de goniômetro de 4 círculos via efeito Borrmann}

Goniômetros de 4 círculos são instrumentos típicos em estações de difração ou espalhamento de raios $\mathrm{X}$. Seja em linhas de luz síncrotron ou em instalações com radiação convencional (mais conhecidos como instalações in-house), o círculo $\chi$ (ou berço de Euler) desses goniômetros é um elemento essencial para a realização de experimentos com monocristais. Experimentos com materiais magnéticos, análise de polarização da radiação espalhada e medidas em geometrias de incidência razante são exemplos de aplicações comuns desse tipo de equipamento. Na maioria desses experimentos, uma grande precisão é exigida na orientação do cristal e,consequentemente, no alinhamento do goniômetro com relação ao feixe incidente de raios X. No final da década de 80, durante estudos de polarização em alta resolução, um método de alinhamento baseado no efeito Borrmann $[60,61]$ foi desenvolvido e aplicado em um goniômetro de 4 círculos iluminado por um feixe de raios X convencional (radiação WL1) $[62,63]$. Esta seção demonstra o uso do método de alinhamento de goniômetro de 4 
círculos via feixe de transmissão anômala (efeito Borrmann) e apresenta algumas melhorias com relação aos trabalhos da década de 80.

A grande vantagem de utilizar o efeito Borrmann é o fato do feixe difratado ser parcialmente transmitido (feixe anômalo transmitido) quando o cristal satisfaz a condição de Bragg para uma dada reflexão. Desta forma, o detector fica fixo na posição do feixe direto, $2 \theta=0$, podendo indicar a ocorrência da difração não sendo necessário localizar o feixe difratado por reflexão (feixe anômalo difratado). Uma vez escolhida uma reflexão, realizase curvas de varredura $\theta$ do cristal em geometria Laue (monitoramento do feixe anômalo transmitido) em diferentes posições $\chi$. O difratômetro alinhado por meio do efeito Borrmann é aquele descrito na seção 3.2 instalado no X-ray Lab/UoGuelph. Como cristal de referência utilizou-se um substrato comercial de $\operatorname{Si}(001)$ com espessura de 0,3mm e escolheu-se a reflexão 202 (Fig.A.1) por ser muito intensa e pouco susceptível a efeitos de difração múltipla, fatores que facilitam seu monitoramento durante as varreduras $\chi$.
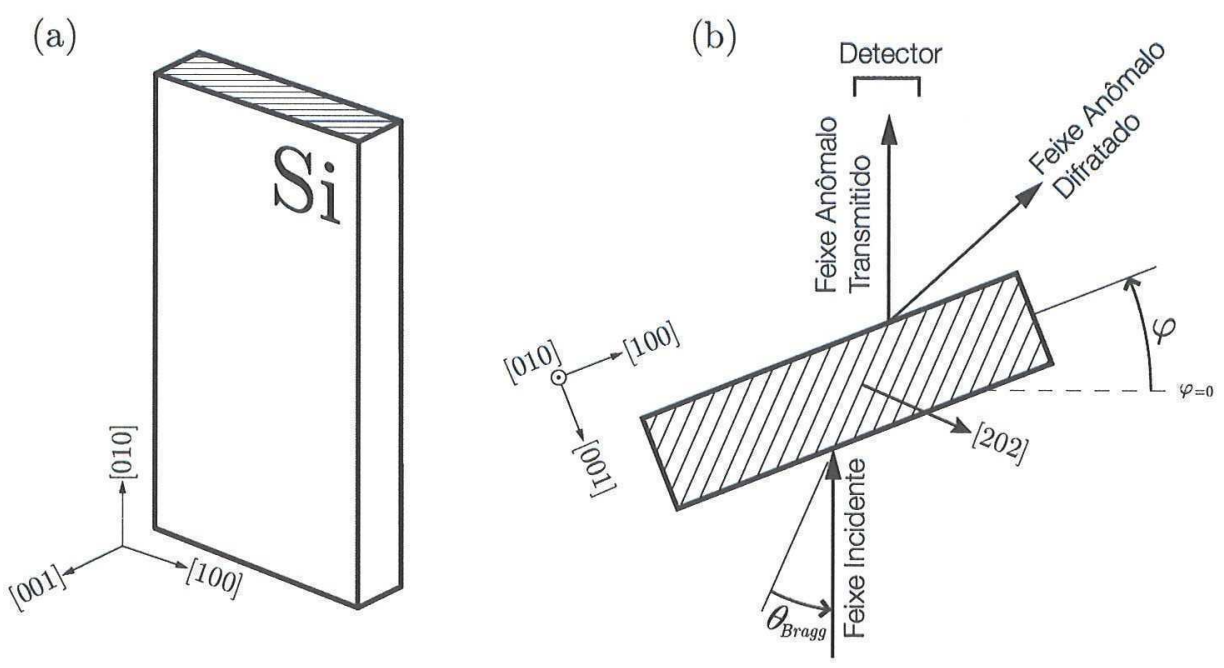

Figura A.1: (a) Substrato de $\operatorname{Si}(001)$ e (b) geometria de difração Laue para a reflexão 202 com indicações dos feixes difratados (anômalos), do ângulo de difração $(\theta)$ e do ângulo de rotação $(\varphi)$. 
Antes da montagem da amostra é feito um alinhamento visual do sistema, com excessão do detetor que é posicionado na direção exata do feixe incidente quando $2 \theta=0$ (valor instrumental), Fig.A.2(a). Com o plano do círculo de Euler (cŕculo $\chi$ ) perpendicular (dentro da acurácia visual) ao feixe incidente e o estágio de rotação $\varphi$ (aquele dentro do círculo $\chi$ ) na posição mais baixa do círculo, os ângulos instrumentais $\theta, \alpha$ e $\chi$ são zerados $(\theta=\alpha=\chi=0)$. O cristal de Si é então fixado na cabeça goniométrica com a face (001) perpendicular ao feixe incidente, e o valor instrumental do ângulo $\varphi$ redefinido como zero $(\varphi=0)$. Após mover $\varphi$ para a posição esperada (caso o difratômetro já estivesse alinhado) da reflexão 202 , i.e., para $\varphi=45^{\circ}-\theta_{202}$, se realiza um mapeamento da condição de difração em função dos ângulos $\chi$ e $\varphi$ como mostrado na Fig.A.3.

O objetivo do procedimento é alinhar o círculo $\chi$ de forma a deixá-lo precisamente perpendicular ao feixe incidente. Para tal, é necessário determinar os desalinhamentos horizontal, $\Delta \theta$, e vertical, $\Delta \alpha$, do círculo, o que pode ser feito por meio de um mapa $\chi-\varphi$ como aquele apresentado na Fig.A.3.

O cálculo dos desalinhamentos horizontal e vertical é dado, respectivamente, pelas expressões:

$$
\Delta \theta=\left(\varphi_{\chi=0}-\varphi_{\chi=180}\right) / 2
$$

e

$$
\Delta \alpha=\left(\varphi_{\chi=90}-\varphi_{\chi=270}\right) / 2
$$

Uma vez que os desalinhamentos tenham sido determinados, basta mover os ângulos instrumentais $\theta$ e $\alpha$ para os valores de $\Delta \theta$ e $\Delta \alpha$ e redefini-los como zero para ter o círculo de Euler alinhado com a direção do feixe incidente. Com base na Fig.A.3, os valores medidos para 


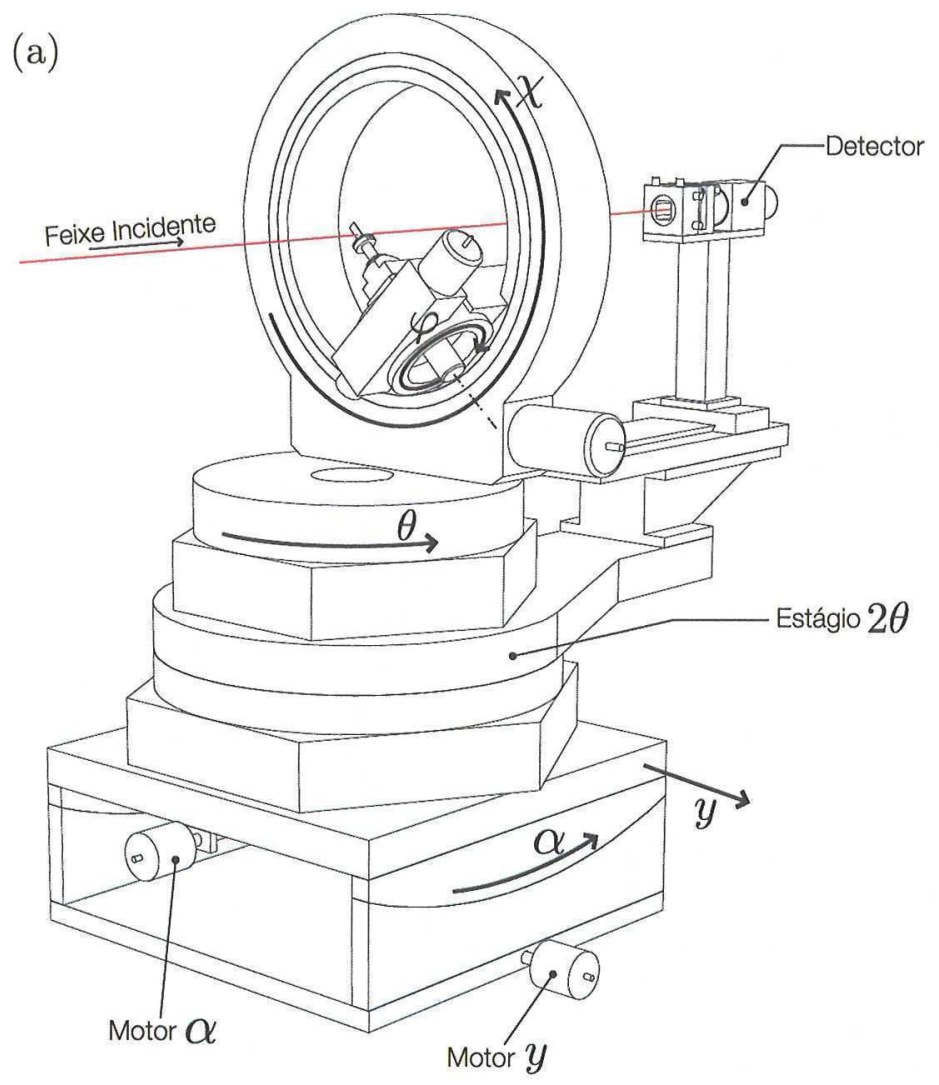

(b)
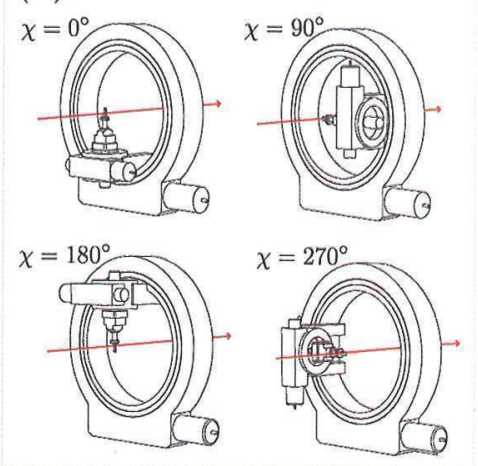

(c)

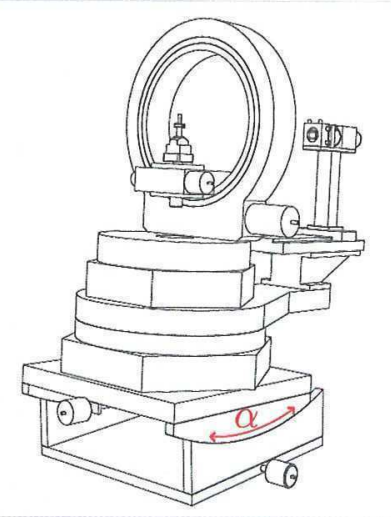

Figura A.2: Esquema do difratômetro de 4 círculos. (a) Estágios de rotação e translação do difratômetro. (b) Referência dos valores instrumentais de $\chi$ em relação à posição do estágio de rotação $\varphi$. (c) Exemplo de movimento do estágio $\alpha$.

as correções foram $\Delta \theta=0,363^{\circ}$ e $\Delta \alpha=0,012^{\circ}$. O mapa $\chi-\varphi$ obtido após a aplicação das correções pode ser visto na Fig.A.4. O alargamento das varreduras $\varphi$ nas posições $\chi=90^{\circ} \mathrm{e}$ $\chi=270^{\circ}$ (curvas de varredura na direção vertical) são devido a polarização parcial causada pelo monocromador no plano horizontal do goniômetro.

Do mapa na Fig.A.4 é possível constatar um desalinhamento residual de $\Delta \theta=$ $0,011^{\circ}$ e $\Delta \alpha=0,001^{\circ}$ após um único procedimento de alinhamento. No trabalho apresentado por Murphy et al., o melhor valor obtido para o alinhamento vertical foi $\Delta \alpha=0,04^{\circ}$ utilizando no mínimo 3 repetições do procedimento de alinhamento. O uso de mapas $\chi-\varphi$ 


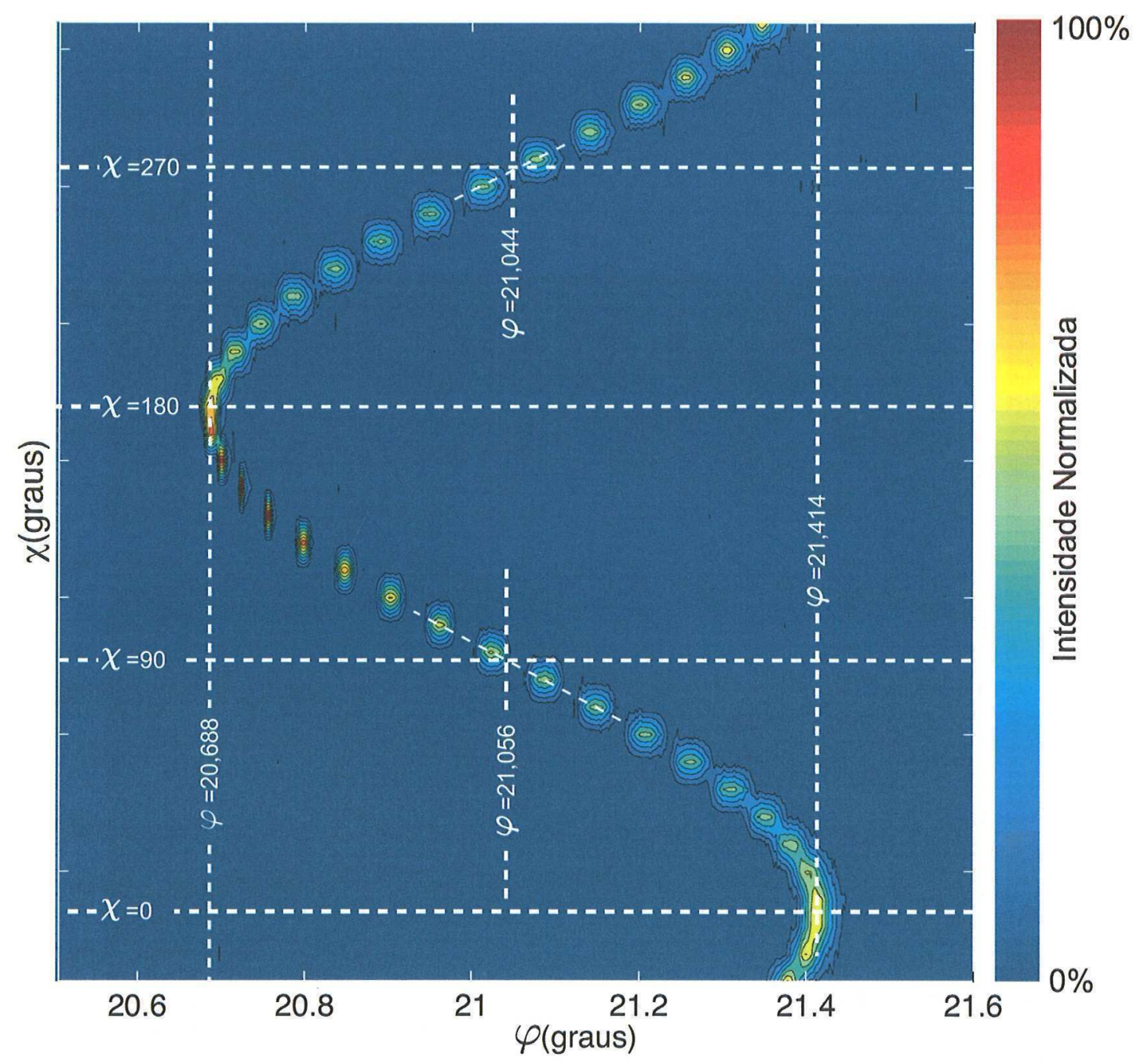

Figura A.3: Mapa $\chi-\varphi$ da reflexão 202 do Si antes do alinhamento do goniômetro.

ao invés das varreduras $\varphi$ nas posições $\chi=0^{\circ}, 90^{\circ}, 180^{\circ}$ e $270^{\circ}$ fornece uma visão ampla da forma da curva de precessão e assim permite a calibração do estágio de rotação $\chi$. Outra facilidade introduzida por este estudo é o fato de utilizar uma única reflexão (Si 202) durante todo o alinhamento enquanto que os trabalhos similares sugerem a utilização de pares de reflexões, tais como Ge 220 e $\overline{2} \overline{2} 0$ (ref.[62]), o que favorece a perda de acurácia do método. Dada a simplicidade e eficiência, este método é fortemente recomendado para estações de raios X dotadas de goniômetros de 4 círculos. 


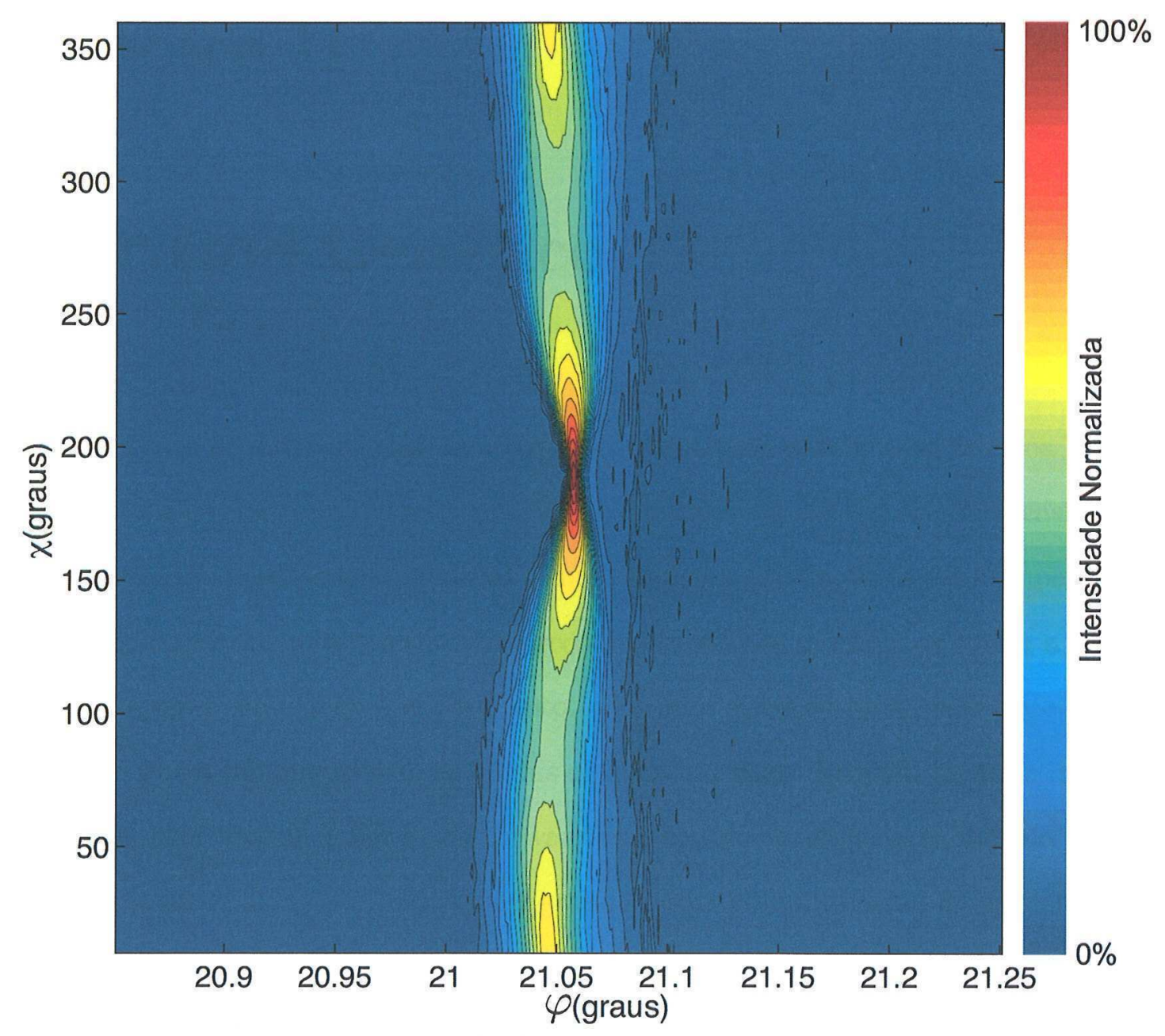

Figura A.4: Mapa $\chi-\varphi$ da reflexão 202 do Si depois do alinhamento do goniômetro. 


\section{Apêndice B}

\section{Algoritmo Genético}

Uma forma típica de determinação de estrutura de materiais por difração de raios X é a construção de modelos estruturais para reproduzir os padrões experimentais de intensidade. Em geral, os dados de espalhamento gerados (simulados) por tais modelos são comparados com os dados experimentais, o que leva a uma reconfiguração dos modelos de forma a minimizar as diferenças entre simulação e experimento. Em uma situação ideal, esse procedimento é repetido até que a diferença entre as curvas alcance um valor desejado (critério de parada). Em modelos com grande quantidade de variáveis correlacionadas, a atribuição de valores para os parâmetros de ajuste pode exigir grande poder computacional e, em determinados casos, é inviável testar todas as combinações possíveis. Dentro desse contexto, métodos de otimização dos valores dos parâmetros são indispensáveis para o ajuste de curvas regidas por grandes conjuntos de variáveis correlacionadas. Este apêndice apresenta a descrição de um algoritmo largamente empregado em programas de ajuste de curvas de espalhamento de raios $\mathrm{X}$ [45], chamado algoritmo genético, o qual foi utilizado no programa de ajuste das curvas de varredura $\theta$ de alta resolução da seção 3.1 e dos perfis de DM da seção 4.2. 
O algoritmo apresentado aqui é uma classe particular de algoritmo genético denominada "evolucionário" pois se baseia em mutações, recombinações e seleção dos parâmetros melhor ajustados, ou seja, os que produzem uma curva simulada mais próxima do dado experimental. A avaliação da qualidade do ajuste é dada por uma função-erro a qual deve ser minimizada com a melhoria do ajuste. Mutação é uma operação reponsável por pequenas mudanças aleatórias a um ou mais indivíduos da população (vetor de parâmetros $\boldsymbol{p}$ ), o que é essencial para a diversidade da população. Recombinação é uma operação complementar destinada a gerar novos vetores de parâmetros (prole) a partir da combinação entre os indivíduos (vetores de parâmetro) da população/geração anterior, uma etapa essencial no acesso à regiões promissoras do espaço de parâmetros. A seleção garante que os melhores parâmetros sejam propagados para as próximas gerações. Em suma, algoritmos evolucionários diferem de outros métodos de otimização de parâmetros por i) otimizarem o equilíbrio entre a exploração de novos indivíduos no espaço de parâmetros (mutação) e usarem a informação obitida até então (recombinação) e ii) por operarem em várias soluções simultaneamente (paralelismo implícito).

\section{B.1 Procedimento de ajuste dos dados}

Seja $\left(\theta_{j}, I_{j}\right)$ o conjunto de dados experimentais onde $\theta_{j}$ é o ângulo de incidência, $I_{j}$ é a intensidade medida em $\theta_{j}$ e $j=1,2, \ldots, N$. Os dados simulados $I\left(\theta_{j}, \boldsymbol{p}\right)$ são obtidos assumindo uma estrutura modelo com $n$ parâmetros ajustáveis representados pelo vetor $\boldsymbol{p}=\left[p_{1}, p_{2}, \ldots, p_{n}\right]$. Portanto, cada vetor de parâmetros $\boldsymbol{p}$ gera uma curva simulada a ser comparada com a experimental por meio de uma função-erro $E(\boldsymbol{p})$. Guiado por $E(\boldsymbol{p})$, o algoritmo otimiza os vetores de parâmetros $p$ por um ciclo repetitivo de mutação, recombinação e seleção. Os parâmetros são armazenados em uma matriz de população $\boldsymbol{P}=\left[\boldsymbol{p}_{0}, \boldsymbol{p}_{1}, \ldots, \boldsymbol{p}_{m-1}\right]$ e o 
tamanho da população $(m)$ é de livre escolha, sendo nesse trabalho $m=10 \times n$. O vetor de parâmetros $\boldsymbol{p}_{0}$ contém os valores iniciais dos parâmetros definidos pelo usuário como melhor estimativa para a estrutura, enquanto os demais $m-1$ vetores são gerados aleatoriamente dentro de intervalos pré-estabelecidos de valores. Uma vez que todos os vetores de parâmetros são gerados, é aplicada a função-erro em cada um dos vetores $\boldsymbol{p}_{i}$. O vetor de parâmetros com menor erro é armazenado no vetor de melhor ajuste $\boldsymbol{b}=\left[b_{1}, b_{2}, \ldots, b_{n}\right]$. Este vetor é então usado no monitoramento do progresso da otimização e é atualizado sempre que outro vetor apresente um ajuste melhor.

A idéia central do algoritmo é a criação de novos membros na população. Dois vetores $\boldsymbol{p}_{u}$ e $\boldsymbol{p}_{v}$ são escolhidos aleatoriamente dentro da população atual e a diferença entre eles, $\left(\boldsymbol{p}_{u}-\boldsymbol{p}_{v}\right)$, é usada na mutação do até então vetor de melhor ajuste $\boldsymbol{b}$, de acordo com a expressão

$$
b^{\prime}=b+k_{m}\left(p_{u}-p_{v}\right)
$$

onde $k_{m}{ }^{1}$ denota a constante de mutação. Obtido o vetor $\boldsymbol{b}^{\prime}$, o mesmo é atribuido a um "vetor-tentativa" $\boldsymbol{t}=\left[t_{1}, t_{2}, \ldots, t_{n}\right]$ o qual irá competir com o vetor $\boldsymbol{p}_{0}$. Começando aleatoriamente pelo $j$-ésimo parâmetro, os parâmetros-tentativa $t_{j}$ são consecutivamente carregados de ambos $\boldsymbol{b}^{\prime}$ e $\boldsymbol{p}_{0}$, os quais são selecionados de acordo com uma distribuição binomial. Um número aleatório entre 0 e 1 é comparado com uma constante de recombinação $k_{r}$ : se o número aleatório é menor ou igual a $k_{r}, t_{j}$ é definido como o $j$-ésimo parâmetro de $\boldsymbol{b}^{\prime}$; na outra opção, $t_{j}$ é definido como o $j$-ésimo parâmetro de $\boldsymbol{p}_{0}$. Neste trabalho utilizou-se $k_{r}=0,5$. Depois de $n-1$ recombinações, $\boldsymbol{t}$ é forçado a coletar seu último parâmetro de $\boldsymbol{b}^{\prime}$, assim pelo menos um parâmetro de $\boldsymbol{t}$ é diferente de $\boldsymbol{p}_{0}$. O vetor de parâmetros $\boldsymbol{t}$ é gerado

\footnotetext{
${ }^{1} \mathrm{O}$ valor de $k_{m}$ é uma escolha empírica a qual fornece maior eficiência de convergência e neste trabalho utilizou-se $k_{m}=0,7$.
} 
sem restrições e assim pode conter parâmetros fora dos limites pré-definidos pelo usuário. Caso isto aconteça, este parâmetro pode ser substituído pelo seguinte parâmetro aleatório:

$$
t_{j}=p_{j}^{\min }+\operatorname{rand}\left(p_{j}^{\max }-p_{j}^{\min }\right)
$$

onde $p_{j}^{\min }$ e $p_{j}^{\max }$ denotam os limites inferior e superior para os valores permitidos para o $j$ ésimo parâmetro, respectivamente. Se o vetor $\boldsymbol{t}$ satisfaz a desigualdade $E(\boldsymbol{t}) \leqslant E\left(\boldsymbol{p}_{0}\right)$, então $\boldsymbol{t}$ é selecionado para substituir $\boldsymbol{p}_{0}$, caso contrário $\boldsymbol{p}_{0}$ é propagado para a próxima geração. $\mathrm{O}$ procedimento é repetido para todos os vetores de parâmetros remanescentes na população $\boldsymbol{P}$, isto é, $\boldsymbol{p}_{i}$ sendo $i=1,2, \ldots, m-1$, com um novo vetor $\boldsymbol{b}^{\prime}$ calculado a cada geração. Finalmente o algoritmo é iterado sobre várias gerações até que $E(\boldsymbol{b})$ pare de decrescer, ou seja, até que o vetor de melhor ajuste $\boldsymbol{b}$ tenha convergido ao mínimo global da função-erro.

\section{B.2 Aplicação em sistemas de camadas epitaxiais}

A Fig.3.4 na seção 3.1 apresenta um exemplo de aplicação do algoritmo genético na análise de curvas de varredura de alta resolução em um sistema epitaxial de 2 camadas. O programa desenvolvido nessa tese atuou no ajuste dos parâmetros: espessura $(T)$, deformação no-plano $(\epsilon)$, relaxação $(R)$ e fator de normalização $(K)$ de cada camada, totalizando 8 parâmetros de ajuste, conforme o código fonte para Matlab apresentado na próxima seção. O modelo teórico é baseado na teoria cinemática e levou em conta o campo espalhado pelas camadas com diferentes parâmetros estruturais somado ao campo espalhado pelo substrato [64]. O campo do substrato foi definido pela expressão

$$
A_{\text {sub }}=(K / 2 \pi i)\left(Q-q_{0}\right)^{-1},
$$


onde $K$ é uma constante de normalização, $Q$ é o vetor recíproco dado por um determinado $\theta$ da varredura e $q_{0}$ é o vetor recíproco referência, no caso para a reflexão 004 do GaAs para energia de $8047,78 \mathrm{eV}$. O campo da primeira camada é dado por

$$
A_{1}=K \frac{e^{2 \pi i\left(Q-q_{1}\right) T_{1}}-1}{2 \pi i\left(Q-q_{1}\right)}
$$

onde $q_{1}$ e $T_{1}$ são o vetor recíproco referência e espessura da primeira camada sobre o substrato, respectivamente. O campo para as demais camadas é dado por

$$
A_{n c>1}=K\left(\frac{e^{2 \pi i\left(Q-q_{n c}\right) T_{n c}}-1}{2 \pi i\left(Q-q_{n c}\right)}\right) e^{2 \pi i\left(Q-q_{n c-1}\right)},
$$

onde $n c$ refere-se ao número da camada. Os campos do substrato e das camadas são somados para cada conjunto de parâmetros $\boldsymbol{p}_{i}$ conforme as linhas 98 a 109 do aquivo fonte da seção B.3. A intensidade simulada é obtida pelo módulo ao quadrado do campo resultante da camadas (linha 114 do arquivo fonte). Os dados simulados são comparados com os dados experimentais via função-erro

$$
E(\boldsymbol{p})=(1 /(N p-1)) \sum_{j=1}^{N p}\left|\log I_{j}-\log I\left(\theta_{j} ; \boldsymbol{p}\right)\right|,
$$

sendo $N p$ o número de pontos da varredura, $I_{j}$ é o $j$-ésimo valor de intensidade experimental e $I\left(\theta_{j} ; \boldsymbol{p}\right)$ é o $j$-ésimo valor de intensidade simulada para o conjunto de parâmetros $\boldsymbol{p}$. Mais detalhes sobre os critérios de escolha de funções-erro são encontrados em [45]. O arquivo fonte da seção B.3 apresenta os detalhes do ajuste do modelo de camadas dado pelas expressões B.3, B.4 e B.5 aos dados experimentais. Para comprovação da acurácia do modelo de camadas e da eficiência do algoritmo genético na definição dos parâmetros de ajuste, utilizou-se o programa comercial RADS Mercury da empresa Bede Scientific Instruments Ltd na geração 
de curvas teóricas as quais foram ajustadas pelo algoritmo apresentado nessa tese. No RADS é possível pré-definir os parâmetros das camadas e gerar uma curva teórica, portanto, várias configurações de camadas foram testadas. A Fig.B.1 ilustra uma das curvas geradas pelo RADS e ajustada pelo algoritmo aqui desenvolvido. O perfil simulado pelo algoritmo genético (linha contínua), obtido depois de 200 gerações do algoritmo (contador "g" na linha 313 do código fonte), é ilustrado sobre-posto aos dados gerados no RADS (círculos abertos). O número de gerações é regulado pelo critério de parada o qual é ativado quando $E(\boldsymbol{b}) \leqslant E_{\text {stop }}$ ( $E_{\text {stop }}$ é definido na linha 70).

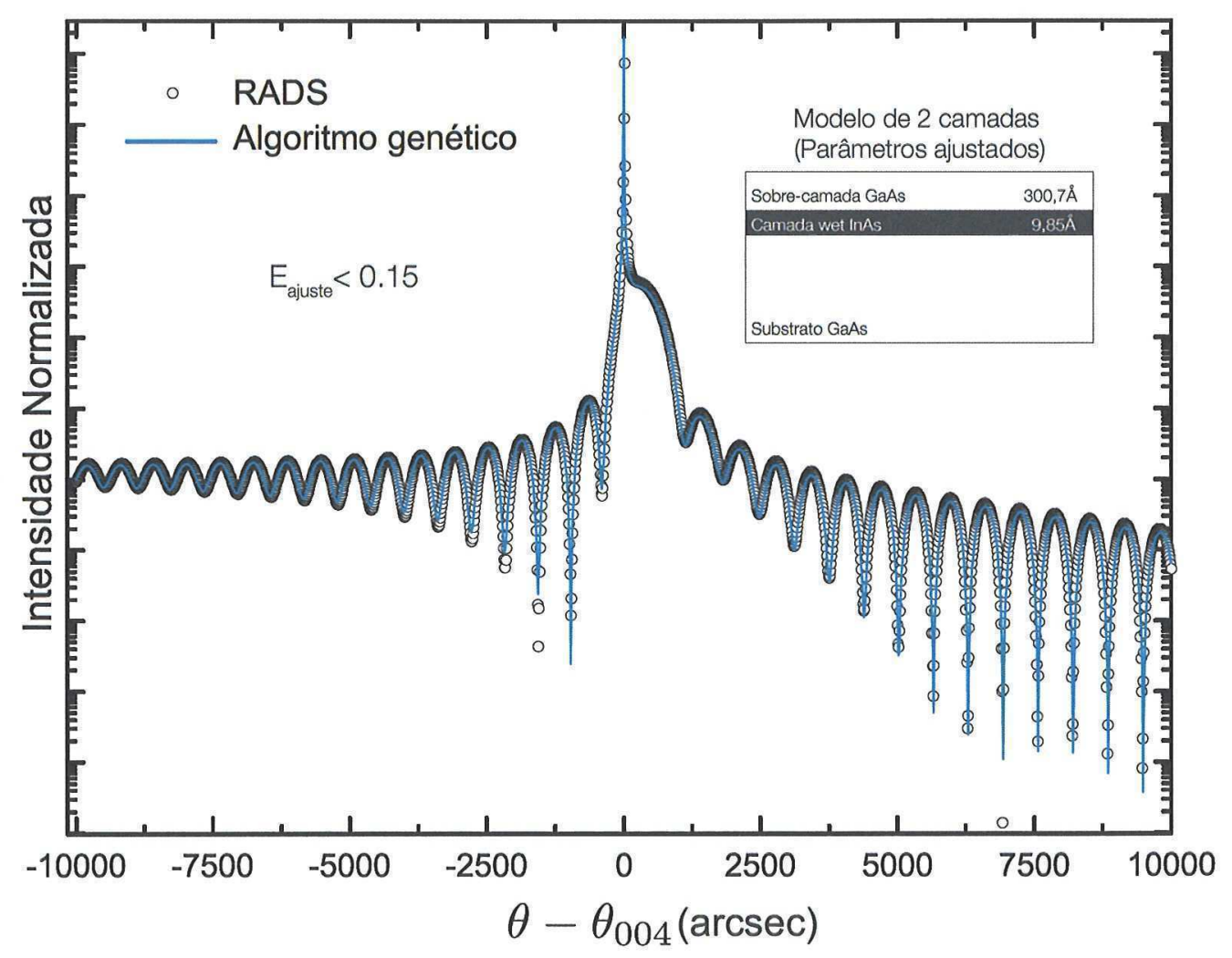

Figura B.1: Ajuste de dados do RADS pelo modelo de camadas com escolha de parâmetros via algoritmo genético. No detalhe, espessuras obtidas no ajuste. O valor $E_{a j u s t e}$ corresponde ao desvio logaritmico médio (Eq.B.6) para o ajuste.

A estimativa inicial $\left(\boldsymbol{p}_{0}\right)$ e os limites inferior e superior para o ajuste possuem um 
papel importante no número de gerações. O número de gerações do programa apresentado aqui não exige grande poder computacional, porém, ainda assim é possível otimizar os dados de entrada substituindo $\boldsymbol{p}_{0}$ pelo vetor de melhor ajuste $\boldsymbol{b}$, resultante de uma primeira tentativa, assim como definindo limites mais próximos da nova estimativa inicial. Este procedimento pode reduzir o número de gerações assim como minimiza a incerteza dos parâmetros ajustados. Substituindo os parâmetros de $\boldsymbol{p}_{0}$ (linha 58) pelos parâmetros da Tabela B.1 ocasionou em uma redução de $10 \times$ no número de gerações e de $50 \%$ na incerteza do parâmetro espessura. A Tabela B.1 ilustra os parâmetros resultantes de ajuste ilustrado na Fig.B.1 utilizando os parâmetros de entrada contidos nas linhas 58 a 60 do programa. A Tabela B.1 apresenta os parâmetros obtidos no ajuste com o algoritmo genético comparados com os obtidos no ajuste do programa RADS do capítulo 3. Na Fig.B.1 e nos valores da Tabela B.1 observa-se uma compatibilidade razoável entre as curvas geradas pelo algoritmo genético e os dados do RADS, confirmando que o modelo é apropriado para a análise do sistema gerado no RADS assim como confirma a viabilidade de convergência do algoritmo genético na escolha dos parâmetros de ajuste. A qualidade do ajuste é apresentada na Fig.B.1 como $E_{a j u s t e}$ e é estimada pela função-erro da Eq.B.6, a qual fornece um desvio logaritmico médio entre os dados experimentais e a curva teórica. Embora o modelo tenha sido aplicado a sistemas de duas camadas nesse trabalho, o mesmo pode ser extendido para sistemas de N-camadas de diferentes materiais, espessuras, deformação e relaxação. 
B.3 Código fonte de programa Matlab para ajuste de curvas de varredura $\theta$ em sistemas de camadas epitaxiais

\begin{tabular}{clrc}
\hline Camada & Parâmetro & RADS & Presente Trabalho \\
\hline \multirow{4}{*}{1} & Espessura $(\AA)$ & 10,0 & 9,85 \\
& Deformação & 0,0005 & 0,0003 \\
& Relaxação & 0,05 & 0,05 \\
& Coef. Normalização & - & $4,80 \times 10^{-7}$ \\
\hline \multirow{4}{*}{2} & Espessura $(\AA)$ & 300,0 & 300,7 \\
& Deformação & 0,0 & 0,0 \\
& Relaxação & 0,0 & 0,0 \\
& Coef. Normalização & - & $4,80 \times 10^{-7}$ \\
\hline
\end{tabular}

Tabela B.1: Parâmetros estruturais obtidos no ajuste do modelo de camadas via algoritmo genético comparados aos dados do programa RADS. As camadas são contadas a partir do substrato. O parâmetro "Deformação" corresponde à razão $\Delta a / a_{0}=\left(a_{\|}-a_{0}\right) / a_{0}$, onde $a_{\|}$e $a_{0}$ correspondem às constantes de rede no-plano e do GaAs, respectivamente. O parâmetro "Relaxação" pode assumir valores entre 0 e 1, sendo 1 referente a uma célula unitária totalmente relaxada.

\section{B.3 Código fonte de programa Matlab para ajuste de}

\section{curvas de varredura $\theta$ em sistemas de camadas epi-}

\section{taxiais}

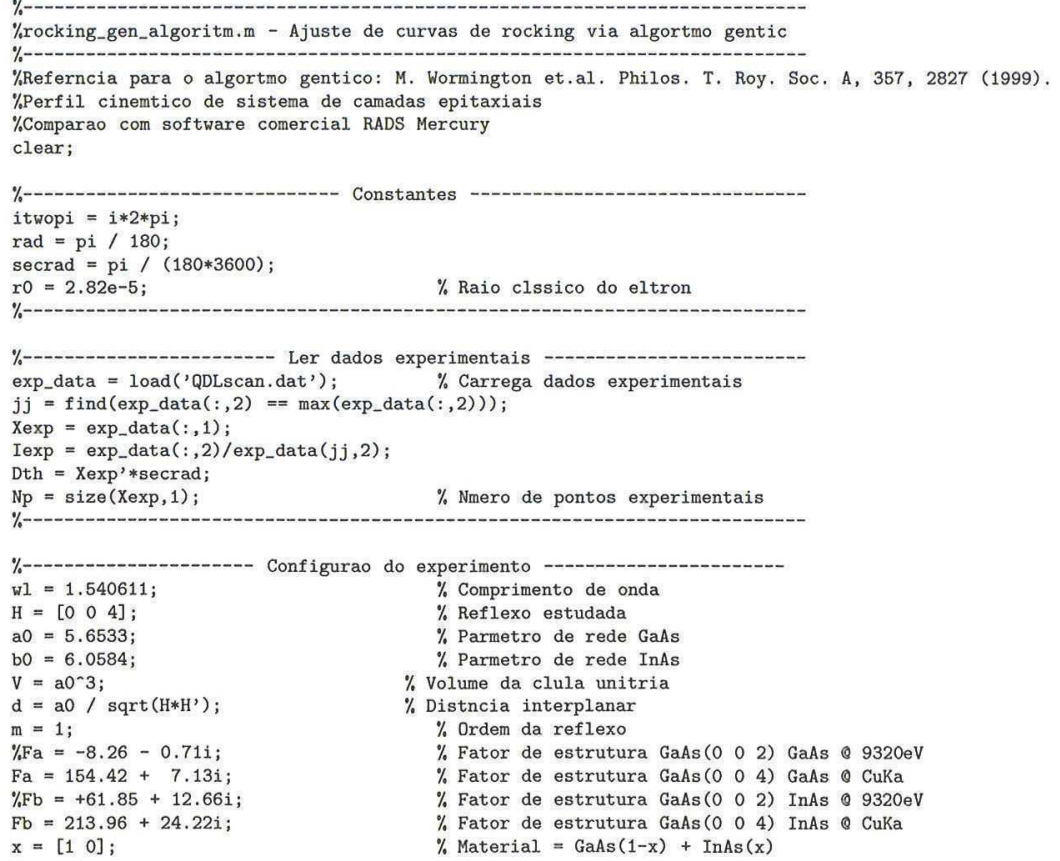


B.3 Código fonte de programa Matlab para ajuste de curvas de varredura $\theta$ em sistemas de camadas epitaxiais

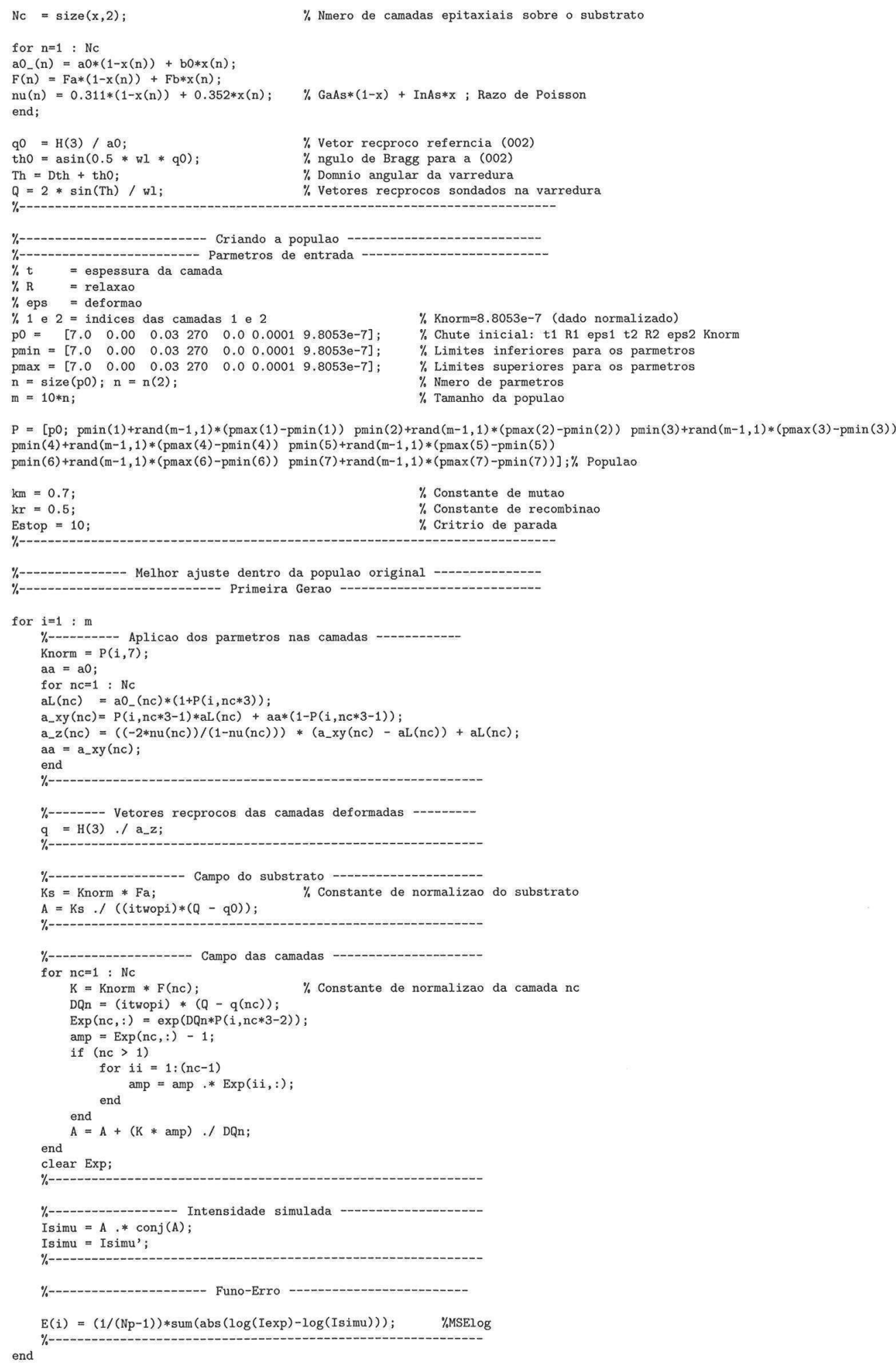


B.3 Código fonte de programa Matlab para ajuste de curvas de varredura $\theta$ em sistemas de camadas epitaxiais

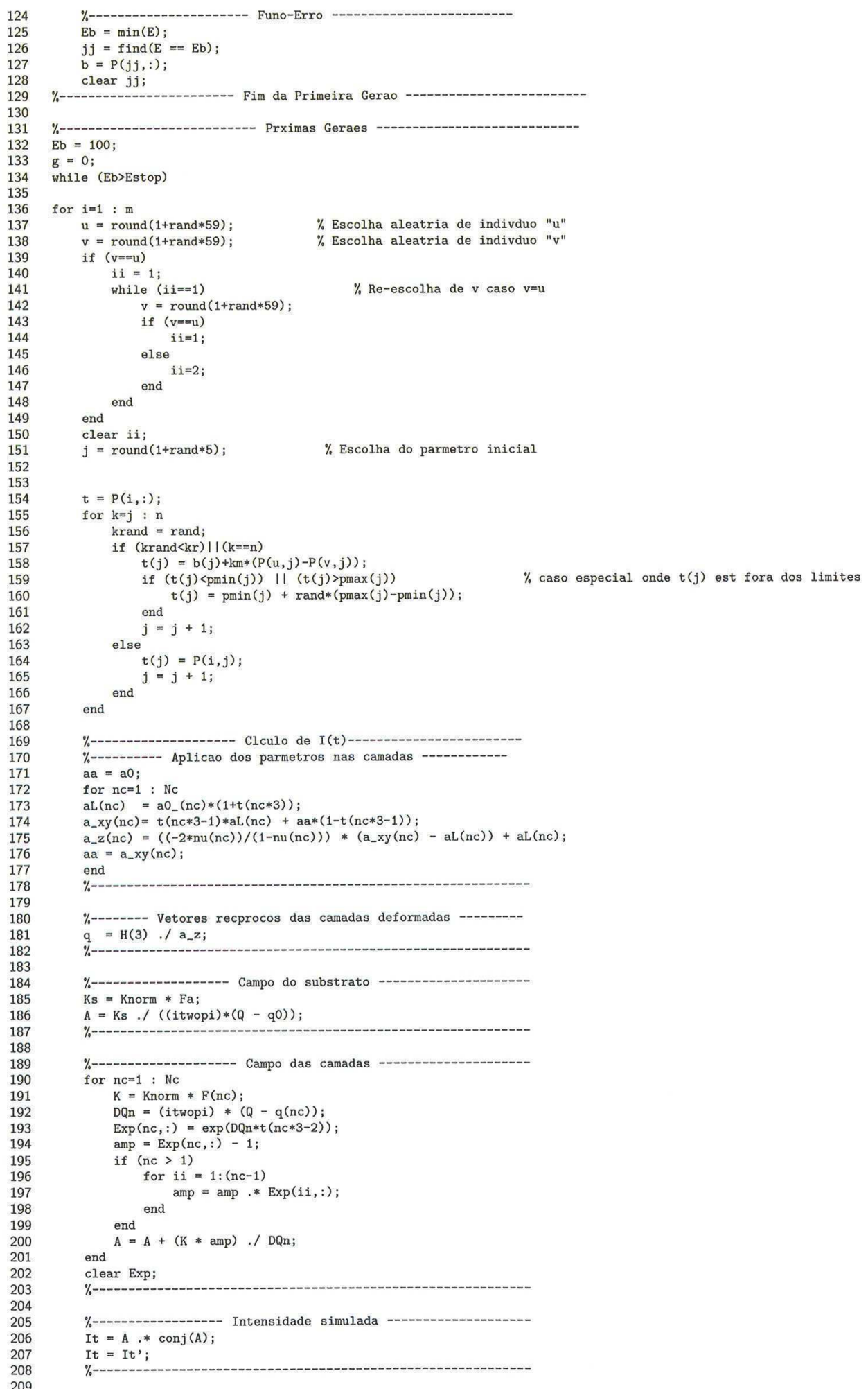


B.3 Código fonte de programa Matlab para ajuste de curvas de varredura $\theta$ em sistemas de camadas epitaxiais

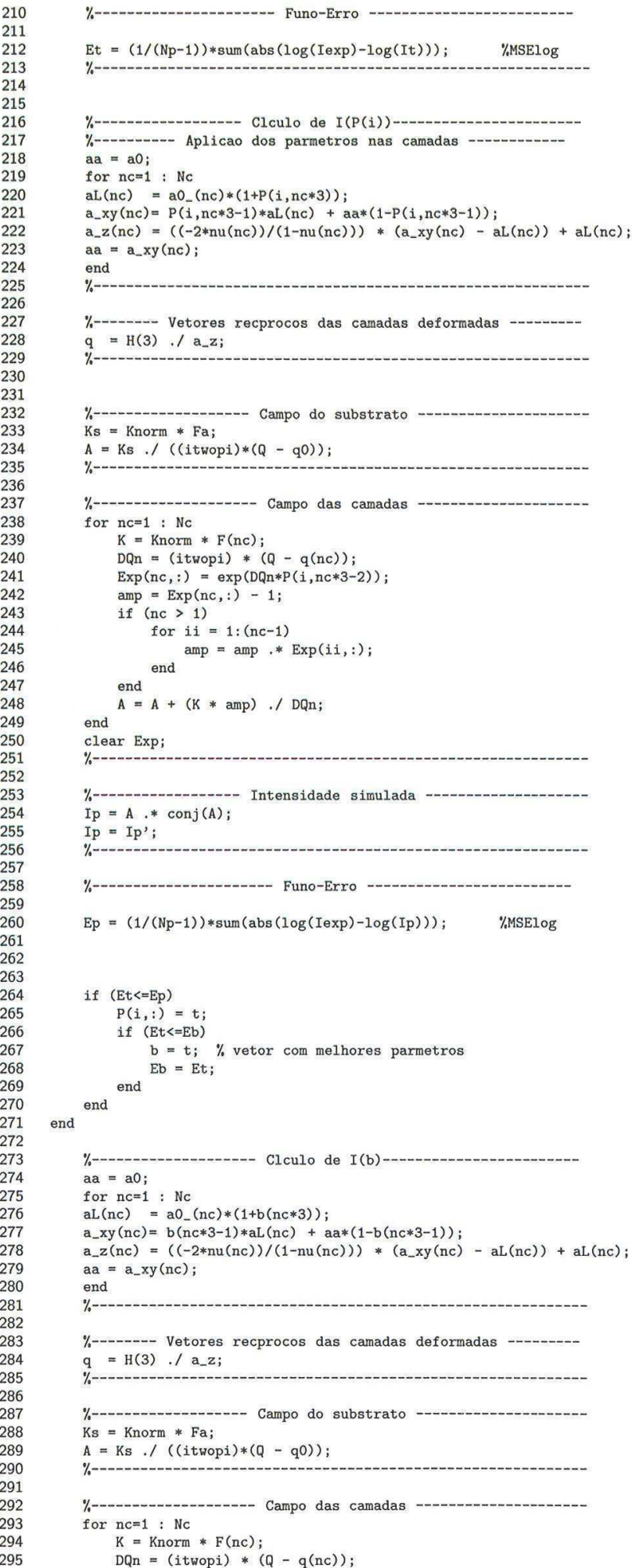


B.3 Código fonte de programa Matlab para ajuste de curvas de varredura $\theta$ em sistemas de camadas epitaxiais

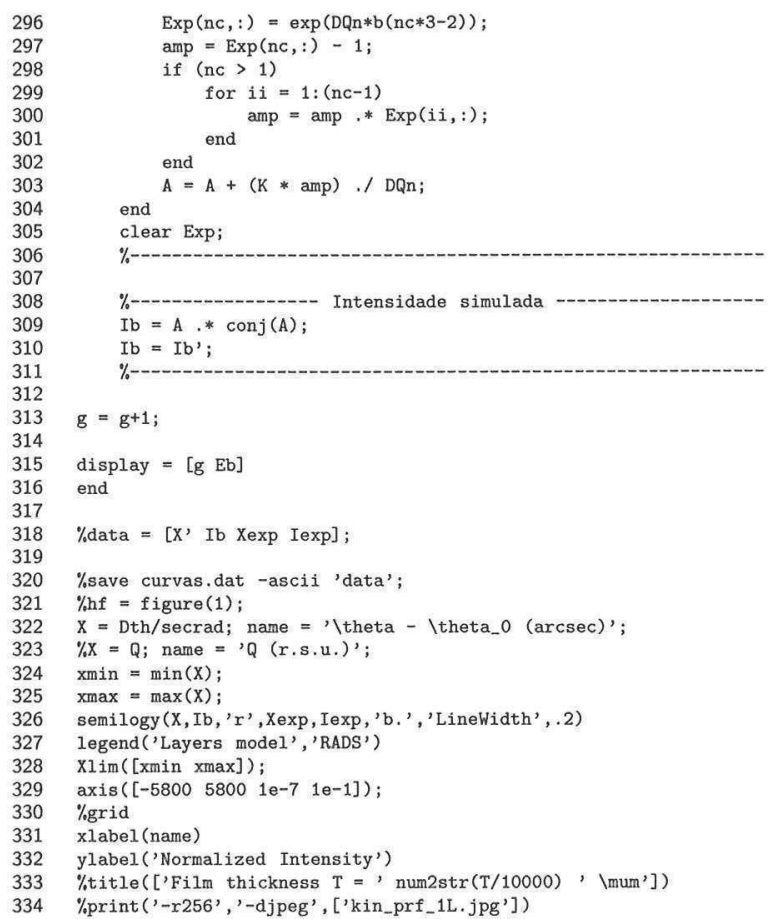




\section{Apêndice C}

\section{Arquivo fonte de programa para ajuste de picos de DM - FITTER}

Neste apêndice é apresentado o arquivo fonte do programa baseado na teoria dinâmica da difração de raios X, denominado FITTER, o qual foi utilizado no ajuste dos perfis de DM para os experimentos de determinação do parâmetro de rede via XRS. O programa foi desenvolvido em código C++ e é capaz de realizar o ajuste dos parâmetros i) Largura Intrínseca, ii) Razão das amplitudes, iii) Fator de coerência, iv) Largura instrumental, v) Aufhellung e vi) Posição dos picos de DM. Os 6 parâmetros são ajustados via algoritmo genético a partir de estimativas iniciais. Os detalhes do algoritmo são descritos no apêndice B.

\#define MAXLINE $200 / *$ Line maximum size*/

\#define MAXNofP 500 /*Maximum number of points per phi scan*/

\#define NUM_PAR $6 \quad$ /* Number of adjustable parameters by the DEA*/

\#define POP_MAX 10*NUM_PAR/* Number of parameter-vectors in each generation*/

\#define GEN_MAX $100 \quad / *$ Maximum number of generations*/

typedef complex<double $>$ double_complex; 


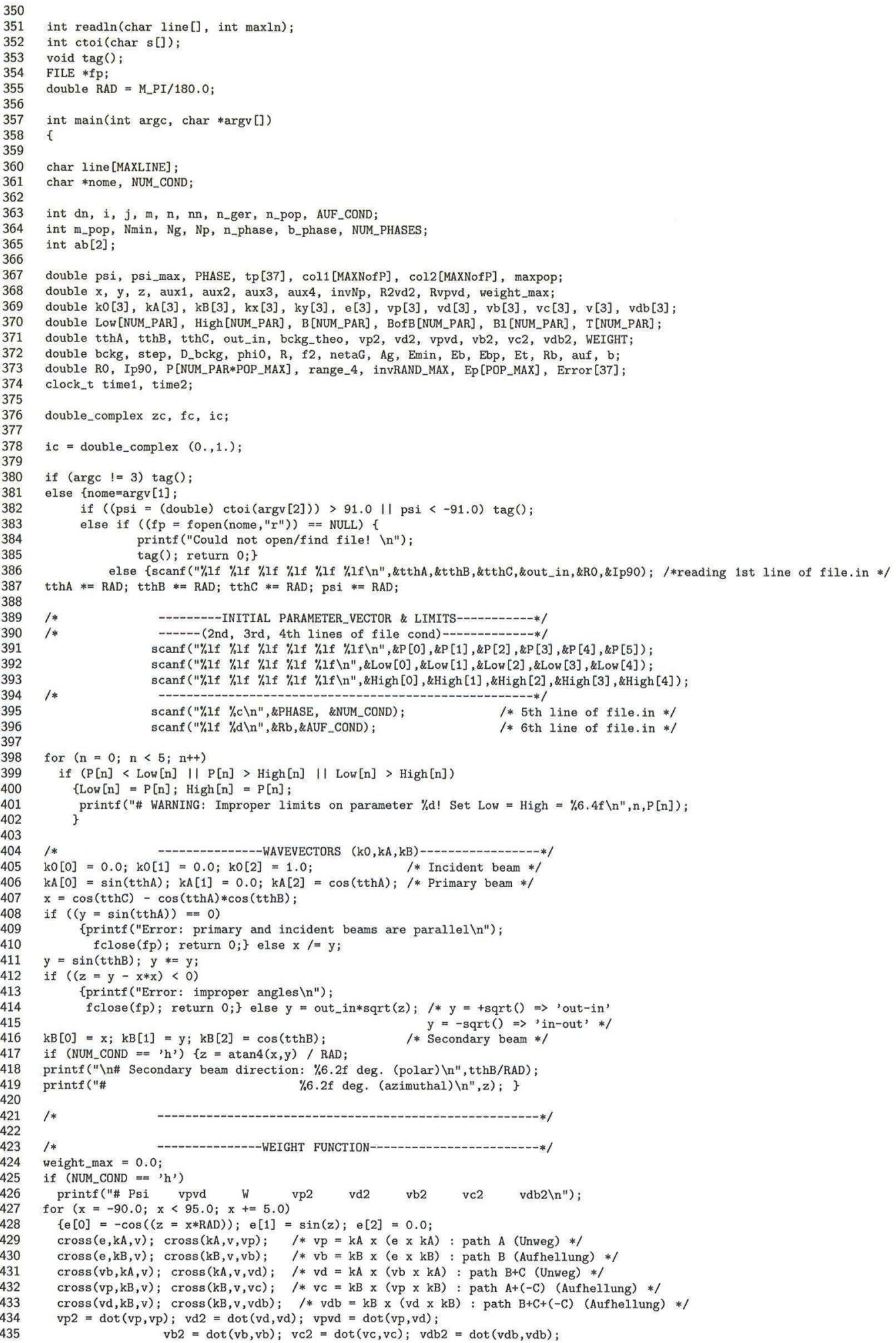




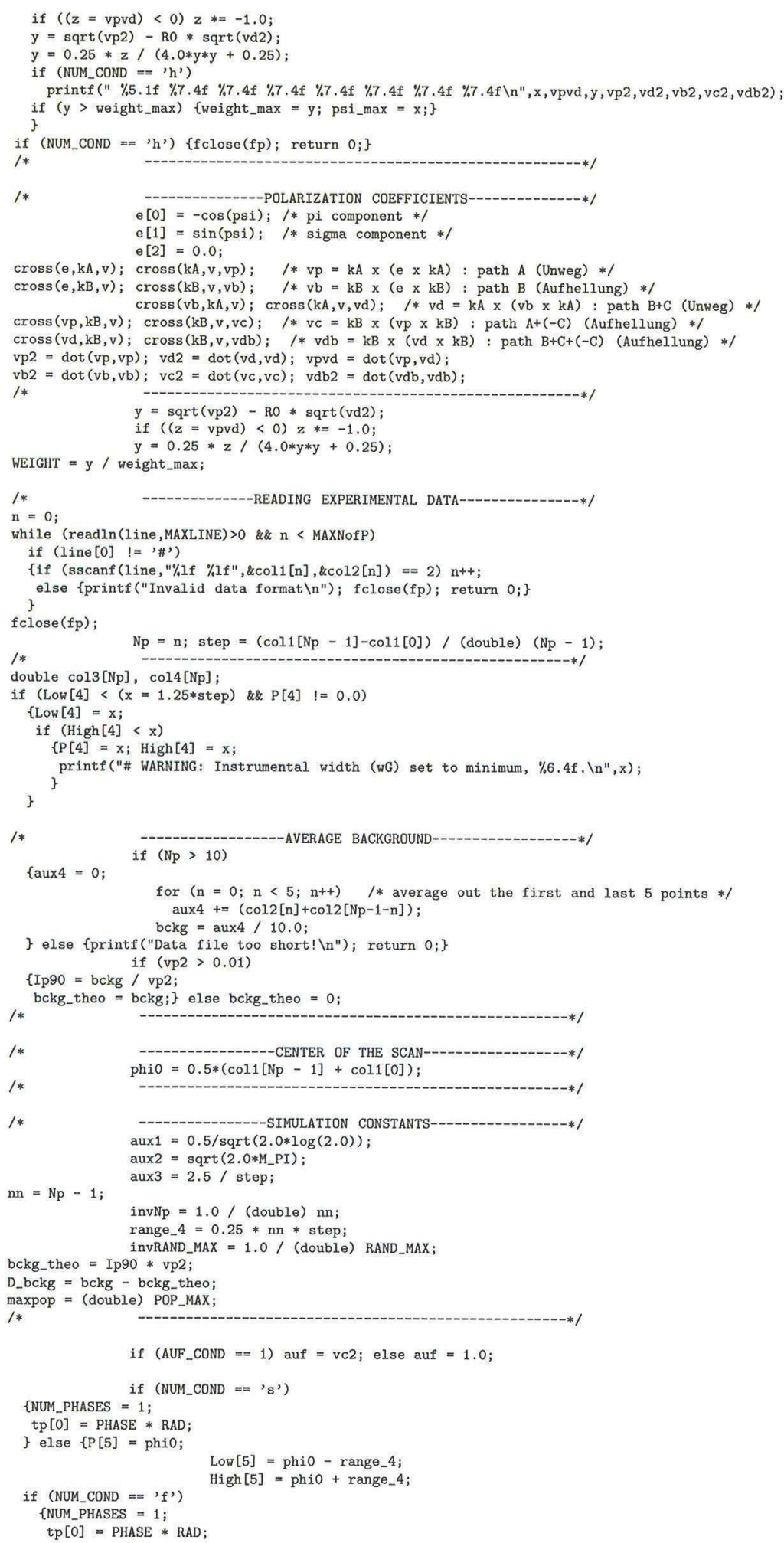




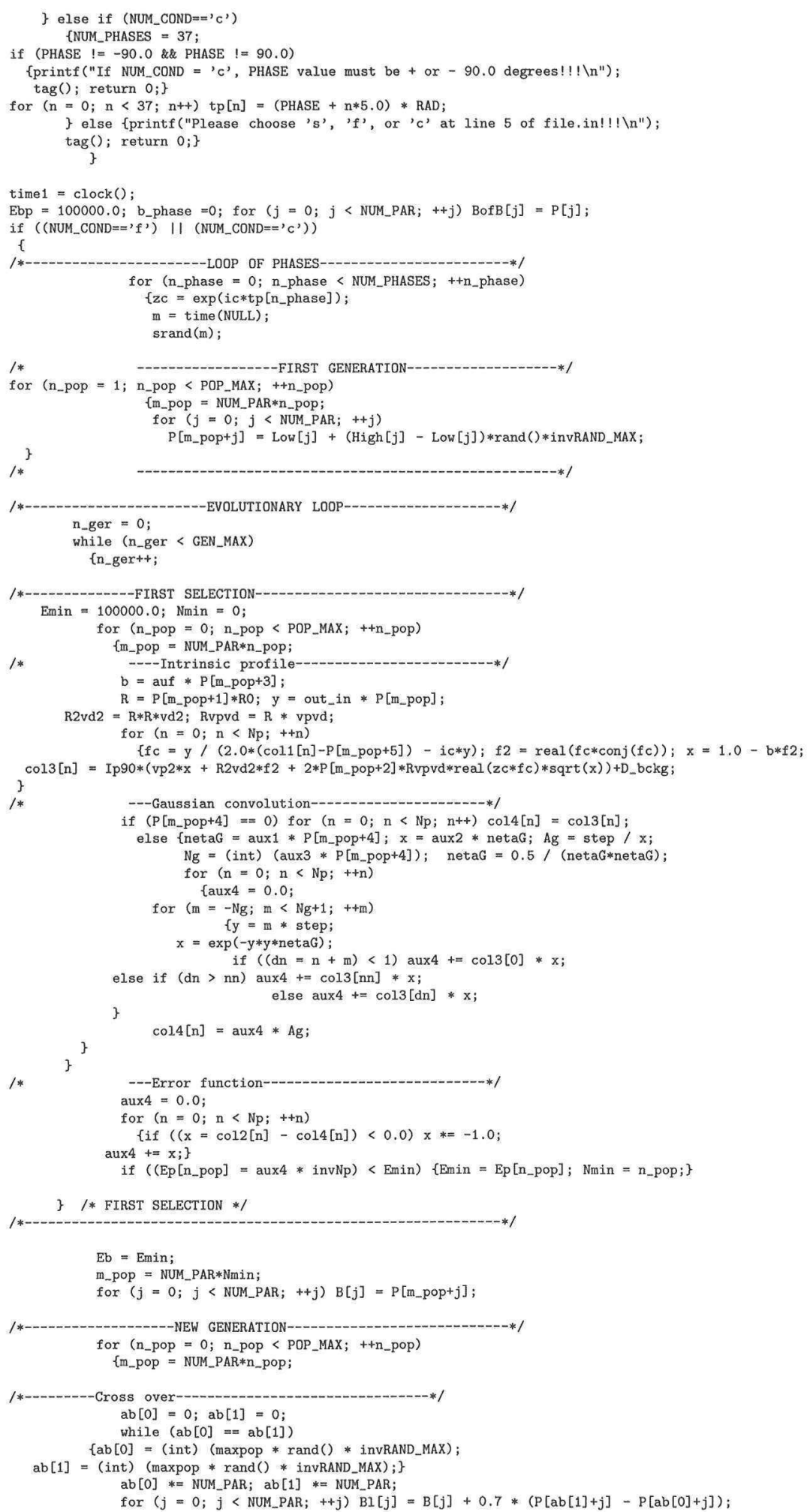




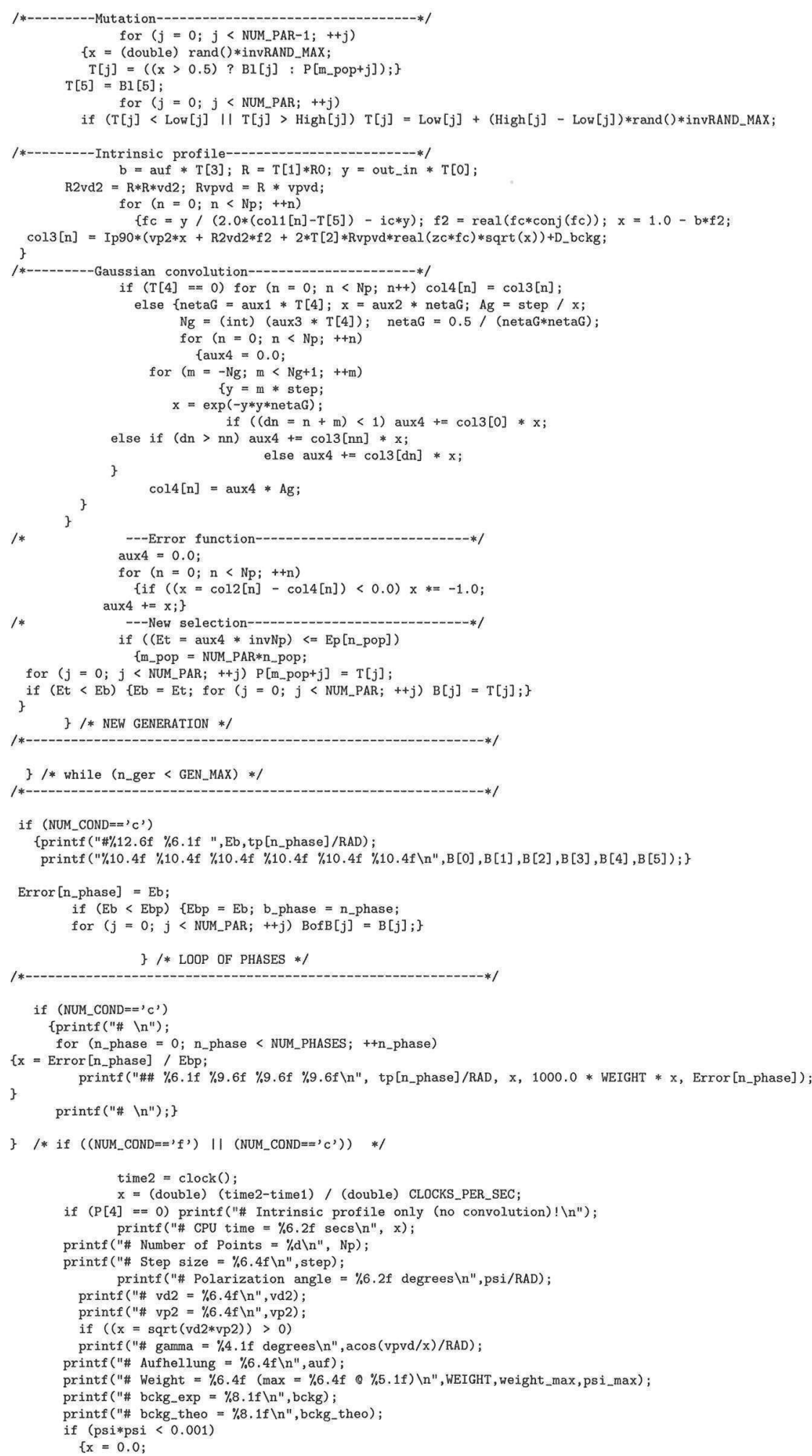




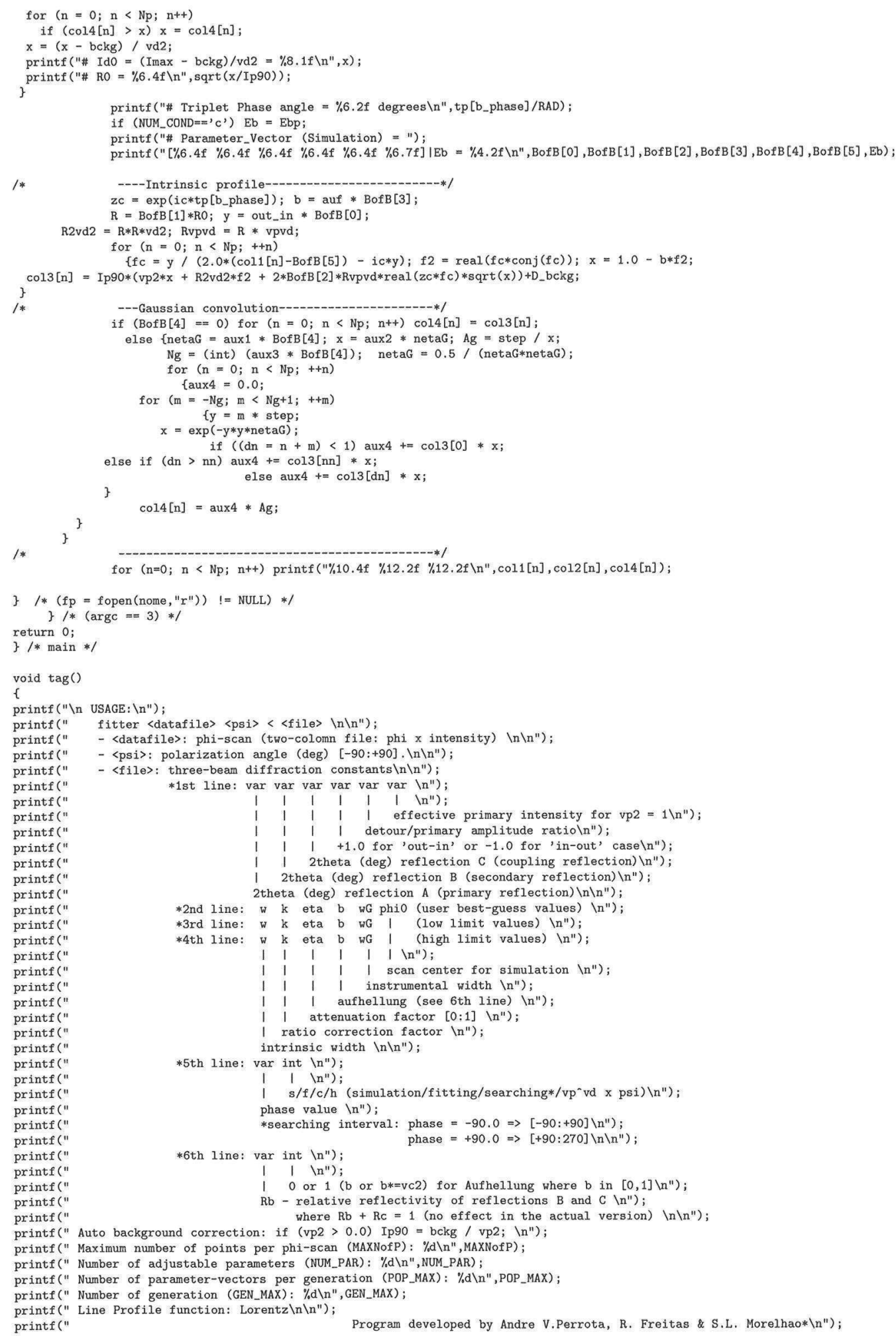




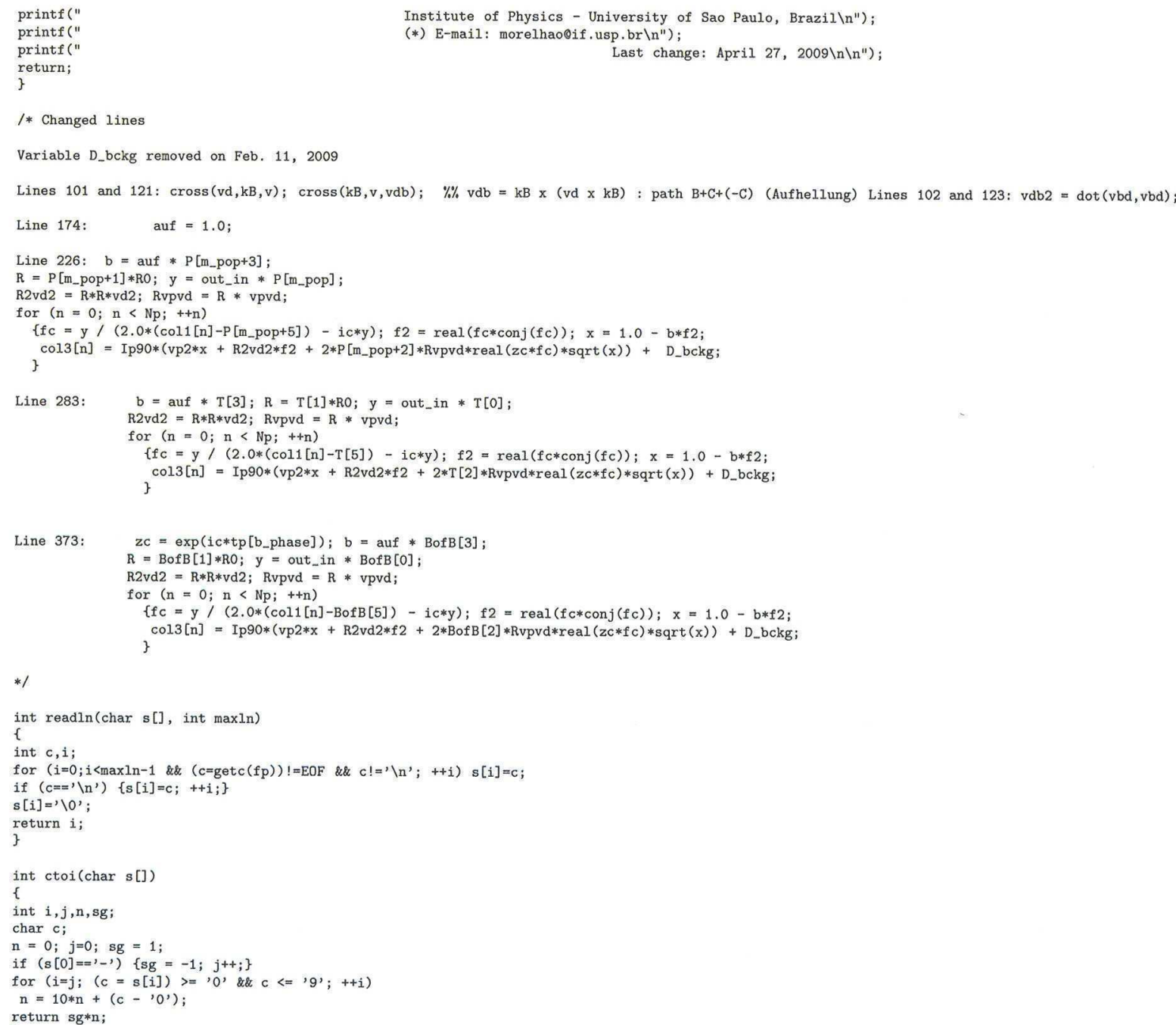




\section{Lista de Publicações}

\section{Livros e periódicos}

1. Sérgio L. Morelhão, Cláudio M. R. Remédios, Raul O. Freitas and A. O. dos Santos, J. Appl. Crystallogr. 44, 93 (2011).

2. A. Malachias, R. Freitas, S. Morelhão, R. Magalhães-Paniago, S. Kycia and G. Medeiros-Ribeiro. Handbook of Instrumentation and Techniques for Semiconductor Nanostructures Characterization - Chapter 10, aceito, World Scientific Publishers, 2010 .

3. Raul O. Freitas, Alain A. Quivy and Sérgio L. Morelhão, J. Appl. Phys. 105, 036104 (2009).

4. Raul O. Freitas, Beatriz Diaz, Eduardo Abramof, Alain A. Quivy and Sérgio L. Morelhão, Phys. Stat. Sol. A 206, 1714 (2009).

5. Raul O. Freitas, Tomás E. Lamas, Alain A. Quivy and Sérgio L. Morelhão, Phys. Stat. Sol. A 204, 2548 (2007).

6. S.L. Morelhão, L.H. Avanci, R. Freitas and A.A. Quivy, Microelectr. J. 36, 219 (2005).

\section{Proceedings e Activity Reports}

- Influence of Quantum-Dots Density on Average In-Plane Strain of Optoelectronic Devices by X-Ray Renninger Scanning

Raul O. Freitas, Sérgio L. Morelhão and Alain A. Quivy

AIP Conference Proceedings, p. 351 (2010).

- Strong CTR-cap-layer coupling for X-ray scattering in InAs/GaAs (001) quantum dots systems

R. O. Freitas, S. L. Morelhão and A. A. Quivy

LNLS Brazilian Synchrotron Light Laboratory Activity Report, (2008). 
- Internal stress mechanism in Mn doped KDP crystals by X-ray phase measurements S. L. Morelhão, R. O. Freitas, C. M. R. Remedios and A. O. Santos LNLS Brazilian Synchrotron Light Laboratory Activity Report, (2007).

- Synchrotron X-ray Renninger scanning for studying strain in InAs/GaAs quantum dot system

R. O. Freitas, T. E. Lamas, A. A. Quivy and S. L. Morelhão LNLS Brazilian Synchrotron Light Laboratory Activity Report, (2006). 


\section{Apresentação em conferências}

\section{Escola São Paulo de Ciência Avançada (ESPCA) - FAPESP}

New Developments in the Field of Synchrotron Radiation

Bragg-Surface Diffraction on the study of epitaxial systems based on InAs/GaAs quantum dots.

R. O. Freitas, Stefan Kycia and Sérgio L. Morelhão

Campinas - Brazil

Janeiro/2011

2. $10^{\text {th }}$ Biennial Conference on High Resolution X-Ray Diffraction and Imaging (XTOP)

Synchrotron X-ray Renninger scanning for studying nanostrucured semiconductor devices.

R. O. Freitas, T. E. Lamas, A. A. Quivy and S. L. Morelhão

Warwick - United Kingdom

Setembro/2006

3. $10^{\text {th }}$ Biennial Conference on High Resolution X-Ray Diffraction and Imaging (XTOP)

Interface defects in capped quantum dots probed with Bragg-surface diffraction.

Raul O. Freitas, A. D. Maia, Alain. A. Quivy, Stefan Kycia and Sérgio L. Morelhão Coventry - United Kingdom

Setembro/2010

4. $11^{\text {th }}$ International Conference on Advanced Materials

Bragg Surface Diffraction as probe for studying surface/interface defects in opto-electronic devices grown on GaAs(001) substrates.

R. O. Freitas, S. W. Kycia, A. A. Quivy and S. L. Morelhão

Rio de Janeiro - Brazil

Setembro/2009

5. American Crystallographic Association - Annual meeting Bragg Surface Diffraction as a Probe for Studying InAs/GaAs Free-Standing Quantum Dots Systems. 
R. O. Freitas, S. W. Kycia, A. A. Quivy and S. L. Morelhão

Toronto - Canada

Julho/2009

6. Materials Science and Engineering 2008 - Congress and Exhibition on Advanced Materials and Processes

Influence of quantum dots density on average in-plane strain of opto-electronic devices by X-ray Renninger scanning.

R. O. Freitas, Alain A. Quivy and S.L. Morelhão

Nürnberg - Germany

Setembro/2008

7. $29^{\text {th }}$ International Conference on the Physics of Semiconductors (ICPS)

Bragg-Surface X-ray diffraction for studying self-organized quantum dots.

R. O. Freitas, S. L. Morelhão and Alain A. Quivy

Rio de Janeiro - Brazil

Julho/2008

8. $13^{\text {th }}$ Brazilian Workshop on Semiconductor Physics

Hybrid reciprocal space for X-ray diffraction in epitaxial layers.

R. O. Freitas, S. L. Morelhão and J. Z. Domagala

São Paulo - Brazil

Setembro/2007

9. $18^{a}$ Reunião da Associação Brasileira de Cristalografia

Bragg-surface X-ray diffraction for studying self-organized quantum dots.

R. O. Freitas, A. A. Quivy and S.L. Morelhão

Campinas - Brazil

Julho/2007

10. $5^{\circ}$ Encontro da Sociedade Brasileira de Pesquisa em Materiais (SBPMat) Combining synchrotron X-ray techniques for studying nanostructured semiconductor devices.

R. O. Freitas, S.L. Morelhão, A. V. Perrota, A. A. Quivy and T. E. Lamas Florianópolis - Brazil

Outubro/2006

11. $8^{\text {th }}$ Biennial Conference on High Resolution X-Ray Diffraction and Imaging (XTOP)

Synchrotron X-ray Renninger scanning for studying nanostrucured semiconductor devices.

R. O. Freitas, T. E. Lamas, A. A. Quivy and S. L. Morelhão

Baden-Baden/Karlsruhe - Germany

Setembro/2006 
12. XXIX Encontro Nacional de Física da Matéria Condensada

Synchrotron X-ray techniques for studying nanostructured semiconductor devices.

R. O. Freitas, T. E. Lamas, A. V. Perrota, S.L. Morelhão and A. A. Quivy

São Lourenço - Brazil

Maio/2006 


\section{Lista de Figuras}

2.1 Espalhamento de uma frente de onda por um plano atômico qualquer onde $\boldsymbol{k}_{0}$ e $\boldsymbol{k}$ são os vetores de onda incidente e espalhado, respectivamente. $r$ é o vetor

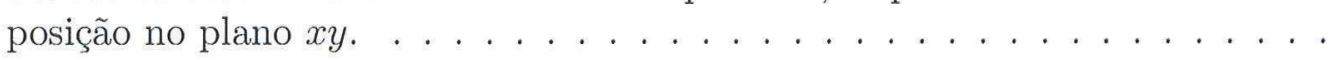

2.2 Difração de raios X por um conjunto de planos atômicos com distância interplanar $d_{h k \ell}$. Para um dado ângulo de incidência $\theta$, a diferença de caminho $\overline{\mathrm{MOP}}=2 d_{h k \ell} \sin \theta$, percorrida pela onda entre planos adjacentes, será um múltiplo inteiro do comprimentos de onda na condição de difração dada pela Lei de Bragg, Eq. (2.6). $\boldsymbol{k}_{0}$ e $\boldsymbol{k}$ representam os vetores de onda da radiação incidente e difratada, respectivamente. . . . . . . . . . . . . . . .

2.3 (a) Diferença de caminho $\overline{\mathrm{MON}}$ em relação à origem associada ao espalhamento de um feixe de raios $\mathrm{X}$ por um elemento de carga $d q$ localizado em $\mathrm{P}$ dentro do volume $V \cdot \overline{\mathrm{MO}}=-\hat{\mathbf{S}}_{0} \cdot r, \overline{\mathrm{ON}}=\hat{\mathbf{S}} \cdot r$, tal que $\overline{\mathrm{MON}}=\left(\hat{\mathbf{S}}-\hat{\mathbf{S}}_{0}\right) \cdot r$, onde $\hat{\mathbf{S}}_{0}$ e $\hat{\mathbf{S}}$ são versores nas direções incidente e espalhada, e $r$ é o vetor posição dentro do volume. (b) Definição do vetor de espalhamento. . . . . . .

2.4 Rede cristalina formada por células unitárias cujas arestas determinam os vetores de translação, ou vetores de rede $\boldsymbol{a}, \boldsymbol{b}$ e $\boldsymbol{c}$. O vetor $\boldsymbol{R}_{m n p}$, Eq. (2.12), fornece a localização das células unitárias no cristal. . . . . . . . . . . . . . .

2.5 Estrutura blenda de zinco do (a) GaAs e (b) InAs. (c) Monocamadas (MC) ao longo da direção [001] na célula unitária cúbica de aresta $a_{0} . \ldots \ldots$. . .

2.6 Modelo de atenuação de um feixe paralelo de raios X por uma fatia material de espessura $x$. O feixe incidente $I_{0}$ interage com os centros absorvedores do material e é transmitido com intensidade $I$. A atenuação de $I_{0}$ depende da densidade de centros absorvedores e da eficiência de absorção dos mesmos. 
2.7 (a)Ressonância atômica: fótons de raios $\mathrm{X}$ ejetam elétrons de camadas profundas (K ou L) para níveis quânticos intermediários vazios nos arredores do átomo que, ao retornarem ao estado inicial, reemitem fótons de mesma energia mas com defasagem de $\pi / 2$. (b) Absorção de raios X: a lacuna deixada pelo elétron ejetado é preenchida por um elétron de outro nível atômico, efetivando o processo de absorção e gerando fótons de menor energia que os fótons primários. . . . . . . . . . . . . . . . . . .

2.8 Diagrama de obtenção de correção da dispersão $f^{\prime}(\mathcal{E})$ e $f^{\prime \prime}(\mathcal{E})$. . . . . . . . . .

2.9 Representação tridimensional da condição de difração para (a) uma reflexão simétrica e (b) para o caso assimétrico. O feixe incidente $\boldsymbol{k}_{0}$, o qual incide num ângulo $\theta_{G}$ com os planos atômicos, satisfaz a condição de Bragg para o vetor de difração $\boldsymbol{G}$. O vetor de onda $\boldsymbol{k}$ representa o feixe difratado e o ângulo $\varphi$ denota rotações azimutais no cristal. . . . . . . . . . . . . . . . .

2.10 Representação no espaço recíproco da condição de difração de uma reflexão simétrica por meio da construção de Ewald. Um ponto recíproco (neste caso o ponto vermelho em destaque) é colocado em condição de difração ao tocar a casca esférica de raio $1 / \lambda$. O feixe difratado sempre sairá na direção formada pela linha que liga o centro da esfera ao ponto recíproco em condição de difração, direção esta que sempre estará a $2 \theta_{G}$ do feixe incidente, sendo $\theta_{G}$ o ângulo entre o feixe incidente e os planos difratantes (ângulo de Bragg). . . .

3.1 Sequência com as amostras analisadas as quais representam os principais estágios da construção do dispositivo opto-eletrônico via MBE. (a) Substrato comercial de GaAs(001), (b) crescimento da camada "tampão" de GaAs, (c) deposição da camada "wet" de InAs, (d) nucleação das ilhas de InAs e (e) adição da sobre-camada de GaAs. . . . . . . . . . . . . . . . . . . . . . . .

3.2 Esquema do experimento in situ de RHEED dentro do equipamento de MBE. Células de efusão de Índio e Arsênio são aquecidas a temperaturas da ordem de $1500^{\circ} \mathrm{C}$ de forma a evaporar In e $\mathrm{As}_{4}$ gerando o feixe molecular de deposição de InAs (detalhe). O feixe de elétrons do experimento RHEED é difratado pelas novas camadas de InAs e o padrão de difração é monitorado em uma tela de fósforo. . . . . . . . . . . . . . . . . . . . . . . .

3.3 Esquema de formação das ilhas de InAs no modo de crescimento StranskiKrastanov: (a) cobertura parcial do substrato, (b) formação da camada wet, (c) nucleação das ilhas de InAs com parte do material da camada wet e (d) aumento do volume das ilhas. Imagens in situ de RHEED durante processamento do dispositivo opto-eletrônico: (e) antes e (f) depois da nucleação dos QDs de InAs. . . . . . . . . . . . . . . . . . . . . . . . 
3.4 Curvas de varredura $\theta$ de alta resolução da reflexão 004 do GaAs com respectivas simulações de sistema de duas camadas para (a) amostra \#8 (camada wet com sobre-camada) e (b) amostra \#5 (QDs com sobre-camada). Os valores $E_{\text {ajuste }}$ correspondem ao desvio logaritmico médio (Eq.B.6) para os respectivos ajustes em (a) e (b). . . . . . . . . . . . . . . . . . .

3.5 Caracterização superficial de amostras com QDs expostos via AFM. (a) e (b) imagens AFM, amostra \#3 com densidade superficial 360QDs $/ \mu m^{2}$, em perspectiva e de topo, respectivamente. (c) e (d) imagens AFM, amostra \#4 com densidade superficial 200QDs $/ \mu m^{2}$, em perspectiva e de topo, respectivamente. 35

3.6 Análise das dimensões e formas dos QDs. (a) Seção transversal de QDs ao longo da linha diagonal ilustrada em Fig.3.5(b). Seta aponta para QD indicado na Fig.3.5(b). (b) histograma da altura dos QDs compreendidos no retângulo demarcado na Fig.3.5(b). . . . . . . . . . . . . . . . . .

3.7 Curvas de PL para amostras com QDs de InAs cobertos crescidos com diferentes taxas de deposição de InAs. . . . . . . . . . . . . . . .

3.8 Goniômetro de 3 eixos instalado da linha de difração XRD1 do LNLS. Quarto estágio de rotação (berço $\chi$ ) permite escolha da polarização via rotação do plano de incidência em torno do feixe de raios X. . . . . . . . . . . .

3.9 Goniômetro de 4 círculos instalado no laboratório de espalhamento e difração de raios X da Universidade de Guelph-Canadá. . . . . . . . . . . . . . . . . 40

3.10 Goniômetro 4-círculos da linha de difração XRD2 do LNLS. . . . . . . . . . 41

3.11 Resíduos de Índio provenientes da solda utilizada para fixação dos substratos na câmara de MBE. Os locais mais escuros correspondem ao substrato de GaAs e as manchas de cor prata correspondem aos resíduos da solda de Índio.

3.12 (a,b) Esquema de montagem com gota de cêra no centro da face da amostra, (c,d) Esquema de montagem com esferas metálicas embebidas na cêra. (e) Foto de amostra montada com o método das esferas ou método dos 3 contatos. 44

3.13 Diagramas polar da reflexão 002 de um substrato de GaAs: (a) montado de forma convencional, e.g. Fig.3.12(b). AA e BB indicam as direções plana e curvada, respectivamente; e (b) montado com o método das esferas, e.g.

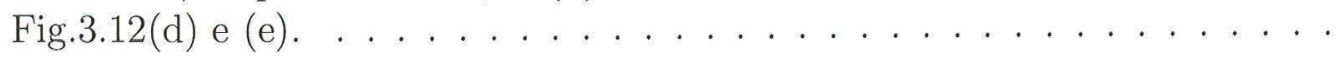

3.14 Larguras à meia altura (FWHM) da reflexão 004 do GaAs em função do azimute da amostra para dois tamanhos de feixe incidente. . . . . . . . .

4.1 Representação geométrica da difração múltipla de 3 feixes (a) esquema planar no espaço direto (planos atômicos do cristal) e (b) no espaço recíproco (esfera de Ewald). Os ângulos $\theta_{\mathbf{P}}$ e $\theta_{\mathbf{S}}$ correspondem aos ângulos de Bragg das reflexões primária e secundária, respectivamente. . . . . . . . . . . 
4.2 Padrão de XRS da reflexão 002 do GaAs (reflexão primária) para E=9316eV e polarização $\sigma$. Índices duplos indicam casos de 4 feixes (2 reflexões secundárias). No Detalhe, ajuste do pico de DM $111_{\text {in-out }}$. . . . . . . . . . .

4.3 (a) Representação esquemática (vista de topo) das 8 posições de DM escolhidas para a determinação do parâmetro de rede. Cada reflexão secundária possui um par (in-out/out-in) de posições $\varphi$ onde ocorre a DM. (b) Esquema de cones de Bragg das reflexões primária e secundária: a intersecção dos cones denota condição de DM. . . . . . . . . . . . . . . . . . . . . . .

4.4 Sistema $x y z$ de coordenadas usado para descrever o feixe incidente $k_{0}$ em função dos ângulos instrumentais $\theta$ e $\varphi$, assim como os vetores recíprocos $\mathbf{P}$ e

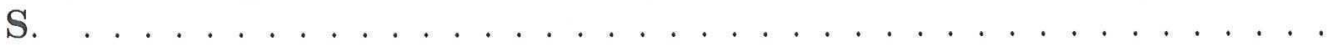

4.5 Procedimento de alinhamento da amostra \#1 via curvas de varredura $\theta$ da reflexão 002 do GaAs obtidas nos azimutes $0^{\circ}, 90^{\circ}, 180^{\circ}$ e $270^{\circ}$. . . . . . . .

4.6 Arquivo de entrada para o programa FITTER (Apêndice C). Os parâmetros $\omega_{S}, R, \varrho, b, \omega_{G}$ e $\varphi_{0}$ são ajustados pelo algoritmo genético (Apêndice B). . .

4.7 Perfis umwegs experimentais (círculos) e ajustados (linhas) pelo FITTER. Energias: (a) $9316 \mathrm{eV}$, (b) $10200 \mathrm{eV}$ e (c) $10500 \mathrm{eV}$. Ao lado das figuras encontramse os respectivos arquivos de entrada do programa FITTER. . . . . . . . . . . 60

4.8 Célula unitária do GaAs: (a) cúbica relaxada e (b) tetragonal tensionada. . .

4.9 Resumo das medidas de parâmetro de rede nas amostras de \#1 a \#6 da Tabela 3.1. . . . . . . . . . . . . . . . . . . . . .

5.1 Geometria da BSD num substrato de GaAs (001). O feixe incidente 1 satisfaz a condição de Bragg para as reflexões $\mathbf{S}$ e $\mathbf{P}$, gerando simultaneamente os feixes 2 e 3 , respectivamente. No detalhe, típico mapa $\theta-\varphi$ com indicação do ângulo $\zeta$ entre os traços das reflexões primária e secundária. . . . . . . . . .

5.2 Geometria da BSD no espaço recíproco. Sendo $\mathbf{P}$ uma reflexão simétrica e $\mathbf{S} \cdot \mathbf{P}=|\mathbf{P}|^{2} / 2$, o feixe difratado $\boldsymbol{k}_{\mathbf{S}}$ é paralelo à superfície macroscópica da amostra. . . . . . . . . . . . . . . . . . .

5.3 Profundidade de extinção $\Lambda_{\alpha}$ para uma reflexão Bragg assimétrica genérica G. Para reflexões simétricas, $\alpha=\theta_{G}$ e, portanto, $\Lambda=\Lambda_{\alpha}$. . . . . . . . . .

5.4 Profundidade de extinção em função do ângulo de incidência. A redução da penetração em $\alpha=13,61^{\circ}\left(\theta_{002}\right)$ ocorre devido à contribuição da (002) no processo de reflexão da onda incidente. . . . . . . . . . . . . . . . . .

5.5 Esquema da profundidade de extinção na condição da BSD ( $\mathrm{E}=9316 \mathrm{eV})$ na escala dos dispositivos analisados. 
5.6 Mapas $\theta-\varphi$ na série de amostras da Tabela 3.1. (a) Substrato comercial de GaAs (amostra \#1) com indicação do ângulo $\zeta$ entre os traços das reflexões primária (horizontal) e secundária (diagonal). (b) Substrato comercial submetido a ataque químico em sua superfície. QDs crescidos à taxa de deposição 0,09MC/s (c) antes e (d) depois da deposição de 30nm de Sobre-camada de GaAs. QDs crescidos à taxa de deposição $0,007 \mathrm{MC} / \mathrm{s}$ (e) antes e (f) depois da deposição da Sobre-camada. Barra de escala 100". . . . . . . . . . . . . .

5.7 (a) Modelo de discordância de redes na interface QD/Sobre-camada para QD com formato (a) "lente" e (b) "pirâmide". A discordância perpendicular é elasticamente acomodada via inclinação da rede da Sobre-camada pelo ângulo $\tau$, o qual depende da inclinação $\xi$ das faces dos QDs. . . . . . . . . . . .

5.8 Mapa $\theta-\varphi$ de amostra com QDs cobertos. O período $\Delta \theta$ das franjas é determinado pela espessura de $30 \mathrm{~nm}$ da sobre-camada. . . . . . . . . . . . . .

5.9 Observação de traço secundário extra em mapa BSD de amostra com QDs cobertos. Detalhe superior: varredura $\varphi$ para $\theta \simeq 13,16^{\circ}$. Detalhe inferior: ampliação parcial do mapa com indicação do ângulo entre os traços. . . . . .

5.10 Geometrias BSD: (a) vista em corte dos planos atômicos e (b) esquema no espaço recíproco conforme modelo de acoplamento cinemático. Os detetores visto separados em (b) representam um mesmo detetor no espaço real, e.g.

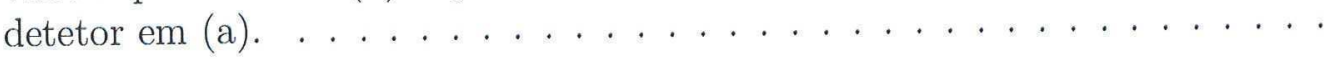

5.11 (a) Diagrama dos feixes de superfície quando vistos de topo com definição das quatro direções de propagação. (b) Vista em perspectiva dos feixes de superfície para as 8 BSD's. . . . . . . . . . . . . . . .

5.12 Perfis de intensidade ao longo do traço para as 8 BSD's da família 111. (a) um Substrato comercial (polido) com curvatura induzida pelo processo de montagem da amostra. (b) Substrato comercial plano. (c) Substrato comercial após desbaste químico da superfície. Nos detalhes, ampliação das curvas e indicação das direções definidas na Fig.5.11(b). (d) e (e), indicação da direção com menor qualidade cristalina de acordo com os perfis mostrados em $(a, b)$ e

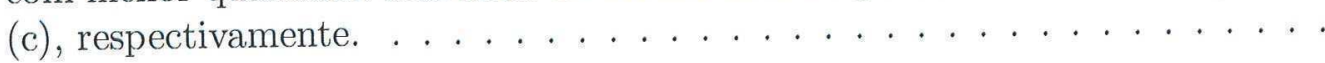

5.13 Varreduras $\ell$ da reflexão GaAs(111) de uma amostra com QDs cobertos em vários ângulos de incidência $\alpha \ldots \ldots \ldots \ldots \ldots$

A.1 (a) Substrato de $\operatorname{Si}(001)$ e (b) geometria de difração Laue para a reflexão 202 com indicações dos feixes difratados (anômalos), do ângulo de difração $(\theta)$ e do ângulo de rotação $(\varphi) . \ldots \ldots \ldots \ldots \ldots \ldots$

A.2 Esquema do difratômetro de 4 círculos. (a) Estágios de rotação e translação do difratômetro. (b) Referência dos valores instrumentais de $\chi$ em relação à posição do estágio de rotação $\varphi$. (c) Exemplo de movimento do estágio $\alpha$. . . 
A.3 Mapa $\chi-\varphi$ da reflexão 202 do Si antes do alinhamento do goniômetro. . . . . 96

A.4 Mapa $\chi-\varphi$ da reflexão 202 do Si depois do alinhamento do goniômetro. . . . 97

B.1 Ajuste de dados do RADS pelo modelo de camadas com escolha de parâmetros via algoritmo genético. No detalhe, espessuras obtidas no ajuste. $O$ valor $E_{\text {ajuste }}$ corresponde ao desvio logaritmico médio (Eq.B.6) para o ajuste. . . . 103 


\section{Lista de Tabelas}

2.1 Posições fracionárias dos átomos de Ga, In e As nas células unitárias (a) do GaAs e (b) do InAs. Ambas as estruturas, chamadas blenda de zinco, são resultantes da soma de duas redes FCC com origens deslocadas de (1/4 1/4 1/4). 16

2.2 Fator de estrutura do GaAs para diferentes combinações de reflexões $h k \ell$. $n \in \mathbb{Z}$ e mistos indica ímpares e pares. . . . . . . . . . . . . . . . . 17

3.1 Especificações do conjunto de amostras. A amostra \#1 refere-se ao wafer comercial de GaAs o qual foi utilizado como substrato em todas as demais amostras. A amostra \#8 não contém ilhas e trata-se de uma monocamada simples de InAs coberta por uma sobre-camada de 30nm de GaAs. . . . . . .

4.1 Indexação parcial da XRS da reflexão 002 GaAs. Valores angulares (em graus) calculados para $\mathrm{E}=9316 \mathrm{eV}$ e $\mathbf{M}=[110] \ldots \ldots \ldots$. . . . . . . . . .

4.2 Resultado do ajuste dos parâmetros para as energias $9316 \mathrm{eV}, 10200 \mathrm{eV}$ e

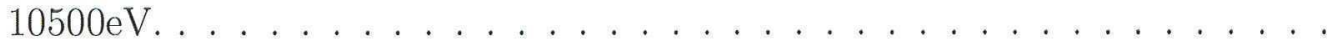

4.3 Posições $\varphi$ dos umwegs com reflexões secundárias $111, \overline{1} 11, \overline{1} 11$, e $1 \overline{1} 1$ obtidas em XRS na amostra \#1. Cada posição $\varphi$ foi medida 3 vezes (linhas 1,2 and 3 ) como detalhado no texto. $\beta=\left(\varphi_{\text {in-out }}-\varphi_{\text {out-in }}\right) / 2, \bar{\beta}$ são valores médios sem efeitos de desalinhamentos residuais. Todos os valores angulares são dados em graus. . . . . . . . . . . . . . . . . . . . . .

4.4 Valores experimentais de $\bar{\beta}$ e da deformação no-plano, $\epsilon_{\|}$, para as amostras de \#1 a \#6 especificadas na Tabela 3.1. . . . . . . . . . . . . . . . . . . . . 64

4.5 Parâmetros de rede no-plano do GaAs medidos nas direções [110] e [1110]. . . 64

5.1 Valores experimentais do ângulo de inclinação $\zeta$ extraídos dos mapas $\theta-\varphi$ apresentados na Fig.5.6. $\Delta \zeta$ corresponde à inclinação relativa à amostra referência \#1. *Ataque químico. . . . . . . . . . . . . . . . . . . 
B.1 Parâmetros estruturais obtidos no ajuste do modelo de camadas via algoritmo genético comparados aos dados do programa RADS. As camadas são contadas a partir do substrato. O parâmetro "Deformação" corresponde à razão $\Delta a / a_{0}=\left(a_{\|}-a_{0}\right) / a_{0}$, onde $a_{\|}$e $a_{0}$ correspondem às constantes de rede noplano e do GaAs, respectivamente. O parâmetro "Relaxação" pode assumir valores entre 0 e 1 , sendo 1 referente a uma célula unitária totalmente relaxada. 105 


\section{Bibliografia}

[1] D. Bimberg, M. Grundman, and N. N. Ledensov. Quantum Dot Heterostructures. Willey, 1999.

[2] L. Chang, L. Esaki, and R. Tsu. Appl. Phys. Lett., 24, 593 (1974).

[3] J. Faist, F. Capasso, D. L. Sivco, C. Sirtori, A. L. Hutchinson, and A. Y. Cho. Science, 264, 553 (1994).

[4] J. Faist, F. Capasso, D. L. Sivco, C. Sirtori, A. L. Hutchinson, and A. Y. Cho. Electron. Lett., 30, 829 (1994).

[5] R. P. Mirin, J. P. Ibbetson, K. Nishi, A. C. Gossard, and J. E. Bowers. Appl. Phys. Lett., 67, 3975 (1995).

[6] E. C. L. Ru, P. Howe, T. S. Jones, and R. Murray. Phys. Rev. B, 67, 165303 (2003).

[7] J. Tatebayashi, J. M. Nishioka, and Y. Arakawa. Appl. Phys. Lett., 78, 3469 (2001).

[8] J. D. Jackson. Classical Electrodynamics - Third Edition. Willey, 1999.

[9] A. J. Shields. Nature Photonics, 1, 215 (2007).

[10] A. Létoublon, Favre-Nicolin, H. Renevier, M. Proietti, C. Monat, M. Gendry, O. Marty, and C. Priester. Phys. Rev. Lett., 92, 186101 (2004).

[11] J. Coraux, M. G. Proietti, V. Favre-Nicolin, H. Renevier, and B. Daudin. Phys. Rev. $B, 73,205343$ (2006).

[12] Q. Gong, P. Offermans, R. Nötzel, P. M. Koenraad, and J. H. Wolter. Appl. Phys. Lett., 85, 5697 (2004).

[13] A. Malachias, S. Kycia, G. Medeiros-Ribeiro, R. Magalhães-Paniago, T. I. Kamins, and R. Stanley Williams. Phys. Rev. Lett., 91, 176101 (2003).

[14] A. Malachias, T. U. Schülli, G. Medeiros-Ribeiro, L. G. Cançado, M. Stoffel, O. G. Schmidt, T. H. Metzger, and R. Magalhães-Paniago. Phys. Rev. B, 72, 165315 (2005). 
[15] I. Kegel, T. H. Metzger, A. Lorke, J. Peisl, J. Stangl, G. Bauer, J. M. García, and P. M. Petroff. Phys. Rev. Lett., 85, 1694 (2000).

[16] I. Kegel, T. H. Metzger, A. Lorke, J. Peisl, J. Stangl, G. Bauer, K. Nordlund, W. V. Schoenfeld, and P. M. Petroff. Phys. Rev. B, 63, 035318 (2001).

[17] J. Coraux, H. Renevier, V. Favre-Nicolin, G. Renaud, and B. Daudin. Appl. Phys. Lett., 88, 153125 (2006).

[18] W. C. Sun, H. C. Chang, B. K. Wu, Y. R. Chen, C. H. Chu, S. L. Chang, M. Hong, M. T. Tang, and Yu. P. Stetsko. Appl. Phys. Lett., 89, 091915 (2006).

[19] S. L. Morelhão and E. Abramof. J. Appl. Crystallogr., 33, 871 (1999).

[20] M. A. Hayashi, S. L. Morelhão, L. H. Avanci, L. P. Cardoso, J. M. Sasakid, L. C. Kretly, and S. L. Chang. Appl. Phys. Lett., 71, 2614 (1997).

[21] Frederico Sodré Borges. Elementos de Cristalografia. Fundação Calouste Gulbenkian, 1982.

[22] B. D. Cullity and S. R. Stock. Elements of X-Ray Diffraction - third edition. Prentice Hall, 2001.

[23] André Guinier. X-ray diffraction in crystals, imperfect crystals, and amorphous bodies. Dover, 1994.

[24] D. R. Hartree. Proc. Cambridge Phil. Soc., 24, 89 (1928).

[25] V. Fock. Z. f. Phys., 61, 126 (1930).

[26] E. Prince. International Tables for Crystallography. Volume C, Mathematical, physical and chemical tables. IUCr, 2006.

[27] D. T. Cromer and D. Liberman. J. Chem. Phys., 53, 1891 (1970).

[28] A. S. Davydov. Quantum Mechanics. NEO Press, 1963.

[29] S. W. Lovesey and S. P. Collins. X-ray Scattering and Absorption by Magnetic Materials. Oxford University Press, 1996.

[30] V. A. Shchukin, N. N. Ledentson, and D. Bimberg. Epitaxy of Nanostructures. Springer, 2004.

[31] H. C. Chung, Y. F. Lai, C. P. Liu, Y. L. Lai, Y. C. Fang, and L. Hsu. Appl. Phys. Lett., 92, 051903 (2008).

[32] T. U. Schülli, M. Sztucki, V. Chamard, T. H. Metzger, and D. Schuh. Appl. Phys. Lett., 81, 448 (2002). 
[33] R. Magalhães-Paniago, G. Medeiros-Ribeiro, A. Malachias, S. Kycia, T. I. Kamins, and R. S. Williams. Phys. Rev. B, 66, 245312 (2002).

[34] T. U. Schülli, J. Stangl, Z. Zhong, R. T. Lechner, M. Sztucki, T. H. Metzger, and G. Bauer. Phys. Rev. Lett., 90, 066105 (2003).

[35] K. Barnham and D. Vvedensky. Low-Dimensional Semiconductor structures. Cambridge University Press, 2001.

[36] G. M. Williams and I. M. Young. J. Cryst. Growth, 62, 219 (1983).

[37] M. Renninger. Z. Kristallogr., 97, 107 (1937).

[38] S. Caticha-Ellis. Acta Crystallogr., A25, 666 (1969).

[39] S. L. Chang and B. Post. Acta Crystallogr., A31, 832 (1975).

[40] L. Avanci, L. Cardoso, S. Girdwood, D. Pugh, J. Sherwood, and K. Roberts. Phys. Rev. Lett., 81, 5426 (1998).

[41] S. L. Chang. X-Ray Multiple-Wave Diffraction: Theory and Application. SpringerVerlag, 2004.

[42] E. Wagner. Phys. Zs., 21, 632 (1920).

[43] R. Colella. Acta Crystallogr. A, 30, 413 (1974).

[44] E. Weckert and K. Hümmer. Acta Crystallogr. A, 53, 108 (1997).

[45] M. Wormington, C. Panaccione, K. M. Matney, and D. K. Bowen. Philos. T. Roy. Soc. A, 357, 2827 (1999).

[46] S. L. Morelhão, C. M. R. Remédios, R. O. Freitas, and A. O. dos Santos. J. Appl. Crystallogr., 44, - (2011).

[47] J. M. Garcia, G. Medeiros-Ribeiro, K. Schmidt, T. Ngo, J. L. Feng, A. Lorke, J. Kotthaus, and P. M. Petroff. Appl. Phys. Lett., 71, 2014 (1997).

[48] Qianghua Xie, P. Chen, and A. Madhukar. Appl. Phys. Lett., 65, 2051 (1994).

[49] X. W. Lin, J. Washburn, Z. Lilientalweber, E. R. Weber, A. Sasaki, A. Wakahara, and Y. Nabetani. Appl. Phys. Lett., 65, 1677 (1994).

[50] Q. H. Xie, A. Madhukar, P. Chen, and N. P. Kobayashi. Phys. Rev. Lett., 75, 2542 (1995).

[51] Q. H. Xie, N. P. Kobayashi, T. R. Ramachandran, A. Kalburge, P. Chen, and A. Madhukar. J. Vac. Sci. Technol. B, 14, 2203 (1995). 
[52] E. Petitprez, N. T. Moshegov, E. Marega, A. Mazel, D. Dorignac, and R. Fourmeaux. J. Vac. Sci. Technol. B, 18, 1493 (2000).

[53] S. L. Morelhão and L. P. Cardoso. J. Appl. Crystallogr., 29, 446 (1996).

[54] M. A. Hayashi, S. L. Morelhão, L. H. Avanci, and L. P. Cardoso. Appl. Phys. Lett., 71, 2614 (1997).

[55] Jens Als-Nielsen and Des McMorrow. Elements of Modern X-ray Physics. Wiley, 2001.

[56] André Authier. Dynamical Theory of X-Ray Diffraction. Oxford University Press, 2003.

[57] Mou Yang, S. J. Xu, and Jian Wang. Appl. Phys. Lett., 92, 083112 (2008).

[58] Raul O. Freitas, Alain A. Quivy, and Sérgio L. Morelhão. J. Appl. Phys., 105, 036104 (2009).

[59] Sérgio L. Morelhão and Jarek Z. Domagala. J. Appl. Crystallogr., 40, 556 (2007).

[60] G. Bormann. Phys. Z., 42, 157 (1941).

[61] G. Borrmann. Z. Phys., 127, 297 (1950).

[62] W. J. Murphy, L. D. Chapman, J. L. Staudenmann, and G. L. Liedl. J. Appl. Cryst., 18, 71 (1985).

[63] J. L. Staudenmann and L. D. Chapman. J. Appl. Cryst., 22, 162 (1989).

[64] Ullrich Pietsch, Václav Holý, and Tilo Baumbach. High-Resolution X-Ray Scattering: From Thin Films to Lateral Nanostructures. Springer, 2004. 